\title{
Investigation of Cluster-Nozzle Concepts for Direct Injection Diesel Engines
}

\author{
Von der Fakultät für Maschinenwesen der \\ Rheinisch-Westfälischen Technischen Hochschule Aachen \\ zur Erlangung des akademischen Grades eines Doktors der \\ Ingenieurwissenschaften genehmigte Dissertation
}

vorgelegt von

Hyun Woo Won

Berichter: Univ.-Prof. Dr.-Ing. Dr. h.c. Dr.-Ing. E.h. N. Peters Univ.-Prof. Dr.-Ing. (USA) S. Pischinger

Tag der mündlichen Prüfung: 23. Februar 2010

Diese Dissertation ist auf den Internetseiten der Hochschulbibliothek online verfügbar. 
Berichte aus der Energietechnik

Hyun Woo Won

Investigation of Cluster-Nozzle Concepts for Direct Injection Diesel Engines

Shaker Verlag

Aachen 2010 
Bibliographic information published by the Deutsche Nationalbibliothek The Deutsche Nationalbibliothek lists this publication in the Deutsche Nationalbibliografie; detailed bibliographic data are available in the Internet at http://dnb.d-nb.de.

Zugl.: D 82 (Diss. RWTH Aachen University, 2010)

Copyright Shaker Verlag 2010

All rights reserved. No part of this publication may be reproduced, stored in a retrieval system, or transmitted, in any form or by any means, electronic, mechanical, photocopying, recording or otherwise, without the prior permission of the publishers.

Printed in Germany.

ISBN 978-3-8322-9035-1

ISSN 0945-0726

Shaker Verlag GmbH • P.O. BOX 101818 • D-52018 Aachen

Phone: 0049/2407/9596-0 • Telefax: 0049/2407/9596-9

Internet:www.shaker.de • e-mail:info@shaker.de 


\section{Vorwort / Preface}

Diese Arbeit entstand während meiner Tätigkeit als wissenschaftlicher Mitarbeiter am Institut für Technische Verbrennung (ehemals Institut für Technische Mechanik) der RWTH Aachen University. Sie wurde im Rahmen des Projekts ,, Untersuchung von Cluster-Düsen-Konzepten für Dieselmotoren" innerhalb des "Collaborative Research Laboratory“ in Zusammenarbeit mit General Motors R\&D and Strategic Planning, Warren, MI, USA durchgeführt. Ein Teil der Arbeit ist außerdem innerhalb des Sonderforschungsbereichs 686 Modellbasierte Regelung der homogenisierten Niedertemperatur-Verbrennung entstanden, der an der RWTH Aachen University und der Universität Bielefeld bearbeitet wird. General Motors and der Deutschen Forschungsgemeinschaft danke ich in diesem Zusammenhang für die finanzielle Förderung.

Mein besonderer Dank gilt Herrn Professor Dr.-Ing. Dr. h.c. Dr.-Ing. E.h. Norbert Peters für seine Unterstützung, seine kritischen Anmerkungen und die mir gewährte Freiheit. Herrn Professor Dr. -Ing. (USA) Stefan Pischinger danke ich für sein stetiges Interesse an meiner Arbeit und für die Tätigkeit als weiterer Berichter. Herrn Professor Dr.-Ing. Reinhold Kneer danke ich für die Übernahme des Vorsitzes der Prüfungskommission.

Ausdrücklich möchte ich mich bei Abhinav Sharma, Seun-Eun Moon und Min-Soo Youn bedanken, die mich durch ihre Arbeit als wissenschaftliche Hilfskräfte tatkräftig unterstützt haben. Außerdem gilt mein Dank allen jetzigen und ehemaligen Mitarbeitern des Institut für Technische Verbrennung, die ebenfalls zum Gelingen dieser Arbeit beigetragen haben. Ich bedanke mich bei Abdelilah Louki, Peter Spiekermann, Christoph Kortschik, Rainer Dahms, Anyelo Vanegas, Olaf Röhl, Peng Zeng, Joachim Beeckmann, Lipo Wang, Dieter Osthoff, Bernd Binninger, Günter Paczko, Jens Henrik Göbbert, Maung Maung Aye, Bernhard Jochim, Klaus-Dieter Stoehr, Tomoya Wada, Dirk Grüterich, Henry Krüger, Juan Pablo Higuera Gomez, Frank Backes und Leo Kuck.

Ich möchte mich ganz besonders bei Christian Hasse, Stefan Vogel, Jost Weber, Vivak Luckhchoura, Peter Hottenbach, Adam Pawlowski und Maria Cardenas, die am GM-Projekt beteiligt waren, bedanken.

I would like to thank John Pinson for making my research stays at General Motors R\&D in Warren, MI, USA, possible. Furthermore, I would like to thank Norbert Siewert, Andreas Lippert, Rossell Durrett, Alejandro H. Plazas T., Satbir Singh for our good collaboration.

Ein großer Dank gilt meinen Eltern und Schwiegereltern, die mich in jeder Phase meiner Ausbildung unterstützt und motiviert haben.

Meiner Frau Mina Lee und meiner Tochter Yeun danke ich ebenfalls sehr für ihre außerordentliche Unterstützung, auf die ich mich immer verlassen konnte.

Aachen, im März 2010

Hyun-Woo Won 
Meiner Mutter 


\section{Investigation of Cluster-Nozzle Concepts for Direct Injection Diesel Engines}

\section{Zusammenfassung}

In den letzten Jahrzehnten ist die Reduzierung von kritischen Schadstoffemissionen wie NOx und Ruß bei Dieselmotoren sehr weit fortgeschritten. Jedoch verlangen verschärfte Emissionsgesetzgebungen weitere zusätzliche Anstrengungen. Trotz dauernder Verbesserungen bei der Abgasnachbehandlung müssen die Schadstoffemissionen weiter gesenkt und zugleich der Verbrennungsprozess weiter optimiert werden, um die Kosten der Abgasnachbehandlung so gering wie möglich zu halten. Ein viel versprechender Schlüsselparameter, der den Verbrennungprozess bei der kontrollierten Diffusionsverbrennung beeinflusst, ist das Luft-Brennstoff-Gemisch, das hauptsächlich von den Kraftstoffeinspritzparametern geregelt wird. Das Einspritzkonzept mit Clusterdüsen ist eine der fortgeschrittensten Technologien, welche die Gemischbildung bei der Kraftstoffeinspritzung verbessert.

Beruhend auf vorherigen Untersuchungen mit Cluster-Düsen wurden für diese Studie modifizierte Cluster-Düsen entworfen. Das hier verwendete Cluster-Düsen-Konzept besteht aus paarweise kleinen gleich grossen Öffnungen. Ziel ist es, verbesserte Emissionswerte, erstens, bei der Niedertemperaturverbrennung unter Teillastbedingungen auf niedrigerem Emissionsniveau und zweitens bei der Hochdruckeinspritzung unter hohen Lastbedingungen und verringertem Kraftstoffverbrauch, zu erreichen. Hierbei wurden bei den Düsen die Anzahl von Loch-Paaren und die geometrische Konfigurationen modifiziert. Die Parameter während des Motorexperiments waren der Drall, der Einspritzdruck und die Kolbengeometrie. Die Studie trägt dazu bei, die Eigenschaften der innermotorischen Verbrennung besser zu verstehen und somit die Leistung und die Emissionswerte zu verbessern. Die Ergebnisse der Cluster-Düsen wurden mit den Ergebnissen der herkömmlichen Düsen verglichen, die als Referenzdüsen bezeichnet wurden.

Die Cluster-Düsen, die kleine Öffnungen haben, wurden bei der Niedertempertaturverbrennung unter Teillastbedingungen verwendet. Bei dieser Bedingung zeigte sich eine Verbesserung der Emissionswerte und des Kraftstoffverbrauchs. Auch bei Mittel- und Hochlast war es möglich, bei einer richtigen Kombination aus Düsentyp, Innenzylindergeometrie und hohem Spritzendruck ein niedrigeres Partikel-Emissionsniveau und einen gesenkten Kraftstoffverbrauch zu erreichen. Auch unter hoher Geschwindigkeit und Vollast (was eine schnelle 
Verbrennungsgeschwindigkeit verlangt) war mit einer optimierten Düsenbauform sowie einer optimierten Innenzylindergeometrie eine Verbesserung hinsichtlich Kraftstoffverbrauchs und Schadstoffemissionen $\mathrm{zu}$ erkennen. Unter Niedriglastbedingungen wurden die Emissionen, die bereits bei den Referenzdüsen niedrig waren, weiter reduziert und gleichzeitig wurde eine beträchtliche Verminderung von Rauchgasemissionen im Vergleich zu der Referenzdüse, die auch schon mit einer veränderten Kolbenmulde lief, festgestellt.

Als Fazit dieser Arbeit kann festgehalten werden, dass das Cluster-Düsen-Konzept kombiniert mit einer angepassten Muldengeometrie und einem optimalen Drall Emissionen reduzieren kann und den Kraftstoffverbrauch über den ganzen Betriebsbereich eines Dieselmotors verbessert. Man kann auch sagen, dass, obwohl es einige Schwierigkeiten in der Anwendung (besonders bei Vollast und bei einer hohen Drehzahl) gab, das Cluster-Düsen-Konzept als eine zuverlässige Lösung für das gegenwärtige Problem angesehen werden kann, um die Verbrennung effektiver zu machen und eine Emissionsverminderung zu erreichen. 


\section{Publications}

This thesis is mainly based on the following publications; some material is updated, together with some new introduced results:

- H. W. Won and N. Peters, "Investigation of Cluster-Nozzle Concepts for Diesel Engines", Journal of Atomization and Sprays, 19(10):983-996, 2009.

- H. W. Won, A. Sharma, P. Hottenbach, M. Gauding, F. X. Robert, N. Peters, G. Grünefeld, R. Durrett, A. H. Plazas T. and S. Singh, "Investigation of Particulate Emissions for Cluster-Nozzle Concepts in DI Diesel Engines", $11^{\text {th }}$ Triennial International Annual Conference on Liquid Atomization and Spray Systems, ICLASS 2009-148, 2009.

- H. W. Won and N. Peters, Optimizing the Injection Pressure for Cluster Nozzle Concepts in DI Diesel Engine, International Journal of Engine Research, Vol. 11 JER05409, 2009.

- H. W. Won and N. Peters, The Effects of Swirl for the Cluster Nozzles in DI Diesel Engine, Proceedings of International Journal of Engine Research, Submitted 2009.

- H. W. Won and N. Peters, Modified Bowl Geometry for Cluster nozzles in DI Diesel engine, Proceedings of the Institution of Mechanical Engineers, Part D, Journal of Automobile Engineering, JAUTO1371R1, 2009. 


\section{Contents}

Title

Vorwort/Preface iii

Zusammenfassung $\quad$ v

Publications vii

$\begin{array}{ll}\text { Contents } & \text { ix }\end{array}$

1 Introduction 1

2 Combustion in Direct Injection Diesel Engine 3

2.1 Spray processes in diesel engine combustion ......................................... 3

2.1.1 Overall spray structure …....................................................... 4

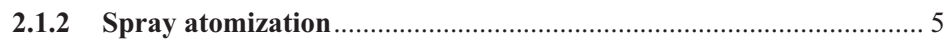

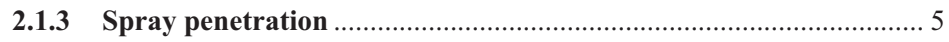

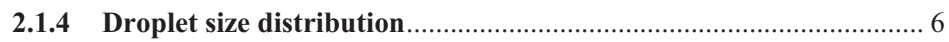

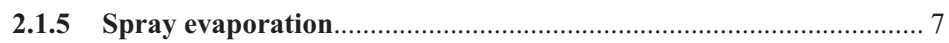

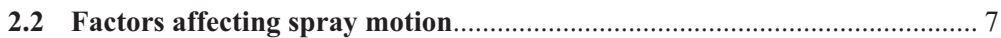

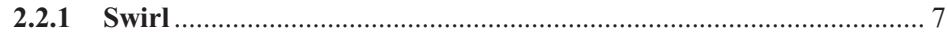


2.2.2 Bowl geometry and spray targeting 8

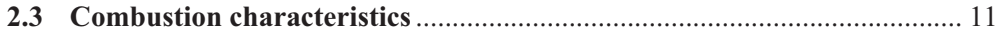

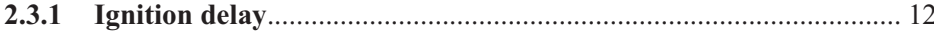

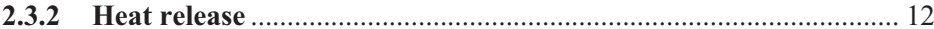

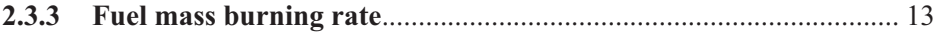

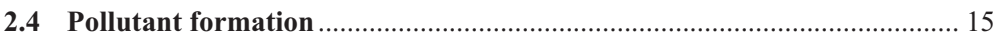

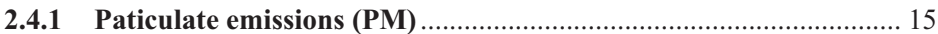

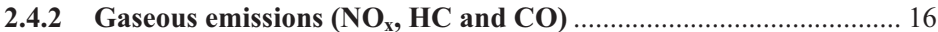

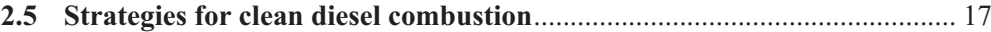

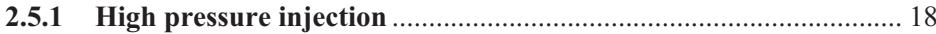

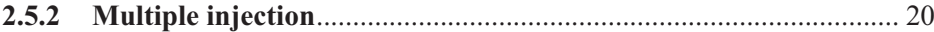

2.5.3 Low temperature combustion................................................... 20

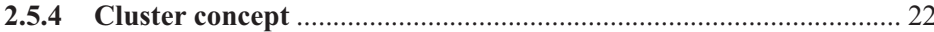

$3 \quad$ Experimental and Numerical Setup $\quad 25$

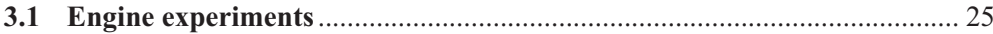

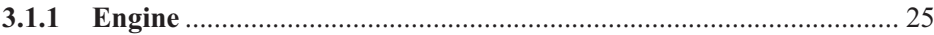

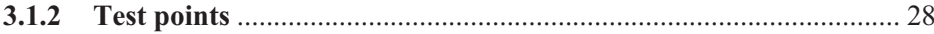

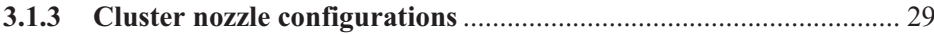




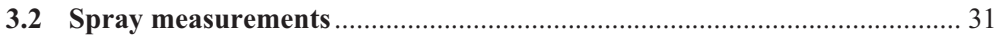

3.2.1 $\mathrm{OH}^{*}$-chemiluminescence imaging .......................................... 31

3.2.2 LII measurements and soot luminosity imaging .......................... 32

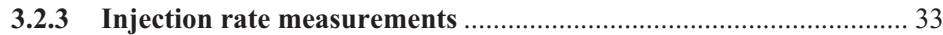

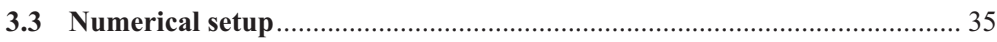

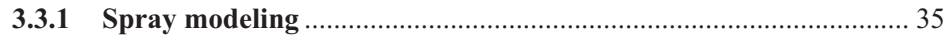

3.3.2 Combustion model (RIF) ......................................................... 35

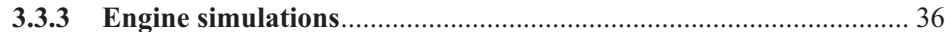

$4 \quad$ Results and Discussion $\quad 39$

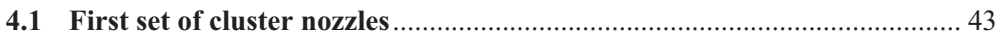

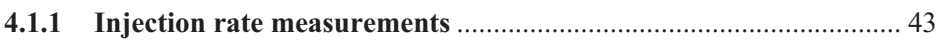

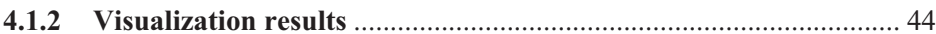

4.1.3 Soot luminosity and LII measurements ........................................ 46

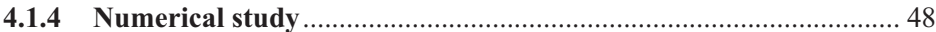

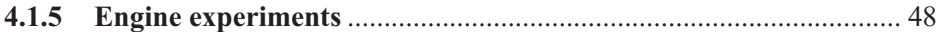

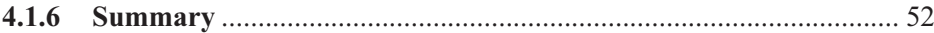

4.2 Second set of clusters and optimization of injection pressure ................... 53

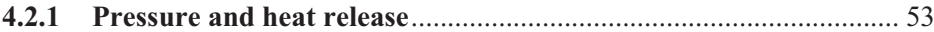

4.2.1.1 Low load condition (TP1) …….......................................... 53 


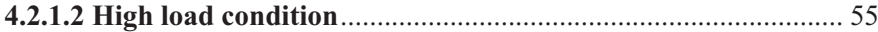

4.2.1.3 Variation of rail pressure …….............................................. 56

4.2.2 Emissions and fuel consumption ................................................ 58

4.2.2.1 Variation of injection pressure …….................................... 58

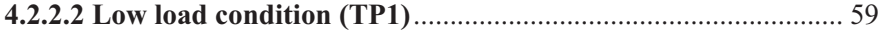

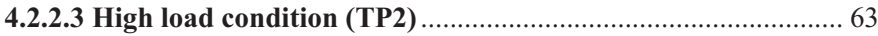

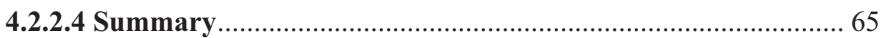

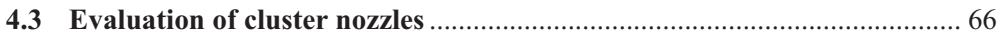

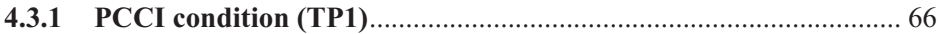

4.3.2 Low engine speed and high load condition (TP2) ........................ 70

4.3.3 High engine speed and medium load condition (TP3) and full load

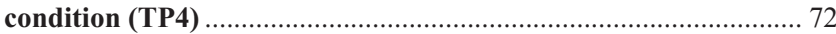

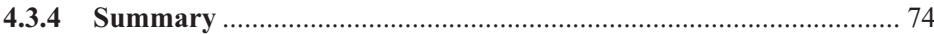

4.4 Effects of swirl ratio for cluster nozzles …......................................... 75

4.4.1 Emissions and fuel consumption ............................................... 75

4.4.1.1 Variation of injection pressure …....................................... 75

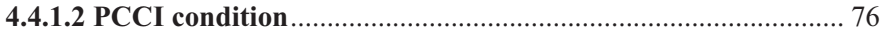

4.4.1.3 Low load condition (TP1) _.................................................. 79

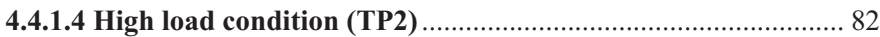

4.4.2 Comparison of a cluster with the conventional nozzle for effect of swirl 
4.5 Modified bowl geometry for cluster nozzles 88

4.5.1 The comparison between the original bowl and the new bowl...... 89

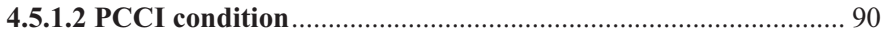

4.5.1.3 Low engine speed and high load condition (TP2) ................. 92

4.5.1.4 High engine speed and medium load condition (TP3) and full load condition (TP4) .................................................................... 95

4.5.2 Parametric study of the selected cluster nozzle ........................... 97

4.5.2.1 Pressure and heat releases................................................... 98

4.5.2.2 Emissions and fuel consumption.............................................. 99

4.5.2.3 Reduction in smoke emissions by using cluster nozzle .......... 103

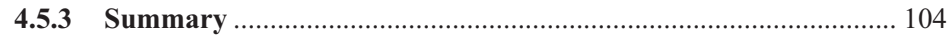

$\begin{array}{llr}5 & \text { Conclusion } & 105\end{array}$

$\begin{array}{lr}\text { Bibliography } & \mathbf{1 0 7}\end{array}$

$\begin{array}{ll}\text { Definitions, Acronyms, Abbreviations } & 117\end{array}$ 


\section{Introduction}

For last several decades, there has been a lot of research about DI (Direct Injection) diesel engines because they have a clear advantage in terms of $\mathrm{CO}_{2}$ (Carbon Dioxide) emissions compared to gasoline engines. Furthermore, because of its ability to operate at low equivalence ratios, the diesel engine produces lower $\mathrm{CO}$ (Carbon Monoxide) and $\mathrm{HC}$ (Hydro-Carbon) emissions. Unfortunately, the diesel engine suffers from relatively high $\mathrm{NO}_{\mathrm{x}}$ (Nitrogen Oxides) and PM (Particulate Matter) emissions. In diesel engine research, keeping low fuel consumption in all operating conditions and reduction of $\mathrm{PM}$ and $\mathrm{NO}_{\mathrm{x}}$ emissions, are both critically important problems which need to be addressed.

For this reason, research about diesel engines is being actively pursued in recent times. $\mathrm{PM}$ and $\mathrm{NO}_{\mathrm{x}}$ could be considerably reduced using low temperature combustion under part load conditions. But, further investigation is also necessary for fuel consumption and emission reduction under high load conditions. Reduction of orifice diameter, multiple injections and high pressure injection are avenues of rigorous research with the injection systems evolving rapidly. Fuel consumption and emission of PM are improved by using high pressure injection due to better air-fuel mixing while there are still problems with $\mathrm{NO}_{\mathrm{x}}$ under all operating conditions and insufficient reduction in $\mathrm{PM}$ emissions under high load conditions. Diesel engine noise and up to some extent, $\mathrm{PM}$ and $\mathrm{NO}_{\mathrm{x}}$ emissions are reduced by the use of multiple injections. However, the reduction achieved by multiple injections is not enough to satisfy the regulations on emission which are becoming more and more stringent. Reduction in diameter of orifices has some positive effects, such as significant reduction of PM and improvement in air-fuel mixing through better atomization and evaporation. On the other hand, it also has a negative effect under high load conditions, which is the reduced spray tip penetration with high temperature and pressure in combustion chamber.

Based on prior knowledge available on cluster nozzles, several cluster nozzles were designed for the present work. They were comprehensively investigated by varying various parameters. Cluster nozzles consist of many groups (pairs in this case) of small orifices, and are aimed to achieve improved emission by low temperature combustion under part load conditions and lower emission levels and fuel consumption levels by high pressure injection under high load conditions. The nozzles were designed with different numbers of hole-pairs and different geometric configurations. Among the parameters varied during the engine experiments were swirl, injection pressure and piston geometry. The study helped in improving the understanding about characteristics of in-cylinder combustion phenomena, performance and emissions were also improved as a consequence. Results from the cluster nozzles were compared with those for a conventional nozzle, henceforth mentioned as the reference nozzle, to check the improvement. The cluster nozzles, having small orifice sizes, were operated with low temperature combustion under part load conditions. Emissions and fuel consumption 
were clearly improved together for this condition. Also at medium and high loads, it was possible to achieve lower PM emission level and fuel consumption by using proper combination of nozzle type, in-cylinder geometry and high injection pressure. Optimized nozzle design and in-cylinder geometry made small improvements under high speed full load condition which requires rapid combustion speed. As a conclusion of this work, it could be said that though there are some difficulties in the application, especially at high load and high speed condition, the cluster nozzle concept can be implemented as a reliable solution for the current problem of achieving better combustion and emission reduction. 


\section{Combustion in Direct Injection Diesel Engine}

Diesel engine is facilitated by the development of modern injection systems that are more flexible and allow significantly higher injection pressures and thus allow better spray atomization and mixture formation for higher power and more efficient combustion. The diesel engines have low ISFC (Indicated Specific Fuel Consumption) and thus low $\mathrm{CO}_{2}$ emissions due to the lack of throttling losses and also due to the higher compression ratio. With the ability to operate at low equivalence ratios, diesel engine produces low CO and $\mathrm{HC}$ emissions. Unfortunately, the diesel engine with high combustion temperatures suffers from high $\mathrm{NO}_{\mathrm{x}}$ and $\mathrm{PM}$ emissions. Reduction of these emissions without a penalty in fuel economy is the main focus of current research in Diesel combustion. These emissions are strongly dependent on the distribution of fuel and its mixing with air. Spray formation and mixing are important parameters which are needed to understand the diesel combustion fundamentals for reduction of emissions [1].

\subsection{Spray processes in diesel engine combustion}

Spray processes play an important role in modern technical systems for Diesel combustion. The fuel is injected directly into the combustion chamber through a nozzle in order to form an ignitable mixture with air. The spray is one of the most effective measures to control the combustion process. Injection pressure in the range of 300 to $2000 \mathrm{~atm}$ is used depending on the engine size and type of the combustion system. At the time of injection the pressure in cylinder is typically in the range of 40 to $150 \mathrm{~atm}$ with the charge temperature around $1000 \mathrm{~K}$ and the density between 15 and $25 \mathrm{~kg} / \mathrm{m}^{3}$. The quantity of fuel injected in each cylinder is controlled according to the engine speed and load requirements. All the processes that occur during the spray formation are presented in Fig. 2.1. As the liquid jet leaves the nozzle it becomes turbulent and spreads out as it entrains and mixes with the surrounding air. Close to the nozzle exit, primary breakup occurs. Ligaments and initial droplets are formed due to cavitation inside the nozzle and strong entrainment of the surrounding air. Downstream of the nozzle, droplets are subjected to secondary breakup, droplet-droplet interaction (collision and coalescence) and evaporation. At the limit, the spray can impinge on the wall and form a film. The highest velocities are on the jet axis. The equivalence ratio is highest on the centerline, decreasing to zero at the spray boundary. The spray significantly affects the ignition behavior, heat release and pollutant formation rates and thus the noise level, fuel consumption and emissions of Diesel engine. Spray formation and atomization has been discussed in detail by Stiesch [2]. Some of the key observations are being discussed here. 


\subsubsection{Overall spray structure}

The fuel is injected in a cone shaped spray through a nozzle. The spray can be divided into different regions based on the composition of the two phase flow which are shown in Fig. 2.1. Directly at the nozzle exit there is an unbroken core of liquid phase, which rapidly breaks into ligaments and further into droplets. Despite breaking up into small droplets, the liquid phase still has a large volume fraction in the region close to the nozzle which is known as thick or dense spray region. The mass fraction of the liquid phase is even greater than the volume fraction due to its much higher density in comparison to the gas phase.

Due to the conical shape of the spray and gradual evaporation of the droplets, the volume fraction of the gas phase keeps on increasing downstream of the nozzle. Thin spray region is defined as the region which has negligible volume fraction of the liquid phase, i.e. practically all of the volume is occupied by the gas phase. Though, due to the higher density, the liquid phase may still have a significant contribution to the total mass, and thus have a significant mass fraction.

The region furthermost from the nozzle, known as very thin or dilute spray, practically consists of only the gas phase. Both the volume and mass fraction of the liquid phase are negligible in this region [2].

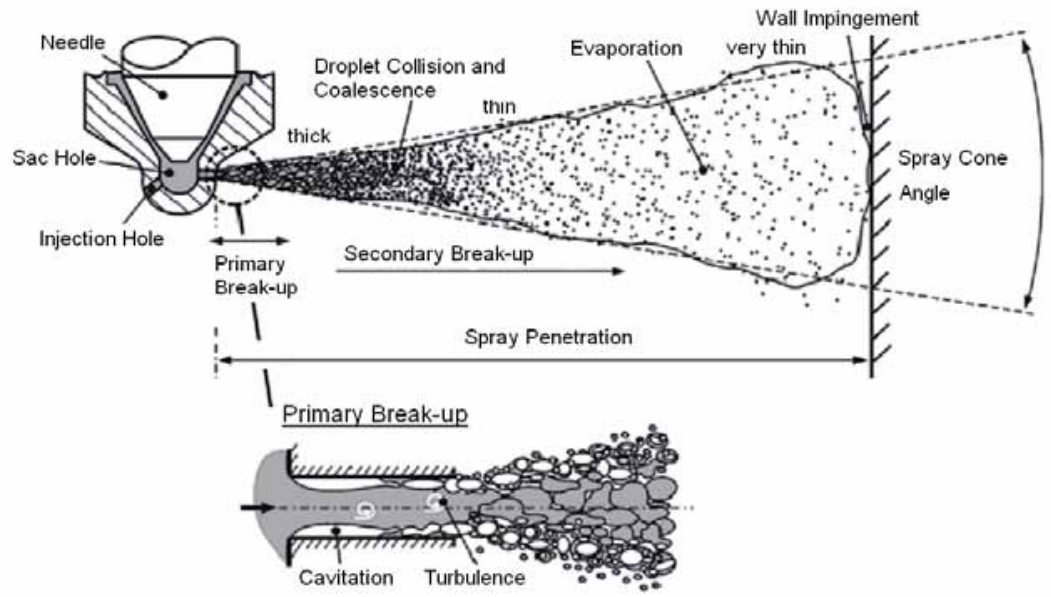

Figure 2.1: Formation of a Diesel spray [3] 


\subsubsection{Spray atomization}

The liquid phase of a spray with high pressure injection system continually disintegrates into small droplets very close to the nozzle and produces droplets with different sizes. The injection pressure is a very important parameter for atomization. The primary atomization, which is the breakup of the intact liquid phase into first droplets, occurs in the direct vicinity of the injection nozzle orifice. Later on, the relatively large initial droplets can be further broken up into smaller secondary droplets. Three mechanisms are considered responsible for the primary breakup of liquid jets. The first mechanism is the destabilizing effect of turbulence on the jet. High level of turbulence is generated due to high accelerations of the liquid under a large pressure drop across the injection nozzle. The second contributing mechanism is cavitation. Sharp edges in the flow path inside the nozzle cause high accelerations, which result in low static pressures inducing cavitation bubbles. The bubbles are swept out of the nozzle into the combustion chamber where they implode and contribute to the disintegration of the spray. The third effect is of the aerodynamic forces that act on the liquid surface. As a result, surface disturbances develop and start to grow which again lead to breakup. Though the details of mechanisms leading to primary breakup in high pressure diesel sprays are not exactly understood, it is generally agreed upon that the effects of liquid phase turbulence and cavitation increase with higher injection pressures [2]. The secondary atomization of liquid fuel drops into even smaller droplets is primarily driven by aerodynamic forces employed on the drops by the surrounding gas phase. The outcome of the droplet atomization depends on the balance between aero dynamical, surface, viscous and inertia forces [4].

\subsubsection{Spray penetration}

The length of spray is one of the important parameters for mixture formation. In diesel combustion systems, an over-penetration causes impingement of liquid fuel on cold quench area and under-penetration gives poor air utilization. Thus, the spray tip penetration has to be considered for the spray in Diesel combustion. Many correlations based on experimental studies and turbulent gas jet theory, have been proposed for fuel spray tip penetration. An evaluation of these correlations indicated that the formula developed by Dent gives the best prediction [5].

$$
S=3.07\left(\frac{\Delta p}{\rho_{g}}\right)^{1 / 4}\left(t d_{n}\right)^{1 / 2}\left(\frac{294}{T_{g}}\right)^{1 / 4}
$$

Where $\Delta p$ is the pressure drop across the nozzle, $\rho_{g}$ is the gas density, $d_{n}$ is the nozzle diameter, and $t$ is the time after the start of injection. The spray tip penetration is generally higher for higher injection pressure, larger orifice diameter and longer time after start of injection. Swirl reduces both, the penetration of the spray and the velocity of spray. High swirl prevents fuel impingement on the walls. Fig. 2.2 shows images of the spray for liquid phase and vapor phase. 

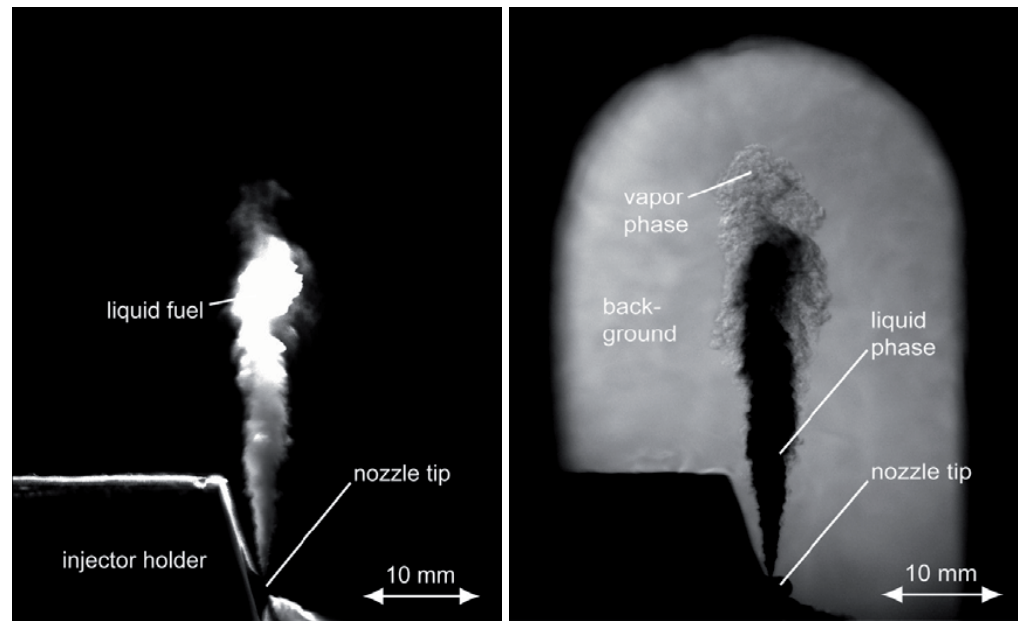

Figure 2.2: Scattering light (left) and a back-lit schlieren image (right) of a spray [6]

\subsubsection{Droplet size distribution}

There are many factors that control the droplet size of injected fuel such as injection pressure, nozzle orifice area and injection rate. As a result, the droplet size distribution in a given location changes according to time during the injection period. In addition, specific behavior of atomization is different in spray core and at the spray edge. The movement of droplets is dependent on their size, initial velocity and location within the spray. The droplet size distribution is very different depending on the location within the spray. According to aerodynamic theory of jet breakup in the atomization region, it is possible to predict the initial average drop diameter $D_{d}$, which is proportional to the length of the most unstable surface waves.

$$
\bar{D}_{d}=C \frac{2 \pi \sigma}{\rho_{g} v_{r}} \lambda
$$

Where $\sigma$ is the liquid fuel surface tension, $\rho_{g}$ is the gas density, $v_{r}$ is the relative velocity between liquid and gas, $\mathrm{C}$ is a constant of order unity and $\lambda$ is the dimensionless wavelength of the fastest growing wave. However, in the first stage of spray which is dense, droplet size distribution and mean diameter change because of secondary atomization phenomena such as coalescence and breakup. Finally the state of spray reaches a balanced stage so that breakup and coalescence cease [1]. 


\subsubsection{Spray evaporation}

After the spray has broken up into small droplets, the fuel evaporates from the liquid phase to the gas phase. The evaporation mostly depends on the properties of fuel, the ambient gas temperature, the pressure in cylinder and the evolution of droplet radius. Increase in temperature and pressure reduce the evaporation time. The fuel evaporation is a process of great importance especially in direct injection diesel engine because the thermodynamic efficiency is affected by the evaporation rate and it also significantly influences the emission formation. The injected fuel is in liquid phase. It is atomized into small drops, and has to evaporate and mix with air before burning. Poor evaporation will typically cause increased smoke and $\mathrm{HC}$, while very rapid evaporation, especially during the ignition delay, will cause an increase in $\mathrm{NO}_{\mathrm{x}}$ because of rapid premixed combustion associated with high temperature [2].

\subsection{Factors affecting spray motion}

In DI diesel engines, the fuel is injected at a high injection pressure using a central multihole nozzle in the combustion chamber which is normally in the shape of a bowl in the piston crown. The momentum and energy of the injected fuel could be sufficient for good mixing if properly utilized. Thus, the spray motion is an important factor in the fuel-air mixing process. Non-optimal spray motion in the combustion chamber may lead to liquid-spray wall impingement or overly rich regions, both of which may lead to increased soot or $\mathrm{HC}$ emissions. The spray motion, due to its effects on mixing, is not only important for pollutant formation but also for the ignition characteristics and combustion efficiency.

There are two major factors which affect the spray motion in a DI diesel engine, namely swirl and the bowl geometry. Both of these factors are discussed in more detail in the following sections.

\subsubsection{Swirl}

The term swirl refers to the rotational motion of the charge along the cylinder axis. Combustion systems having a swirl ratio greater than 1 and relatively deep piston bowl geometry such as reentrant bowl type are called as "swirl supported". The swirl ratio is defined as the ratio between the average angular velocity of the charge along the cylinder axis and the angular velocity of the crankshaft. The level of swirl strongly affects air-fuel mixing which in turn affects the fuel consumption, combustion speed and exhaust emissions [7-9]. Other parameters such as Injection pressure, orifice diameter and piston shape also play a major role in the mixing process. Therefore the swirl level should be carefully matched with the other parameters [10-12]. 
Increased swirl normally reduces particulate emissions but produces higher $\mathrm{NO}_{\mathrm{x}}[10,13]$. Swirl in diesel combustion provides for better air-fuel mixing and improves air-utilization [14]. This causes a leaner and faster premixed combustion phase increasing the cylinder pressure and gas temperature resulting in higher $\mathrm{NO}_{\mathrm{x}}$ emissions. Better mixing has a leaning effect on the spray which should reduce soot production and improve soot oxidation during expansion. The shortened combustion duration also improves fuel consumption [15].

As the swirl increases, it changes the fuel jet direction to use more air as well as reduces the impingement of fuel jet to the cylinder wall because of penetration reduction [16]. Strong swirl increases the relative velocity between the spray and air, thus increasing the heat and mass transfer between the liquid and gaseous phases. It also spreads the spray over a wider region in the direction of swirl increasing the lean flame region downstream of the spray center-line $[10,17]$. Combustion-induced flows have also been found to considerably affect the air-fuel mixing with swirl $[16,18]$. Swirl reduces the ignition delay thus reducing the peak heat release rate and maximum rate of pressure rise. The initial part of mixing controlled combustion is not affected much by swirl level, but the later part shows higher heat release rate for higher swirl [19]. In a study including both conventional and advanced combustion regimes such as LTC (Low Temperature Combustion), it was found that both $\mathrm{NO}_{\mathrm{x}}$ and soot are lower with higher swirl ratios under LTC [20].

There are many positive effects of swirl for better mixing, but excessive swirl tends to worsen the combustion. Overswirl may cause the particulate emissions to increase due to confinement of hot products in the center of the cylinder as a centrifugal action of swirl. Though, Miles [20] did not find any such effects in his study. Other consequences of overswirl include a decrease in spray penetration [8,11 and 14], overlap between adjacent sprays [21] and low mean gas temperatures because of an increased in-cylinder heat transfer. These factors can worsen the soot oxidation by impeding the air-fuel mixing during mixing controlled phase, resulting in higher soot emissions.

\subsubsection{Bowl geometry and spray targeting}

Two combustion chamber types have been prominent for Diesel engines in recent times, namely "re-entrant chamber" and "shallow-dish chamber" bowl geometries.

A re-entrant bowl shape is shown in Fig. 2.3(A). The re-entrant shape strongly affects the fuel distribution along the combustion chamber wall and air-fuel mixing and therefore affects the emissions and performance. A shallow dish bowl shape is shown in Fig. 2.3(B). This system is used more commonly for heavy duty applications because the prevailing high pressure common rail fuel injection system permit greater flexibility in the injection rate and energy available to promote mixing. The spray tip penetration increases more and more with high injection pressure. A large diameter chamber is required to allow more free spray travel, achieving a better air-fuel mixing and reducing the wall impingement and therefore the soot formation $[22,23]$.

For deep bowl geometries, it was reported that a bowl with a round re-entrant lip shape has about 20 percent longer spray path length than one without a re-entrant shape [24]. 
With a reentrant type bowl, the spray targeting is very important for optimal air-fuel mixing. A higher than optimal impingement point will deliver too much fuel to the cylinder head side, causing quenching at the head clearance, while too low an impingement point will deliver too much fuel over the floor of the piston bowl, causing poor mixing with air, owing to the lack of air near the center of the combustion chamber. The optimal impingement strongly depends on engine speed, injection system and combustion chamber diameter.

The central pip occupies a significant part of the piston bowl volume. It is introduced to prevent the fuel traveling further to the central area of the piston bowl where the flow velocity is low. The central pip is also used to induce and generate a vortex in the piston bowl to enhance the air-fuel mixing. However, sometimes too much pip area may trap the fuel spray at the piston bowl bottom and cause a poor air-fuel mixing and high soot emission [25].

\section{A. Re-entrant Bowl Type}

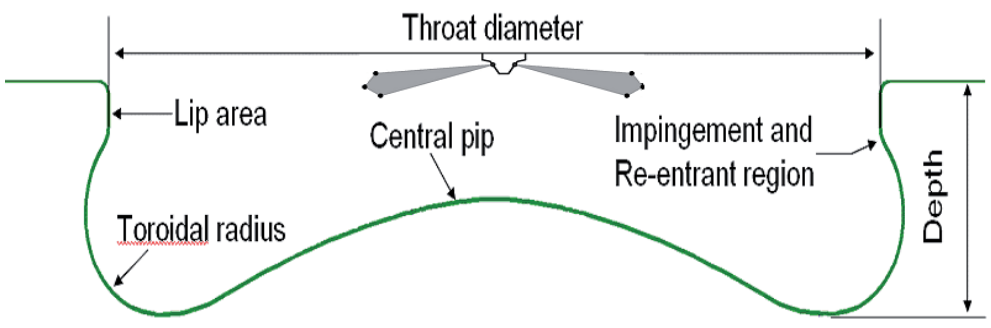

\section{B. Shallow dish bowl type}

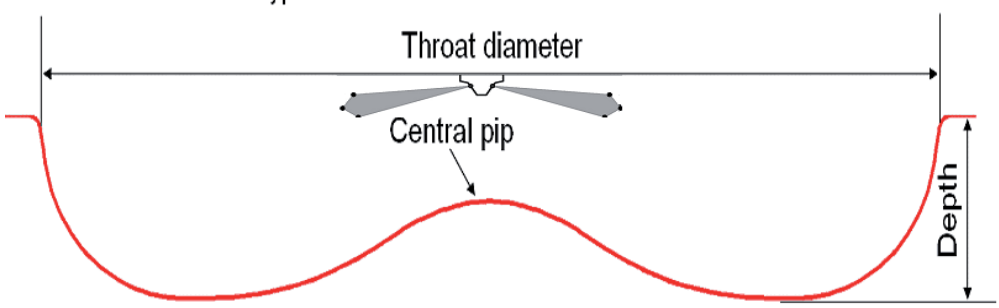

Figure 2.3: Re-entrant bowl shape and shallow dish bowl shape 
Lin et al [26] tested the effects of piston bowl shape on in-cylinder airflow and combustion. They reported on squish and reverse-squish flow for a re-entrant piston bowl similar to the one used in the current study. They showed that the squish flow induces high flow velocities and high turbulence in the whole bowl. However, the reverse squish flow seems to leave the volume along the piston bowl wall, below the rim, unaffected. In other words, the fuel accumulated along the piston bowl wall below the rim cannot rely on reverse-squish for its burnout. High soot concentration under piston bowl rim during the expansion stroke is also reported in calculation of CFD (Computational Fluid Dynamics) by Dahlén [27]. Dahlén also performed a CFD-simulation without injection and combustion to demonstrate how the in cylinder gas flow affects fuel that is located on the piston bowl wall. It shows that the reverse-squish flow aids the mixing of fuel that is accumulated on the bowl rim. Fuel located below the rim mixes much slower with the surrounding air. An effect of the fairly quiescent situation along the wall under the rim during expansion is that we should expect a relationship between how the fuel is distributed along the wall and the subsequent flow of flames into the squish region. Presumably thanks to its sprays heavy impact onto the piston bowl wall that builds up the thickest "blob" of fuel. This fuel then easily moves with the reverse squish flow into the squish region and combusts as it mixes with air.

Y. Zhu et al [28] studied the effect of the re-entrant lip shape and toroidal radii of piston bowl on HSDI (High Speed Direct Injection) diesel engine. The results have shown that the large toroidal radius bowl produces better combustion and hence better engine performance than the small toroidal radius bowl when a high injection pressure is used in an HSDI diesel engine. The larger toroidal radius is effective in lowering the ISFC and soot emission.

Caroline L. et al [29] studied effects of piston bowl geometry on mixture development in a heavy duty diesel engine. The impacts of combustion chamber design on in cylinder mixing processes are explored by comparing three piston bowl diameter of $60 \%, 70 \%$ and $80 \%$ of the cylinder bore. The data show that the piston bowl diameter influences in cylinder mixing and pollutant formation processes by altering jet-jet and jet-wall interactions. When the fuel jets impinge on the bowl wall prior to ignition, adjacent jets merge, forming fuel-rich regions where soot formation occurs. By using a smaller diameter bowl, a strong jet-wall interaction pushes the fuel-rich jet-jet interaction regions into the center of the chamber, where mixtures are predominantly lean. This reduces net soot formation and displaces fuel-lean regions of otherwise incomplete combustion into the combusting regions near the bowl wall.

Middlemiss [30] reported that reducing the combustion chamber throat diameter can enhance the squish flow and improve the air-fuel mixing, therefore reducing the particulate and specific fuel consumption but increasing the $\mathrm{NO}_{\mathrm{x}}$ emission. It was also reported that the bowl with reduced throat diameter and retarded injection timing could reduce not only soot but also $\mathrm{NO}_{\mathrm{x}}$ emission [31-33]. A sharp squish lip shape can reduce the smoke without increasing $\mathrm{NO}_{\mathrm{x}}$ emission in a typical combustion chamber [30]. 


\subsection{Combustion characteristics}

In combustion engines, the liquid fuel is injected at high velocity as one or more jets into the combustion chamber and the fuel vaporizes and mixes with the air in cylinder. The overall mixture formation affects the combustion characteristics. The effects mainly depend on the extent of mixing and the location of lean and rich mixture.

The ignition delay, Heat release and fuel burning rate are important indicators to understand the combustion process in a diesel engine. The major task in diesel combustion is to achieve sufficiently rapid mixing between the injected fuel and the air in cylinder to complete the combustion in a short period of time, close to the TDC (Top Dead Center). Combustion close to the TDC performs the heat addition close to the maximum cylinder pressure and temperatures, which maximizes the fuel efficiency. The cylinder pressure increases above the motoring pressure as combustion of the air-fuel mixture occurs and the heat release can be calculated from the cylinder pressure. The heat release is used to define the rate of the conversion of chemical energy in the fuel by the combustion process. The fuel burn rate, especially during the mixing controlled combustion phase, is also one of the indicators for mixing rate in combustion chamber.

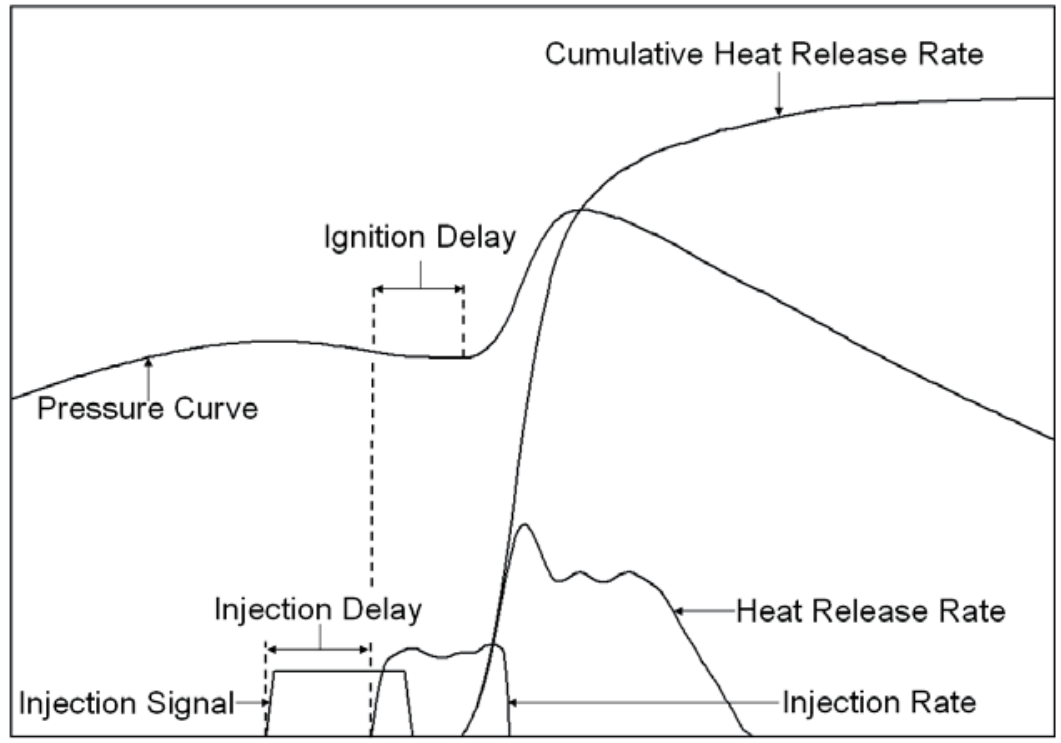

Figure 2.4: Indicators for the combustion process in a diesel engine. 


\subsubsection{Ignition delay}

As indicated by Fig. 2.4 there is generally a time lag between the start of injection and auto ignition in diesel engines. During this time, several physical and chemical subprocesses take place such as fuel atomization, evaporation, fuel air mixing and chemical pre-reactions. This time period is referred to as ignition delay.

In case of diesel combustion, combustion of the fuel, which is injected into high temperature and high pressure chamber directly, starts in an inhomogeneous way due to lack of time to mix the fuel homogeneously. Injection continues until the desired amount of fuel has entered the cylinder. Atomization, vaporization, air-fuel mixing and combustion continue until essentially all the fuel has passed through each process. In addition, mixing of the air remaining in the chamber with burning and already burned gases continues throughout the combustion and expansion processes. The problem with a short delay is that the inhomogeneous combustion directly affects the formation of pollutants such as PM. Accordingly, achieving longer ignition delay than conventional diesel combustion by low temperature combustion and oxygen dilution with higher EGR (Exhaust Gas Recirculation) can be a solution to have better air-fuel mixture and to reduce the formation of soot. However, it is necessary to consider about the trade off between $\mathrm{NO}_{\mathrm{x}}$ and $\mathrm{HC}$ and the inapplicability of high EGR at high speed and high load condition. The delay period between the start of injection and start of combustion must be also controlled to hold the maximum cylinder gas pressure for improving of the efficiency. The cetane number of the fuel must be considered by the optimal ignition delay for diesel combustion $[34,35]$.

\subsubsection{Heat release}

The heat release rate is an important concept to understand combustion. It can be defined as the rate of the chemical energy released by combustion process. It is calculated form cylinder pressure versus crank angle data. In order to obtain combustion information from pressure data, we can use the first law of thermodynamics for a quasi static open system.

$$
\begin{aligned}
& \frac{d Q}{d t}-p \frac{d V}{d t}+\sum_{i} \dot{m}_{i} h_{i}=\frac{d U}{d t} \\
& \frac{d Q}{d t}-p \frac{d V}{d t}+\dot{m}_{f} h_{f}=\frac{d U}{d t}
\end{aligned}
$$

Assuming $U$ and $h_{f}$ in Eq. (2.4) to be sensible internal energy of the cylinder contents and sensible enthalpy of the injected fuel, $d Q / d t$ becomes the difference between the chemical energy or heat release by combustion of fuel and the heat transfer form the system. Because $h_{f} \approx 0$, Eq. (2.4) becomes 


$$
\frac{d Q_{n}}{d t}=\frac{d Q_{c h}}{d t}-\frac{d Q_{h t}}{d t}=p \frac{d V}{d t}+\frac{d V_{s}}{d t}
$$

In this equation, $d Q_{n} / d t$ represents the apparent heat release rate which is the sum of the rate at which work is done on the piston and the rate of change of sensible internal energy of cylinder contents. If it is possible to assume that the contents of the cylinder as an ideal gas, Eq. (2.5) becomes

$$
\frac{d Q_{h}}{d t}=p \frac{d V}{d t}+m c_{v} \frac{d T}{d t}
$$

By applying ideal gas law $P v=m R T$, Eq. (2.6) becomes

$$
\frac{d p}{p}+\frac{d V}{V}=\frac{d T}{T}
$$

With the equations mentioned above, heat release rate can be calculated [34].

\subsubsection{Fuel mass burning rate}

The definition of burning rate is the mass of liquid fuel consumption per unit time. By burning, it means the fuel reacts with oxygen. In fire, in broad prospect, fuel may vaporize but not burn immediately because of limited oxygen. Therefore, it is necessary to distinguish between the mass loss rate of fuel in the fire and mass burning rate. In case of the internal energy of the fuel, air and burned gas in Eq. (2.3) are considered to a consistent datum, then this equation could be used to obtain an apparent fuel mass burning rate from cylinder pressure versus crank angle data.

Then, according to Krieger and Borman, Eq. (2.4) can be written as

$$
\frac{d}{d t}(m u)=-p \frac{d V}{d t}+\frac{d Q}{d t}+h_{f} \frac{d m}{d t}
$$

Where, $Q$ is the heat transfer to the gas in the combustion chamber, $m$ is the mass in the combustion chamber and $d m / d t$ is used instead of $\dot{m}_{f}$. In the cylinder during the combustion, the properties of the gases are generally a function of $p, T$ and the equivalence ratio $\phi$, so

$$
u=u(T, P, \phi) \text { and } R=R(T, P, \phi)
$$

Therefore 


$$
\begin{aligned}
& \frac{d u}{d t}=\frac{\partial u}{\partial T} \frac{d T}{d t}+\frac{\partial u}{\partial p} \frac{d p}{d t}+\frac{\partial u}{\partial \phi} \frac{d \phi}{d t} \\
& \frac{d R}{d t}=\frac{\partial R}{\partial T} \frac{d T}{d t}+\frac{\partial R}{\partial p} \frac{d p}{d t}+\frac{\partial R}{\partial \phi} \frac{d \phi}{d t}
\end{aligned}
$$

Also,

$$
\phi=\phi_{0}+\left(\frac{m}{m_{0}}-1\right) \frac{1+(F / A)_{0}}{(F / A)_{s}}
$$

And

$$
\frac{d \phi}{d t}=\frac{1+(F / A)_{0}}{(F / A)_{s} m_{0}} \frac{d m}{d t}
$$

It then follows that

$$
\frac{1}{m} \frac{d m}{d t}=\frac{-(R T / V)(d V / d t)-(\partial u / \partial p)(d p / d t)+(1 / m)(d Q / d t)-C B}{u-h_{f}+D(\partial u / \partial \phi)-C[1+(D / R)(\partial R / \partial \phi)]}
$$

Where

$$
\begin{gathered}
B=\frac{1}{p} \frac{d p}{d t}-\frac{1}{R} \frac{\partial R}{\partial p} \frac{d p}{d t}+\frac{1}{V} \frac{d V}{d t} \\
C=\frac{T(\partial u / \partial T)}{1+(T / R)(\partial R / \partial T)} \\
D=\frac{\left[1+(F / A)_{0}\right] m}{(F / A)_{s} m_{0}}
\end{gathered}
$$

The actual fuel burning rate is unknown because not all the fuel burns with sufficient air. Around 60 percent of fuel has burned in the first-third of total combustion period. The integral of fuel mass burning rate over combustion process and total fuel mass burned should be same. And the chemical energy continues to be released well into expansion process [34]. 


\subsection{Pollutant formation}

The injection of Diesel into the engine generates a non-uniform fuel distribution. In fuelrich regions, soot-particles are formed. Pollutants as $\mathrm{HC}$ result from a locally, incomplete combustion due to quenching at cold walls and nozzle sac at end of injection. Another major pollutant is $\mathrm{NO}_{\mathrm{x}}$ that is formed in the reaction zone at high temperatures. The objective is to minimize both, NOx and soot emissions to meet the emission regulations. However, $\mathrm{NO}_{\mathrm{x}}$ occurs at high temperatures where soot is burned. At low temperatures, $\mathrm{NO}_{\mathrm{x}}$ emissions are minimized but soot particles are not fully oxidized. This phenomenon is denoted as tradeoff between soot and $\mathrm{NO}_{\mathrm{x}}$. Fig. 2.5 shows the summary of pollutant formation mechanisms in a direct injection diesel engine during premixed and mixing controlled combustion phases [36].
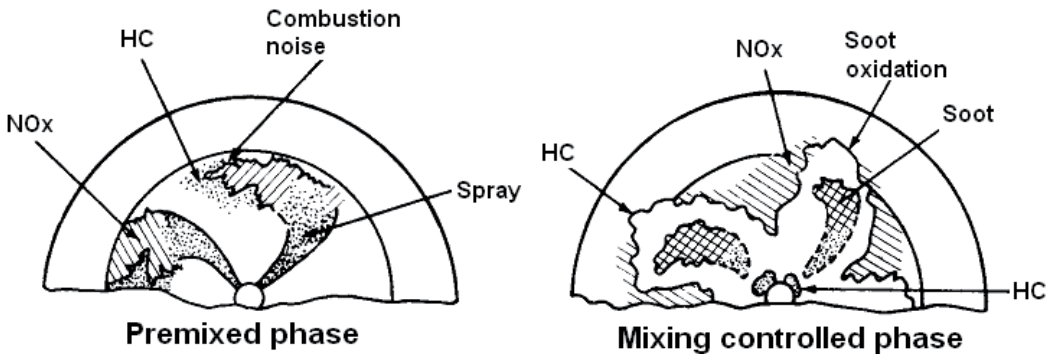

Figure 2.5: Summary of pollutant formation in diesel combustion phases [36]

\subsubsection{Paticulate emissions (PM)}

These particles are formed from PAH (Polycyclic Aromatic Hydrocarbons). The smallest particles are of a weight of $2000 \mathrm{amu}$ with a diameter of about $1.5 \mathrm{~nm}$. These primary particles are formed in the nucleation process and grow due to coagulation with other particles, condensation of hydrocarbons form the gaseous phase and by surface growth up to a size of $50 \mathrm{~nm}$. The shape of the soot particles ranges from spherical particles to irregular shaped agglomerates. The soot growth and oxidation process depends on the local temperature, pressure and mixture conditions. In a non-premixed flame, soot is formed in fuel-rich regions. The temperature must be in a range between 1250 and $1800 \mathrm{~K}$. Lower temperatures limit the formation of soot precursors whereas soot particles are oxidized at higher temperatures. The soot volume fraction depends quadratically on the pressure for pressures up to $10 \mathrm{bar}$ due to the effect of gas compression. At higher pressures, the soot volume fraction is only a linear function of the pressure $[37,38]$. 
Oxidation occurs close to the iso-surface of stoichiometric mixture by $\mathrm{OH}$ - and $\mathrm{O}$ radicals. Local flame quenching at cold walls prevents the soot oxidation process and soot emissions are found in the exhaust gas of a Diesel engine. The Fig. 2.6 shows the schematic of diesel particulate and vapor phase compound.
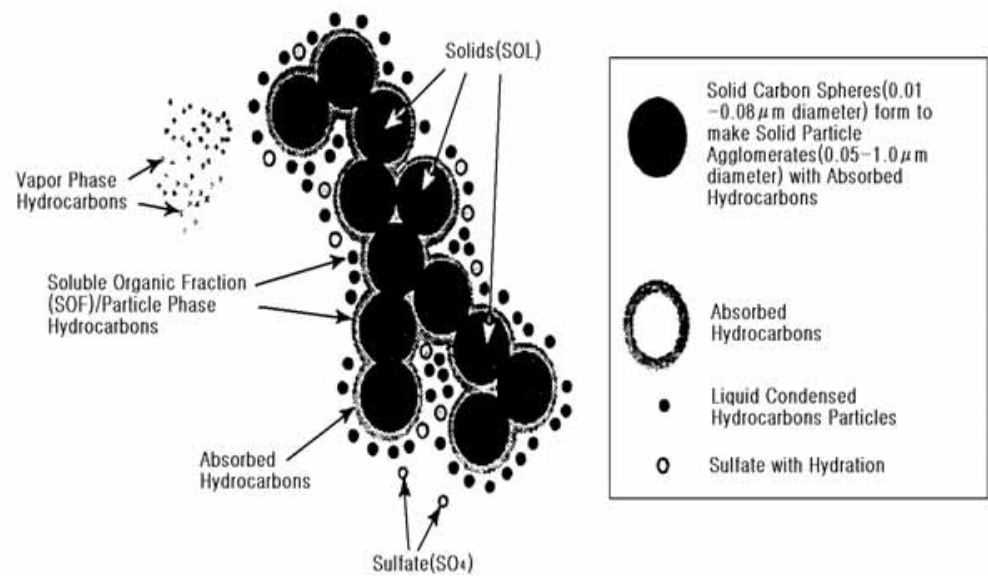

Figure 2.6: Schematic of diesel particulate and vapor phase compound [39]

These particles are very small and can be breathed in easily. They have hundreds of chemicals absorbed onto their surfaces, including many known or suspected mutagens and carcinogens.

\subsubsection{Gaseous emissions ( $\mathrm{NO}_{\mathrm{x}}, \mathrm{HC}$ and $\left.\mathrm{CO}\right)$}

Gaseous emissions of diesel combustion include $\mathrm{NO}_{\mathrm{x}}, \mathrm{HC}$ and $\mathrm{CO}$ which have the potential to cause adverse health effects, including cancer and other pulmonary and cardiovascular diseases. NO forms almost all of the nitrogen oxides emitted from a diesel engine with small amounts of $\mathrm{NO}_{2}$. They are collectively denoted as $\mathrm{NO}_{\mathrm{x}}$. $\mathrm{NO}$ is formed from chemical combination of nitrogen and oxygen in the air at temperatures higher than $1500^{\circ} \mathrm{C}$, and the formation of $\mathrm{NO}$ increases rapidly with an increase in temperature. $\mathrm{CO}_{2}$, $\mathrm{CO}, \mathrm{H}_{2} \mathrm{O}$ and $\mathrm{OH}$ attain equilibrium concentration in about $1 / 1000^{\text {th }}$ of a second after combustion, while NO takes relatively longer time to reach equilibrium concentration. The most important parameters for NO formation are the temperature of the gas, oxygen concentration and the available time at high temperature. Usually the highest NO concentration occurs at lean air-fuel ratios, where the air-fuel ratio is lower compared to the air-fuel ratio of the locations with the highest gas temperature, due to the higher levels 
of oxygen remaining after combustion. The following reaction formula can be used to understand the formation of NO.

$$
\begin{aligned}
& \mathrm{O}+\mathrm{N} 2 \leftarrow \rightarrow \mathrm{NO}+\mathrm{N} \\
& \mathrm{N}+\mathrm{O} 2 \leftarrow \rightarrow \mathrm{NO}+\mathrm{O} \\
& \mathrm{N}+\mathrm{OH} \leftarrow \rightarrow \mathrm{NO}+\mathrm{H}
\end{aligned}
$$

(2.13) and (2.14) represent the well known Zeldovich mechanism and (2.15) represents the extended Zeldovich mechanism.

$\mathrm{CO}$ is mainly formed due to incomplete combustion in excess of fuel in fuel-rich zones. $\mathrm{CO}$ can be oxidized to $\mathrm{CO}_{2}$ in presence of sufficient oxygen at high temperatures. Because diesel engines mainly operate with a lean air-fuel mixture ratio, they provide sufficient oxygen to oxidize $\mathrm{CO}$. Total amount of $\mathrm{CO}$ emission is the sum of $\mathrm{CO}$ from incomplete combustion and $\mathrm{CO}$ made from thermal dissociation. The extent of thermal dissociation depends on the air-fuel ratio, so the concentration of $\mathrm{CO}$ changes according to the actual air-fuel ratio. In diesel engine, $\mathrm{CO}$ emission is low enough to be considered as unimportant because of predominantly lean operation.

$\mathrm{HC}$ is a general term for Hydrocarbons which are unburned or partly burned. HC formation can be classified in three different ways. Air-fuel mixture flowing in to small space in the cylinder such as crevices of gasket and piston, quenching area near the cylinder wall which has relatively low temperature due to heat loss to cooling device and $\mathrm{HC}$ which are absorbed in the thin oil layer and are discharged during expansion are the main reasons of $\mathrm{HC}$ formation. $\mathrm{C}_{8} \mathrm{H}_{14}, \mathrm{CH}_{4}$ or ppm (parts per million) can be used in order to calculate the amount of $\mathrm{HC}$ emissions. It is natural that $\mathrm{HC}$ formation increases in the rich air-fuel mixture regions. However, hydrocarbon emissions also increase at very low air-fuel ratios.

In diesel engine, $\mathrm{HC}$ and $\mathrm{CO}$ emissions are normally very low for conventional operation but they are of major concern in certain conditions such as PCCI (Premixed Charge Compression Ignition) operation, because $\mathrm{CO}$ and $\mathrm{HC}$ emissions are usually higher when combustion temperature is low.

\subsection{Strategies for clean diesel combustion}

There are concerns about meeting the increasingly stringent standards for the exhaust emissions, particularly $\mathrm{NO}_{\mathrm{x}}$ and particulate matter. The euro norms for emissions are shown in Fig. 2.7. Many strategies have been developed to control the in-cylinder combustion process, in addition to the use of exhaust after-treatment devices. The control parameters include injection pressure, number of injections, injection timing, EGR, bowl shape and swirl ratio. In many cases, the strategies that reduce $\mathrm{NO}_{\mathrm{x}}$ increase $\mathrm{PM}$ and vice versa. For example in conventional diesel combustion, increasing injection pressure and swirl ratio reduce soot emissions, but increase $\mathrm{NO}_{\mathrm{x}}$. Also, higher EGR reduces NOx but 
increases soot. This is not the case in some advance diesel combustion concepts [40-45]. For example in the LTC regime, increasing EGR reduces both $\mathrm{NO}_{\mathrm{x}}$ and soot. With the advances in injection technology it is now possible to achieve higher injection pressures and deliver multiple injections with different injection rate-shapes and more accurate timings. Also, with the advances in the design of intake ports, it is possible to develop swirl motions of different ratios [20].

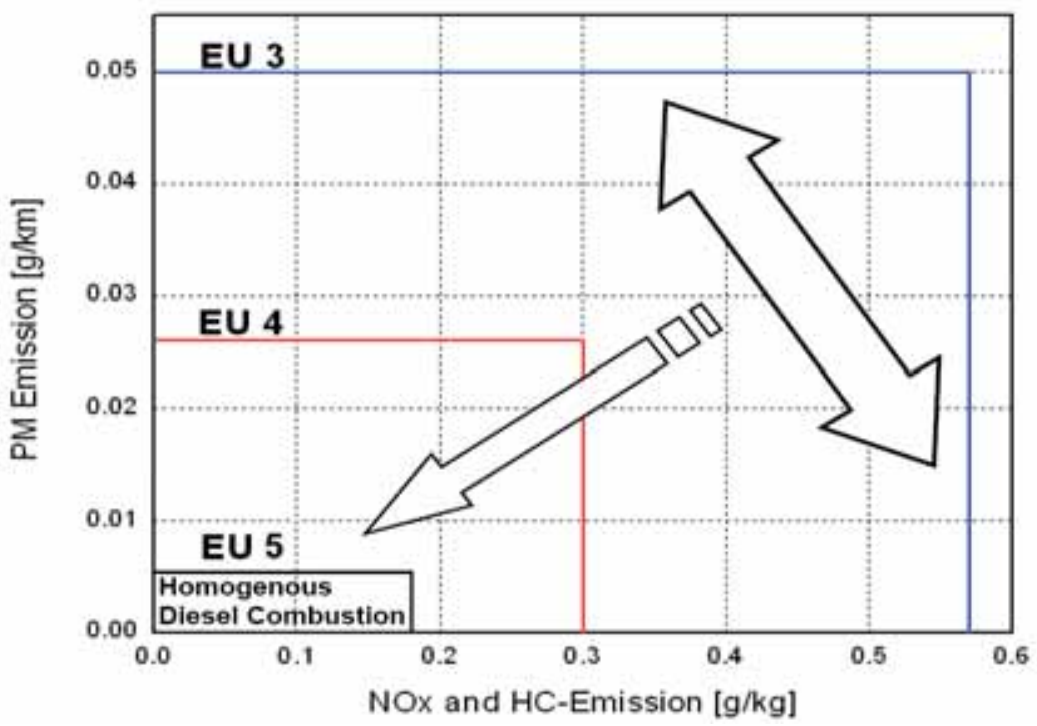

Figure 2.7: Euro norms for the emissions

\subsubsection{High pressure injection}

One possibility to realize the desired decrease in orifice diameter and increase in orifice number is to abandon the equispaced design and to cluster the orifices. The aim of cluster nozzle concept is to keep the spatial distribution of spray as close to a conventional nozzle as possible despite a reduction of the nozzle orifice diameter. But the nozzles with smaller orifice and the cluster nozzle with large positive included angle between the orifices tend to reduce spray tip penetration length while improving the atomization. Spray tip penetration for cluster nozzles with smaller included angles is larger than the clusters with large included angles but is smaller than a conventional nozzle having the same flow number. A combination of high pressure injection and cluster nozzles with small orifices could be one of the alternative hardware configurations to achieve lean combustion for DI diesel engine. In the last few decades, numerous research efforts have 
been devoted to investigating the prospects of increasing injection pressure and reductions in hole-size on diesel combustion and emission.

Nakakita et al. [46] studied the influence of injection pressure and timing on $\mathrm{NO}_{\mathrm{x}}$ and soot. The experiment was conducted at 60 percent of relative speed ratio and from 20 percent to 100 percent of load range. As a result, the formation of soot was reduced significantly with higher injection pressure excluding full load condition where the reduction was small.

Yokota et al. [47] investigated the relationship between the characteristics of nonevaporating sprays and their corresponding flames in a rapid compression machine. After comparing SMD (Sauter Mean Diameter) and mean excess air ratio for sprays with different injection pressures, durations and orifice diameters, they concluded that the main factor which controls the burning rate is excess air ratio, and combustion duration and soot formation is reduced as the injection pressure is increased.

$\mathrm{Su}$ et al. [48] examined the character of high injection pressure, up to $1500 \mathrm{bar}$ with $0.243 \mathrm{~mm}$ and $0.259 \mathrm{~mm}$ hole diameter injectors, using a single cylinder engine and spray tests. Higher injection pressure produces lower soot, higher $\mathrm{NO}_{\mathrm{x}}$ and lower PM because of smaller average droplet size according to SMD measurement. In case $\mathrm{NO}_{\mathrm{x}}$ is kept at the same level, soot formation is significantly reduced by using smaller-hole nozzles.

Varde and Watanabe [49] performed tests using a common rail injection system with intensifier producing pressure up to 1600 bar. They found that the SMD at the outer region of spray decreased with increased injection pressure. Peak and average pressure during injection were found to affect the formation of soot and $\mathrm{NO}_{\mathrm{x}}$. Smoke, $\mathrm{NO}_{\mathrm{x}}$ and fuel consumption rate were improved with variable dynamic injection timing and high injection pressure.

Higher pressure injection produces faster sprays, increasing spray penetration and reducing SMD. As the spray reaches the piston walls, the vapor spreads over a larger surface area, moves further along the wall towards the bottom of the bowl and radially inward to the center of the bowl. This improves the mixing of the fuel with the bulk of the air in the bowl. In additions, higher injection pressures enhance the development of faster wall jets producing more turbulence and better mixing. These three factors increase the premixed combustion fraction. The reduction in soot emissions at the higher injection pressures is mainly due to the improved homogeneity of the charge. Another factor that might have contributed to the drop in soot emission is the reduction in the fraction of the fuel injected in the flame [50-54].

Dec [55] suggests that a premixed standing flame located downstream of the liquid tip is a major source of soot precursors during the mixing controlled combustion phase. Siebers et al. [56] found that doubling the injection velocity increase the lift-off such that more air was entrained into the spray before the fuel reached combustion zones. This has the potential to decrease the soot-precursor formation in the premixed flame zone [57]. 


\subsubsection{Multiple injection}

During the 80's, especially in Europe, the focus started to shift towards DI diesel engine because of its fuel economy advantage. In spite of its advantage of high fuel economy, diesel engine has fundamental problems about high $\mathrm{NO}_{\mathrm{x}}$ and soot emission, and environmental concern of HSDI diesel engine became an important issue. In order to qualify for the strengthening regulations, it was necessary to develop countermeasures against pollutant emissions, such as after-treatment technology, EGR and electronic engine control. Recently, as a result of common rail fuel injection system development, more flexibility in high pressure injection and control of the injection strategy has been attained. It is well known that diesel combustion quality is strongly dependent on the quality of air-fuel mixture condition. Thus, high injection pressure and multiple injections are commonly used as better air-fuel mixture and droplet breaking strategy recently.

In 1937, the multiple injection concepts were first proposed by Jafer. Jafer [58] used multiple injection to reduce combustion noise and to enable the use of poor ignition quality fuel. With the development of injection control systems, multiple injection strategy has been noted and applied for pollutant emission reduction. Multiple-injection is an effective way to reduce combustion noise, due to it shortening the ignition delay with a small amount of pre injection, thus reducing premixed combustion phase and the rapid pressure rise associated with it which is the main reason of noise. Multiple-injection is also a considerable way of achieving low $\mathrm{NO}_{\mathrm{x}}$ emission level because most of the $\mathrm{NO}_{\mathrm{x}}$ is generated during the premixed combustion period. Even though reduced premixed combustion period produces more soot emission, it can be controlled with more precise fuel injection and by after injection strategy. So, it is possible to achieve significant improvements in the trade off between particle matters and $\mathrm{NO}_{\mathrm{x}}$ emission levels.

\subsubsection{Low temperature combustion}

One approach to reduce the emissions in a diesel engine is PCCI which has been studied over the past years by many researchers using engine experiments [59-67] and simulation studies [68-71]. The basic idea of PCCI is to enhance mixing and evaporation by an early fuel injection in the compression cycle before TDC. The injection system and mixture formation are effective means to control the emissions because combustion is controlled by mixing as noted in [73, 74]. In the case of part load conditions, early injection strategies are offering the possibility to enhance the mixing and evaporation process prior the auto-ignition of Diesel fuel. Due to the early injection, ignition and evaporation are separated in time and space. As a result, less fuel-rich pockets occur from where soot could be formed. The simultaneous reduction of $\mathrm{NO}_{\mathrm{x}}$ can be achieved by the use of cooled EGR which dilutes the intake charge. The combustion is shifted to lower temperatures and less $\mathrm{NO}_{\mathrm{x}}$ is formed. The conditions at SOI (Start of Injection) are very important for the ignition process. Mixing of the fresh air with EGR increases the heat capacity and density. Both of effects lead to a decrease in temperature. Therefore, ignition is retarded to later times and the evaporation time is enhanced. The concept of PCCI combustion is not applicable to all operating conditions. If higher amounts of fuel 
are injected, the start of injection has to be advanced to earlier times in order to separate the ignition and evaporation process but is limited by the nozzle design. Fuel-wetting on the liner due to spray-wall interactions has to be avoided by applying a narrow spray angle as proposed and studied in $[74,75]$. The narrow spray angle limits the system only to early injection events and is not suitable to conventional combustion mode at high loads. The additional use of EGR is another way to shorten the spray penetration, as observed in [75] and in [76] where moderately narrow spray angles are investigated, to prevent the fuel-wetting of the liner.

Another major benefit of EGR is to dilute the mixture by which soot and $\mathrm{NO}_{\mathrm{x}}$ can be simultaneously reduced $[77,78]$. The reduction of soot and $\mathrm{NO}_{\mathrm{x}}$ is a goal that has to be achieved and the PCCI combustion mode offers a solution.

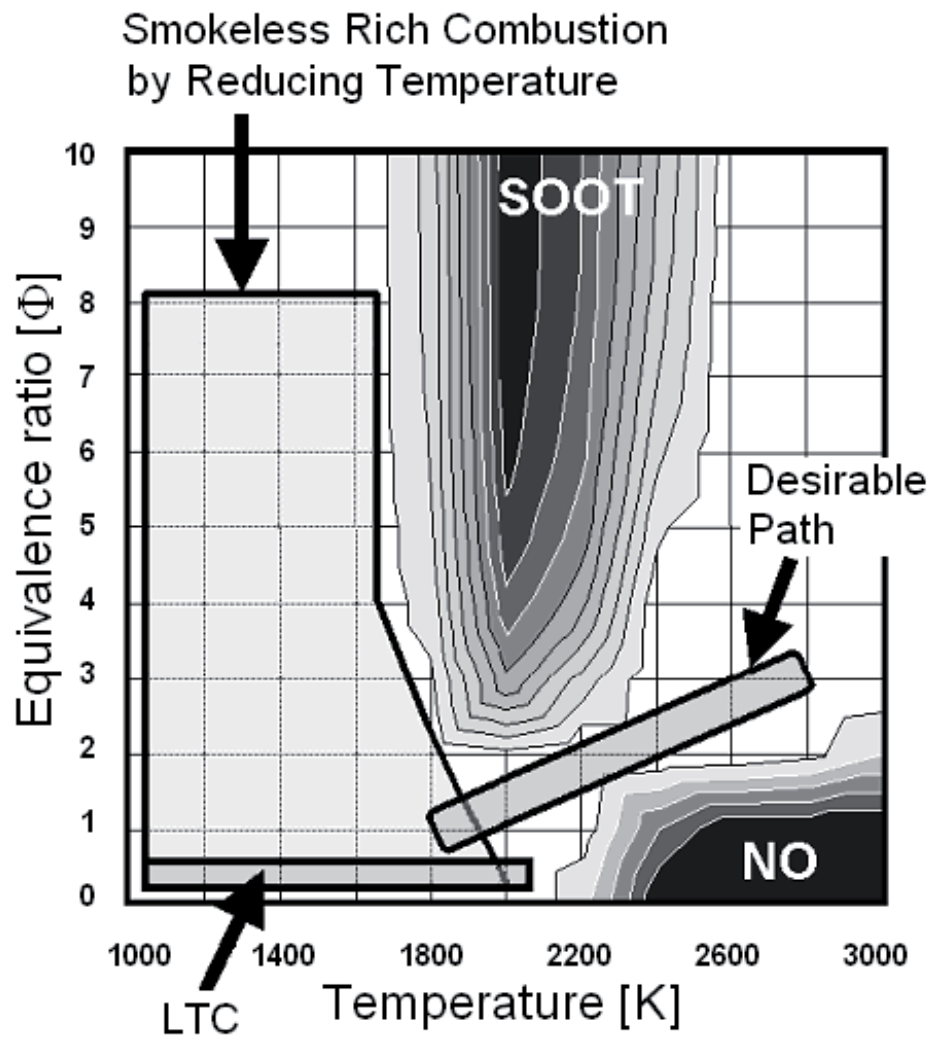

Figure 2.8: Combustion design in $\Phi$ - $\mathrm{T}$ phase space with regions of soot, $\mathrm{NO}_{\mathrm{x}}$ and the desirable path [79] 
In order to obtain smokeless rich diesel combustion, it is necessary to use a large amount of cooled EGR. Since, by lowering the combustion temperature with the use of EGR, it is possible to control smoke and $\mathrm{NO}_{\mathrm{x}}$ at a significantly low level not only under stoichiometric optimal condition but also in a rich fuel condition. Fundamentally, it is well known that the soot formation is suppressed under a low temperature. The formation of air-fuel mixture for smokeless rich diesel combustion is similar to conventional diesel combustion. Even though locally rich mixture exists similar to conventional operation, combustion occurs at the lower temperature part (below 1700K) of $\varphi$-T map due to large amounts of cooled EGR. Also, the temperature of this highly cooled EGR combustion is low enough to avert from $\mathrm{NO}_{\mathrm{x}}$ forming area. Fig. 2.8 shows smoke and $\mathrm{NO}_{\mathrm{x}}$ density distribution on the $\varphi-\mathrm{T}$ map. The soot and $\mathrm{NO}$ reducing methods can be classified depending on the area of the $\varphi$-T map where the combustion occurs. With the homogeneous lean combustion, the temperature of combustion is lowered. HCCI (Homogeneous Charge Compression Ignition) combustion suppresses formation of soot by homogeneous lean fuel mixture and combustion. There is also another possibility to suppress forming of soot by high temperature combustion which is indicated as desirable path on the map. Previously mentioned two methods are the methods which effectively control the formation of soot even though they have different approach.

In lower temperature region (below $1700 \mathrm{~K}$ ), the reaction processes from $\mathrm{PAH}$ to soot particle simultaneously deteriorate and stop suddenly. Usually most of the fuel is burned after combustion, but some unburned fuel still remains after combustion. Some of the remaining fuel components which have low boiling temperatures are emitted as HC. And the other remaining components which have higher boiling temperatures form part of SOF (Soluble Organic Fraction) [79].

\subsubsection{Cluster concept}

Nozzles with more and smaller orifices have contributed significantly to the improvement of Diesel engines in the past years. Kobori et al. [80] have investigated the influence of micro-hole nozzles on combustion in a rapid compression machine. As they reduced the orifice diameter and increased the number of orifices, they noted a reduction of ignition delay and soot emissions.

Pickett and Siebers [81] studied the soot formation process of diesel fuel jets in a constant volume combustion vessel under heavy duty DI diesel engine conditions using a 50 micrometer single orifice nozzle. They observed very low amounts of soot for lower oxygen concentration conditions, which have substantially lower flame temperatures, suggesting that $\mathrm{NO}_{\mathrm{x}}$ and soot can potentially be simultaneously reduced with small orifices and exhaust gas recirculation. They explained this effect by the increased mixing which made the mixture lean enough to prevent the formation of soot.

Benajes et al. [82] have tested an engine with equispaced nozzles with 6,12 and 18 orifices with and without swirling in-cylinder flow (for brevity denoted swirl). Without swirl, the nozzle with 12 orifices leads to the lowest emission. However, the emission 
level in this case is significantly higher than that for 6 orifice nozzle with swirl. They also conducted a test about the effect of the number of nozzle orifices in a single cylinder engine at part and full load and found that 6-hole nozzle was optimal for their $2 \mathrm{~L}$ displacement 4-cylinder engine [83].

Adomeit et al. [84] have performed a study on the number of orifices in nozzles of engines for passenger car applications with 0.4 to 0.551 displacement per cylinder. They find a constant number of 5 orifices per nozzle from the late $80 \mathrm{~s}$ to the late $90 \mathrm{~s}$. In the last 10 years, there are between 6 and 8 orifices per nozzle. From this, they derive a trend indicating that the number of orifices per nozzle increases by about 1.5 every decade. However, the data shown exhibit a noticeable scatter around the trend line. They also plot a trend line for the orifice diameter, showing a decrease of $40 \mu \mathrm{m}$ per decade.

Fasolo et al. [83] investigate the influence of the number of orifices of the injector on soot emissions with CFD and find for their 21 displacement, 4 cylinder engine an optimum at 6 holes.

Also remarkable is the publication by Schommers et al. [85] where the layout of a 5 year old production engine is redesigned and equipped with an injection system from a different supplier in this process. Nonetheless, the number of orifices in the nozzle remains unchanged. A lot of possibilities have emerged recently to manufacture nozzles with small orifices.

A reduction in ignition delay and soot emissions has been observed for a higher number of smaller diameter orifices. Since no benefits were observed by increasing the number of holes in a nozzle above an optimum, and demands of better atomization and mixing require a further reduction of orifice diameter [86], the cluster concept was developed. Compared with the conventional nozzle, the difference is that a cluster nozzle has several groups of orifices; each group consists of two or more smaller orifices placed very close to each other. The orifices may be parallel to each other or have a small included-angle between them. Reduction of the orifice diameter is expected to improve the fuel atomization and evaporation. In addition, the closely-placed orifices are expected to hold the momentum better than a single small diameter orifice, maintaining the penetration of the spray.

Nishida et al. have investigated many group-hole nozzles with different included injection angles and compared them with single-hole nozzles. They showed the included injection angle to be an important parameter for spray formation [87-89]. Nozzles with negative included angles were found to have a similar characteristic compared to a conventional nozzle. Diverging nozzles with positive included angle between the sprays showed a tendency to reduce penetration length while improving the atomization. Penetration length and atomization increase for the cluster nozzles with higher injection pressures $[90,91]$.

Zhang et al. [92] studied group-hole nozzles as an alternative solution of the problems associated with minimization of orifice diameter. They conducted the experiments in a 
high temperature and high pressure constant volume vessel using a common rail injection system. They conclude that the group-hole nozzle has better fuel atomization, fuel evaporation, and air entrainment without a decrease in tip penetration with same total cross-section area of injection.

Adomeit et al. [84] investigated a 4-cylinder engine with a displacement of $1700 \mathrm{~cm} 3$. In part load conditions they find the usage of cluster nozzles advantageous and note improvements in the soot- $\mathrm{NO}_{\mathrm{x}}$ tradeoff. They observe a slight advantage for convergent configurations compared to divergent clusters. However, in full load operation a conventional nozzle with six orifices shows better soot- $\mathrm{NO}_{\mathrm{x}}$ tradeoff than the cluster nozzles.

Dohle et al. [93] have investigated a number of cluster nozzles in a $400 \mathrm{~cm} 3$ single cylinder engine. Among the investigated cluster configurations they also find the convergent layouts to be the most advantageous. Over the whole engine operation range, the best performance is observed in this study for a conventional 7-hole nozzle.

Gao et al. [91] investigated the flame propagation of sprays from a conventional nozzle and a cluster nozzle with two orifice circles and $10^{\circ}$ between the divergent sprays in an optical engine. They observed significantly reduced soot luminosity for the sprays in the test runs with the cluster nozzles. They concluded that these nozzles have major advantages compared to conventional nozzles in terms of soot production in the engine due to the leaner equivalence ratio. As the results reported in [84] and [93] find no emission advantage for such nozzles in engines, it seems that the sprays from cluster nozzles have deficits in terms of soot oxidation. However, none of the studies modified the piston bowl. It is expected that such an approach favors convergent cluster configurations as for them the spray targeting remains the same compared to conventional nozzles.

The numerical observations predict that major soot formation happens in the very fuel rich regions in the center of the spray. Therefore a strategy based on the idea to cluster sprays was considered to lean the mixture on the spray axis which will form a single spray in a certain distance from the nozzle. This arrangement has a potential to improve primary break up (small holes), and provide a wider rich region with conditions leaner compared to a single hole (multiple small holes), while keeping the good penetration behavior of a standard nozzle (merging of the cluster sprays). 


\section{Experimental and Numerical Setup}

\subsection{Engine experiments}

\subsubsection{Engine}

The Duramax 6600 V8 Turbo Diesel engine [94, 95] of General Motors is used with engine experiments for the concept of cluster nozzles. The engine was re-built as a singlecylinder research engine by FEV. Fig. 3.1 shows both of the engines. The engine was converted to a 0.8 liter engine (16.8:1 compression ratio) with 1.5 swirl ratio based on the original engine.

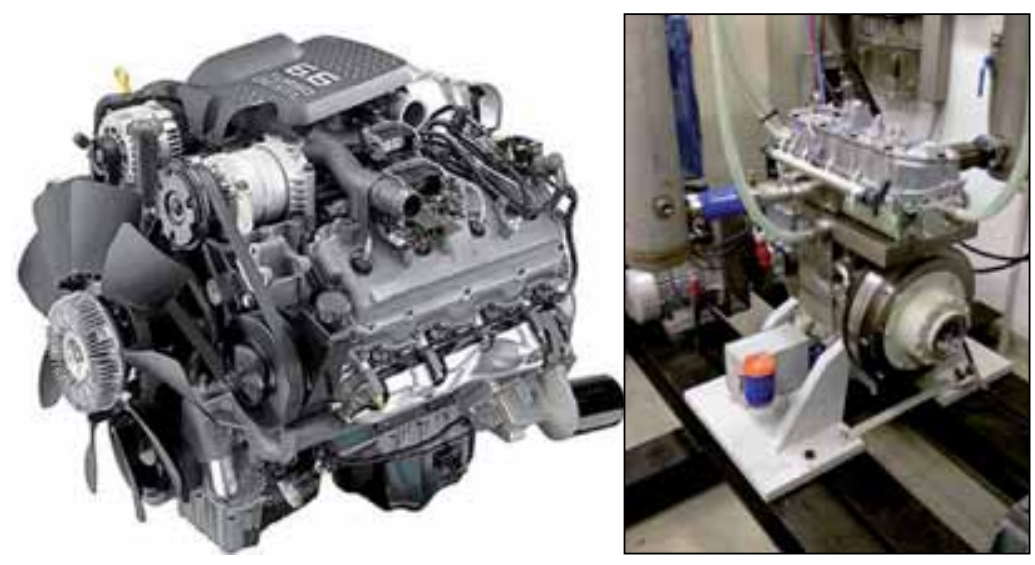

Figure 3.1: Duramax 6600 V8 Diesel engine of GM (left) and Duramax single cylinder engine (right)

The specifications of the single cylinder engine [96] are given in Tab. 3.1. The engine is equipped with a Bosch CRI-3.3 injection system for the cluster nozzles. Piezo injector was used to further improve the combustion. The more accurate control, faster response and higher needle velocities of piezo injectors allow for more precise control of injection duration. The injectors are controlled using a GENOTEC injection controller. The scheme of the engine test cell is shown Fig. 3.2. In order to keep the intake air conditions identical to the real production engine, a 3 stage compressor supplied the required boost 
pressure, while air temperature at the engine intake was controlled by 3 intercoolers, keeping the desired inlet conditions in a surge-tank of the intake pipe. Air-flow-rate was measured by a hot-wire flow meter. The exhaust back pressure produced by a throttle valve in the real engine was simulated by the valve placed in exhaust system, controlling the pressure in the exhaust surge-tank. An EGR-valve allows for control of EGR rate. Dedicated conditioners are used to maintain temperature and pressure of coolant and oil.

Table 3.1: The specifications of the Duramax single cylinder engine

\begin{tabular}{|l|c|}
\hline Engine & Duramax single cylinder engine \\
\hline Displacement volume [1/cylinder] & 0.825 \\
\hline Bore [mm] & 103 \\
\hline Stroke [mm] & 99 \\
\hline Connecting Rod Length [mm] & 188 \\
\hline Piston-pin Offset [mm] & 0.5 \\
\hline Compression Ratio & $16.8: 1$ \\
\hline Squish Height [mm] & 0.7 \\
\hline Swirl ratio & 1.5 \\
\hline Max. Rail Pressure [bar] & 2200 \\
\hline Max. Pressure in Cylinder [bar] & 160 \\
\hline Max. Speed [1/min] & 3600 \\
\hline
\end{tabular}

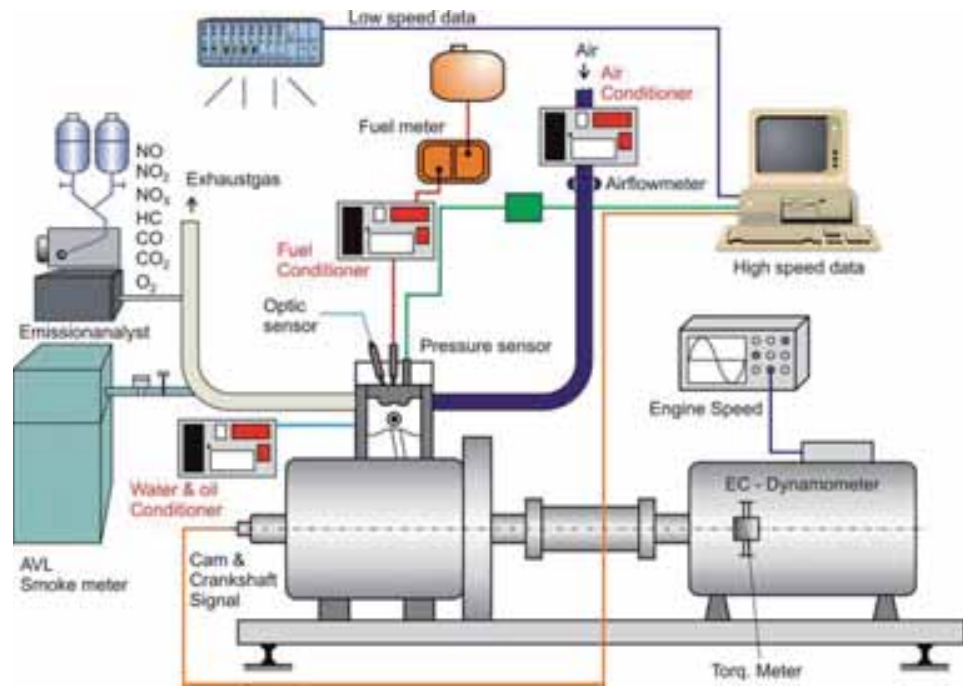

Figure 3.2: Schematic diagram of the engine test cell 
The study was carried out in a test cell equipped with an $\mathrm{ABB}$ emissions bench for gaseous emission measurements in Tab. 3.2. The CO2 [vol. \%], CO [vol. \%], CO [ppm], $\mathrm{O} 2$ [vol. \%], $\mathrm{HC}\left[\mathrm{mg} / \mathrm{m}^{3}\right]$ and $\mathrm{NOx}$ [ppm] measurements were transformed into the emission index $[\mathrm{g} / \mathrm{kg}$ of Fuel]. Particulate mass calculated for this work was based on filter smoke number [FSN (Filtered Smoke Number)].

The FSN numbers were read from an AVL Model 415 smoke meter and the EI (Emission Index) of dry soot in $\mathrm{g} / \mathrm{kg}$ of fuel was calculated using Eq. (3.2) for the "MIRA (Motor Industry Research Association)" correlation [97] that was developed by a European research organization where AFR denotes the air-fuel ratio, and A is a correlation factor calculated using Eq. (3.1):

$$
\begin{aligned}
A= & 0.0307 \times F S N^{5}-0.00669 \times F S N^{4}-0.702 \times F S N^{3} \\
& +14.621 \times F S N^{2}+7.363 \times F S N \\
& \text { MIRA_Dry_Soot_Mass }=A \times\left[\frac{A F R+1}{1000}\right]
\end{aligned}
$$

Further valuable information was extracted from in-cylinder pressure, such as the HRR (Heat Release Rate) and several related parameters, such as combustion duration, ignition delay, etc. It is based on the solution of the energy balance equation inside the cylinder, under assumptions of uniform pressure and temperature across the volume. This gives a possibility to calculate the instantaneous average temperature as well as the instantaneous heat released from the burnt fuel. The accuracy of the emission indices for gaseous emissions is $\pm 1.0 \%$. The accuracy for smoke measurements is $\pm 0.005 \mathrm{FSN}$.

Table 3.2: The emission analyst

\begin{tabular}{|l|l|l|}
\hline \multicolumn{1}{|c|}{ Measurement technic } & \multicolumn{1}{c|}{ Emission } & \multicolumn{1}{c|}{ Analyst } \\
\hline Bosch-filterpaper-methode & Soot & Smoke meter (AVL 415) \\
\hline Chmilumineszenz analyst & $\mathrm{NO}_{\mathrm{x}}\left(\mathrm{NO}, \mathrm{NO}_{2}\right)$ & ECO Physics CLD 700 EL ht \\
\hline Paramagnetic analyst & $\mathrm{O}_{2}$ & ABB Magnos 14 \\
\hline Infrared absorbed analyst & $\mathrm{CO}, \mathrm{CO}_{2}$ & ABB Uras 14 \\
\hline Flame-ionization-detector & Total $\mathrm{HC}$ & ABB Multi FID 14 \\
\hline
\end{tabular}

Europe diesel was used for the experimental measurements. The fuel is Euro-Norm 3 with maximum sulfur content of $10 \mathrm{ppm}$. Diesel fuel properties are: relative specific gravity of 0.8 , viscosity between 3 and $10 \mathrm{~kg} / \mathrm{m} \mathrm{s}$ and surface tension about $3 \times 10^{-2} \mathrm{~N} / \mathrm{m}$ (at $300 \mathrm{~K})$. 


\subsubsection{Test points}

The test points are described in Fig. 3.3 and Tab. 3.3. The test points TP1 and TP2 represent low and high load operation respectively under low engine speed. TP3 and TP4 were used for medium and high load respectively under high engine speed. The test points were defined with their IMEP (Indicated Mean Effective Pressure) and the engine speed, both of which were maintained constant for all the tests under a test point. SOI and rail pressure were varied within the shown limits. The injection duration was varied to maintain the IMEP as specified in Tab. 3.3, while specified levels of $\mathrm{NO}_{\mathrm{x}}$ were achieved by varying EGR. Injection rate measurements were carried out for all the nozzles to determine the actual injected mass for the test points.

Under TP1, the clusters and reference nozzle were first tested for different injection pressures from 500 to $900 \mathrm{bar}$ for an SOI of $-5^{\circ} \mathrm{CA}$ (Crank Angle) aTDC (after Top Dead Center) with $\mathrm{NO}_{\mathrm{x}}$ emission index of $4 \mathrm{~g} / \mathrm{kg}$ of Fuel. Then they were measured for $600 \mathrm{bar}$ and 900 bar rail pressure with varying EGR at variable SOI between $-30^{\circ} \mathrm{CA}$ aTDC and $3^{\circ} \mathrm{CA}$ aTDC in $3^{\circ}$ steps for TP1. Under TP2, TP 3 and TP4 tests with SOI variations were carried out with the rail pressures as specified in Tab. 3.3 respectively. The SOI was varied between $-10^{\circ} \mathrm{CA}$ aTDC to $+4^{\circ} \mathrm{CA}$ aTDC in $2^{\circ}$ steps.

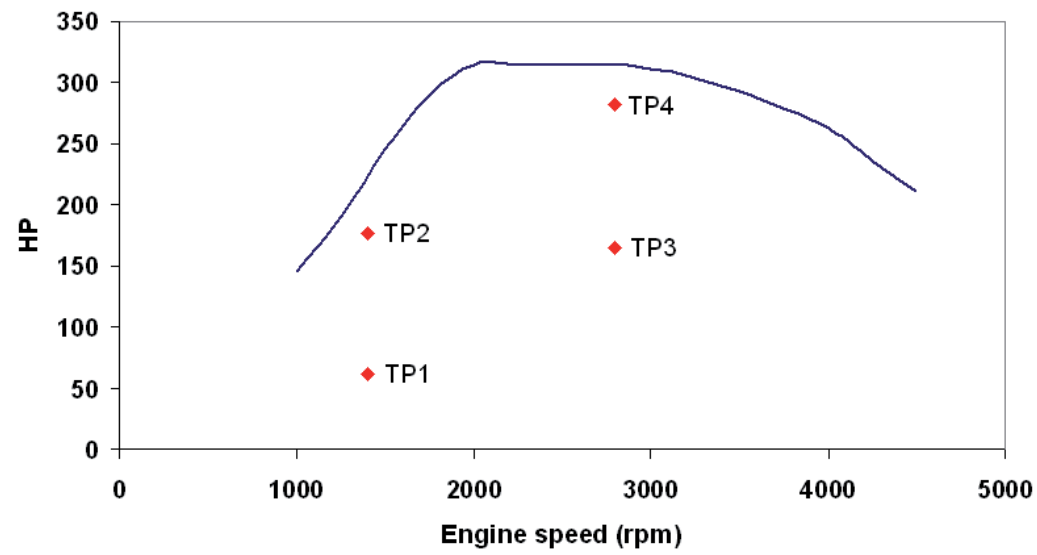

Figure 3.3: 4 Test points for engine experiments 
Table 3.3: The operating condition of 4 test points

\begin{tabular}{|l|c|c|c|c|}
\hline Test point & TP1 & TP2 & TP3 & TP4 \\
\hline Engine Speed [rpm] & 1400 & 1400 & 2800 & 2800 \\
\hline Rail Pressure [bar] & $500-900$ & 1200,1500 & 1800 & 2000 \\
\hline IMEP [bar] & 4.5 & 10.5 & 10.2 & 15.2 \\
\hline Start of Injection [aTDC] & $-30 \sim-3$ & $-10 \sim 4$ & $-10 \sim 4$ & $-10 \sim 4$ \\
\hline Boost Pressure [bar] & 1.13 & 1.57 & 2.3 & 2.35 \\
\hline Boost Temp. $\left[{ }^{\circ} \mathrm{C}\right]$ & 55 & 57 & 60 & 80 \\
\hline Temp. Oil \& Coolant $\left[{ }^{\circ} \mathrm{C}\right]$ & 90 & 90 & 90 & 90 \\
\hline Air / Fuel ratio [-] & $23 \sim 29$ & $18 \sim 20$ & $29 \sim 32$ & $19 \sim 22$ \\
\hline EGR [\%] & $33 \sim 48$ & $23 \sim 33$ & $25 \sim 35$ & $18 \sim 25$ \\
\hline EI NO [ g/kg of Fuel] & $0.5,2.0,4.0$ & 4.5 & 4.5 & 5.0 \\
\hline
\end{tabular}

\subsubsection{Cluster nozzle configurations}

A total of twelve Clusters with different number of hole-pairs and different cluster-angles were designed for the current study. Three clusters were designed as first set of the cluster concepts and they were used to characterize the spray of clusters in diesel engine. After the first study of cluster configuration nozzles, nine cluster nozzles were designed for engine experiments.

All the clusters had groups of two orifices with same hole-diameter, as it leads to reasonable orifice sizes. Tab. 3.4 lists the parameters for the reference nozzle and the clusters. Two different orientations for placing of the orifices were used. Configuration 01 (henceforth mentioned as vertical) has the two orifices of a group placed along the injector axis effectively forming two spray cones, and Configuration 02 (henceforth mentioned as horizontal) had both the orifices placed in a plane perpendicular to the injector axis forming only one spray cone. Fig. 3.4 shows the two orientations of orifice placement and the included angle. Seven of the clusters have the vertical configuration and five have the horizontal configuration. The three clusters as first set were designed with narrower centerline angle $\left(140^{\circ}\right)$ for PCCI operation. But the new horizontal clusters were designed with the same spray cone angle as the reference injector $\left(158^{\circ}\right)$ for better targeting and the outer spray of new vertical clusters were also targeted similar to the spray cone angle as the reference injector $\left(158^{\circ}\right)$. The reason of the wider spray angle was to use the momentum of the spray to make it follow the bowl shape under high load conditions.

The Clusters are named according to their geometry. The first part denotes the total number of orifices $(10,12$ or 14). The two numbers separated by a slash denote the spray cone angle formed by the orifices in different orifice circles (only one orifice circle for Configuration 02). The last part signifies the included angle between the centerlines of 
the two orifices. The reference nozzle has a flow number of 405 , and was designed with a $0.135 \mathrm{~mm}$ orifice diameter. The clusters with 7 hole-pairs (14 orifices) were designed with $0.105 \mathrm{~mm}$ orifice diameter for a flow number of 490 . The flow number is defined as the amount of fuel in cubic centimeters which flows through the nozzle in 30 seconds at a pressure difference of $100 \mathrm{bar}$. The 7 hole-pair clusters were designed with a higher flow number to achieve a similar spray tip penetration as with the reference nozzle. With a change in the number of holes the flow number changes if the orifice diameter is kept the same. It was decided to have the same flow number $\left(490 \mathrm{~cm}^{3} / 30 \mathrm{~s} @ 100 \mathrm{bar}\right)$ for the clusters with 6 and 5 hole-pairs. Therefore they were designed with larger orifice diameters accordingly. However, the Cluster $10 \times 158 / 138 \_10^{\circ}$, has a slightly lower flow number than the other clusters. The only parameters affecting the flow number were the orifice diameter and the number of orifices and the manufacturing processes were the same for all the nozzles.

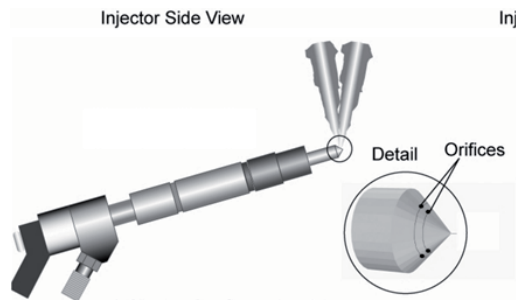

Injector Front View

a) Cluster Configuration 01
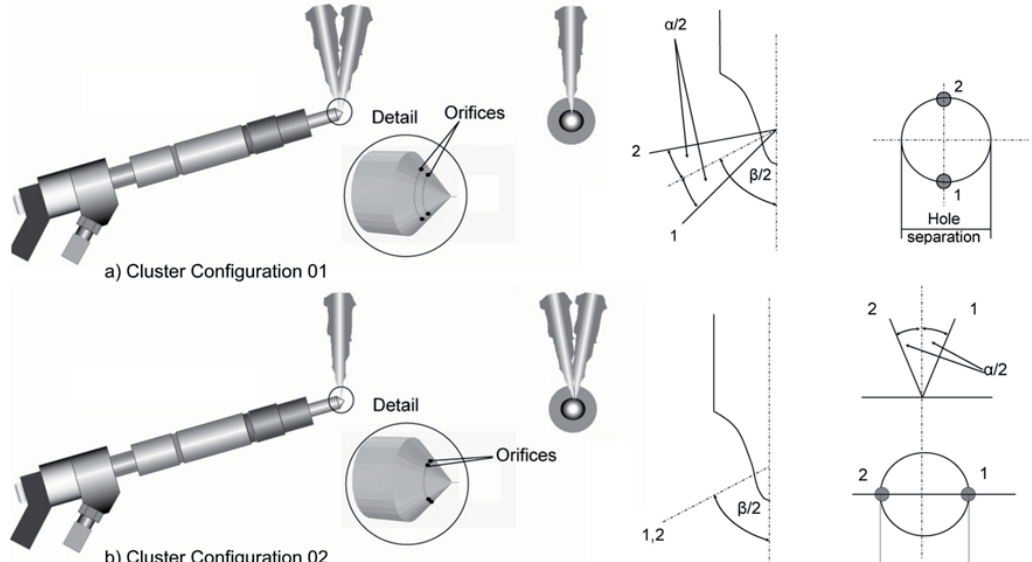

b) Cluster Configuration 02
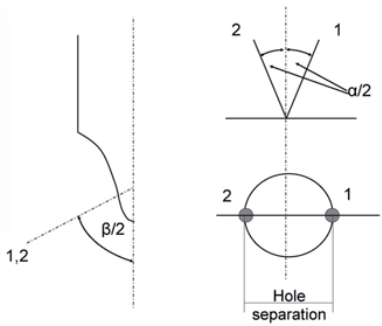

Figure 3.4: Sketch of orifice orientation for cluster nozzles with one (bottom) and two (top) orifice circles 
Table 3.4: The configuration of the cluster and base nozzle

\begin{tabular}{|c|c|c|c|c|c|c|c|}
\hline $\begin{array}{l}\text { Number } \\
\text { of Hole } \\
\text { pairs } \\
\text { (Holes) } \\
\end{array}$ & $\begin{array}{c}\text { Centerline Angle } \\
(\beta)\end{array}$ & $\begin{array}{l}\text { Include } \\
\text { d Angle } \\
(\alpha)\end{array}$ & $\begin{array}{c}\text { Orifice } \\
\text { size } \\
{[\mathrm{mm}]}\end{array}$ & $\begin{array}{c}\text { hole } \\
\text { Separa } \\
\text {-tion } \\
{[\mathrm{mm}]} \\
\end{array}$ & $\begin{array}{c}\text { Flow } \\
\text { Number } \\
{\left[\mathrm{cm}^{3} / 30 \mathrm{~s}\right.} \\
@ 100 \mathrm{bar}] \\
\end{array}$ & $\begin{array}{l}\text { Conf } \\
\text { igur } \\
\text { ation }\end{array}$ & Name \\
\hline $7(7)$ & 158 & - & 0.135 & - & 405 & - & $7 \times 158$ \\
\hline $7(14)$ & 140 & 20 & 0.105 & 0.600 & 490 & 02 & $14 \times 140 / 140 \_20^{\circ}$ \\
\hline $7(14)$ & $140(150 / 130)$ & 10 & 0.105 & 0.600 & 490 & 01 & 14x150/130_10 \\
\hline $7(14)$ & $140(160 / 120)$ & 20 & 0.105 & 0.600 & 490 & 01 & $14 \times 160 / 120 \_20^{\circ}$ \\
\hline $7(14)$ & 158 & 10 & 0.105 & 0.500 & 490 & 02 & $14 \times 158 / 158 \_10^{\circ}$ \\
\hline $6(12)$ & 158 & 10 & 0.113 & 0.600 & 490 & 02 & $12 \times 158 / 158 \_10^{\circ}$ \\
\hline $5(10)$ & 158 & 10 & 0.123 & 0.600 & 490 & 02 & $10 \times 158 / 158 \_10^{\circ}$ \\
\hline $5(10)$ & 158 & 0 & 0.123 & 0.580 & 490 & 02 & 10x158/158_0 $0^{\circ}$ \\
\hline $7(14)$ & $148(158 / 138)$ & 10 & 0.105 & 0.600 & 490 & 01 & $14 \times 158 / 138 \_10^{\circ}$ \\
\hline $6(12)$ & $148(158 / 138)$ & 10 & 0.113 & 0.600 & 490 & 01 & $12 \times 158 / 138 \_10^{\circ}$ \\
\hline $5(10)$ & $148(158 / 138)$ & 10 & 0.113 & 0.600 & 430 & 01 & $10 \times 158 / 138 \_10^{\circ}$ \\
\hline $5(10)$ & $148(158 / 148)$ & 5 & 0.123 & 0.600 & 490 & 01 & $10 \times 158 / 1485^{\circ}$ \\
\hline $5(10)$ & $148(158 / 118)$ & 20 & 0.123 & 0.700 & 490 & 01 & $10 \times 158 / 118 \_20^{\circ}$ \\
\hline
\end{tabular}

\subsection{Spray measurements}

In the following sections the experimental set-ups to investigate the combustion process are described in more detail. The $\mathrm{OH}$-chemiluminescence as well as the Soot luminosity imaging measurements is line of sight, while the laser induced incandescence is a planar sheet measurement technique. The optical set-up of the two imaging techniques is quite simple and consists of an ICCD (Intensified Charge Coupled Device) equipped with an appropriate filter combination.

\subsection{1 $\mathrm{OH}^{*}$-chemiluminescence imaging}

The combustion of Diesel fuel is initiated by a two step ignition process. During the first step the molecules of the fuel are cracked into smaller parts (consumption of the fuel) and a small amount of heat is released. During the second stage the smaller molecules are oxidized and a large amount of heat is released. The first stage is represented by formaldehyde, while the second stage is indicated by the $\mathrm{OH}$ radical, which is formed in an excited state. This $\mathrm{OH}^{*}$ can be detected using an imaging technique with an adequate filter combination. The emission spectrum of a hydrocarbon flame (including the 
emission of the $\mathrm{OH}^{*}$ molecule) as well as the transmission of the used filter combination are depicted in Fig. 3.5.

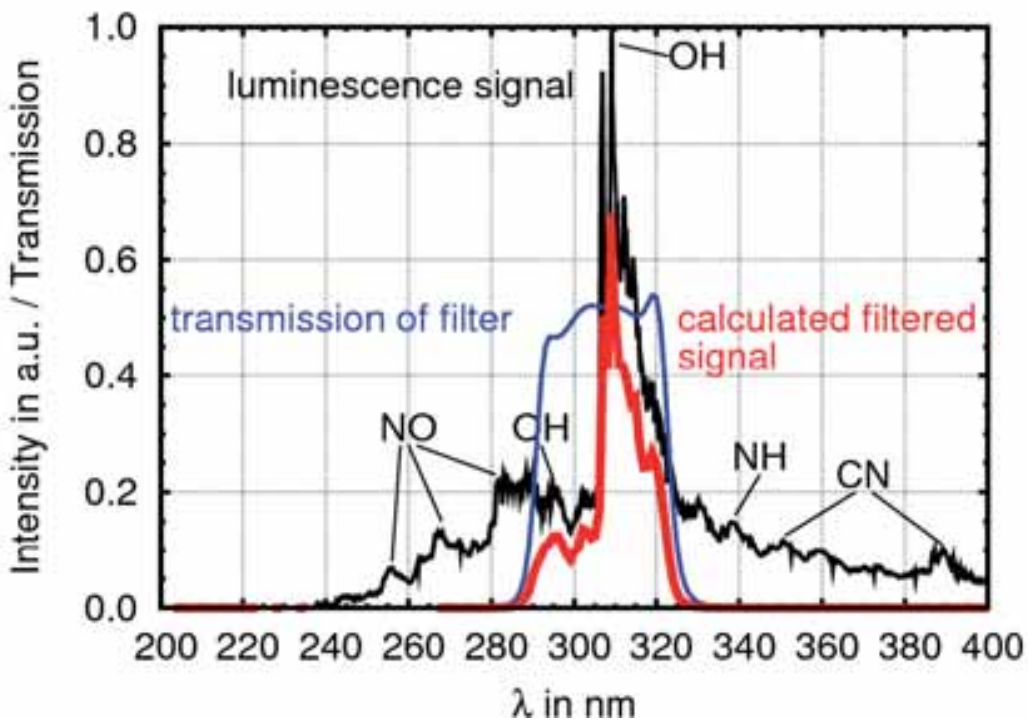

Figure 3.5: Emission spectrum of a hydrocarbon flame and transmission characteristics of the used filter combination

\subsubsection{LII measurements and soot luminosity imaging}

Using the LII (Laser Induced Incandescence) technique it is possible to measure the soot volume fraction Semi-quantitatively. The soot formed during the combustion process emits thermal radiation, which has a temperature dependent broad spectral distribution. This light can be acquired using an imaging technique. The intensity of this soot luminescence is influenced by the soot volume fraction as well as the soot temperature. Therefore, the natural soot luminescence is not directly a measure of the amount of soot. To minimize the temperature differences of the soot particles and make the intensity of the radiation proportional to the soot volume fraction, the soot is heated up to its sublimation temperature using a highly energetic laser pulse formed to a laser light sheet. The LII set-up is depicted in Fig. 3.6. To be able to measure the LII signal and the natural soot luminescence quasi-simultaneously a double-frame ICCD equipped with a band pass filter is used. In addition, a notch filter is used to suppress the scattered laser light. Overall, the elastically scattered laser light is suppressed by approximately twelve orders of magnitude (six for each of the filters). 


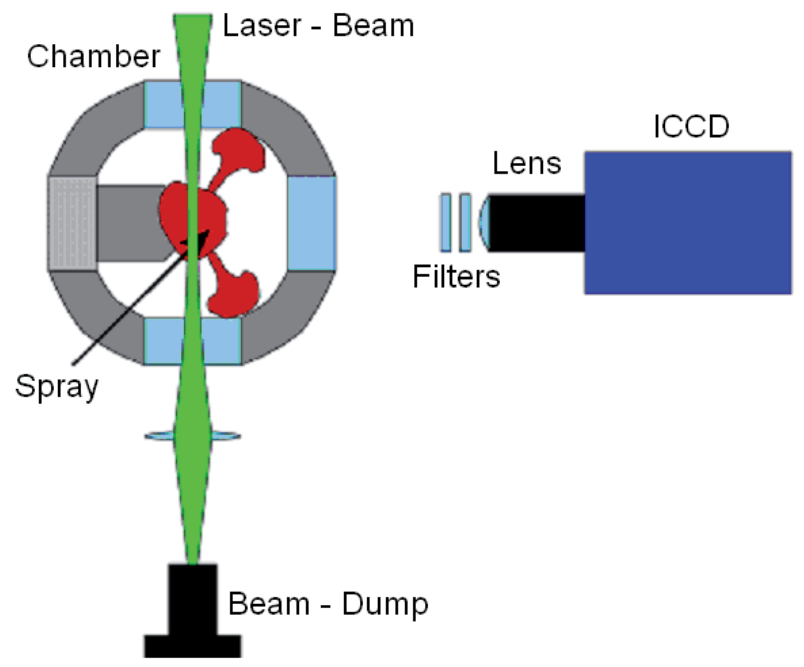

Figure 3.6: Sketch of the LII and soot luminescence imaging set-up (top view)

Using a double-frame camera, capable to acquire two images shortly after each other, it is possible to take one image shortly before and one synchronously to the laser shot. The time between these two images ( $2 \mu \mathrm{s})$ is shorter than the variations in the intensities of the natural soot radiation. The pure LII signal is computed by subtracting the first image (only natural soot luminescence) from the second (natural soot luminescence plus LII signal) corrected for the different gating times.

\subsubsection{Injection rate measurements}

Fig. 3.7 shows a sketch of the injection-rate-meter, which is the same type as developed by Robert Bosch GmbH. The rate meter was designed by ITV [98]. The basic equations from theory:

$$
\begin{aligned}
& \left(\frac{d V}{d t}\right)=\frac{A}{\rho \cdot a} \cdot p(t) \quad \text { with } \quad a=\frac{2 L}{\Delta t_{r e f l}} \\
& V_{i n j .}=\frac{A}{\rho \cdot a} \cdot \int_{t}^{t+\Delta t} p(t) d t
\end{aligned}
$$

where $\mathrm{V}$ is injection volume, $\mathrm{A}$ is measurement cross section, $\rho$ is density of fuel in rate meter tube, $\mathrm{p}(\mathrm{t})$ measured instantaneous pressure in tube due to pressure wave from 
injection, a is velocity of sound of fuel, $\mathrm{L}$ is length of rate meter tube between injector nozzle tip and throttle of rate meter and $\Delta t_{\text {refl. }}$ is time between measured pressure wave form injection and measured pressure wave of first reflection of pressure wave. If local fuel density and velocity of sound is known at the measurement location, injection rate and injected volume are determined by Eq. (3.3) and (3.4). In general the local density of the fuel and the velocity of sound are not known at the measurement location.

Injection rate is calculated by the following procedure. The injected mass per injection is calculated first by collected injected mass from several injections, while average pressure $p(t)$ is obtained by averaging the measured signal from several injections. The averaged $\mathrm{p}(\mathrm{t})$ is normalized by its integral (integral $\mathrm{p}(\mathrm{t})=1$ ). Finally, the normalized $\mathrm{p}(\mathrm{t})$ is multiplied with the injected mass to deliver the injection rate.

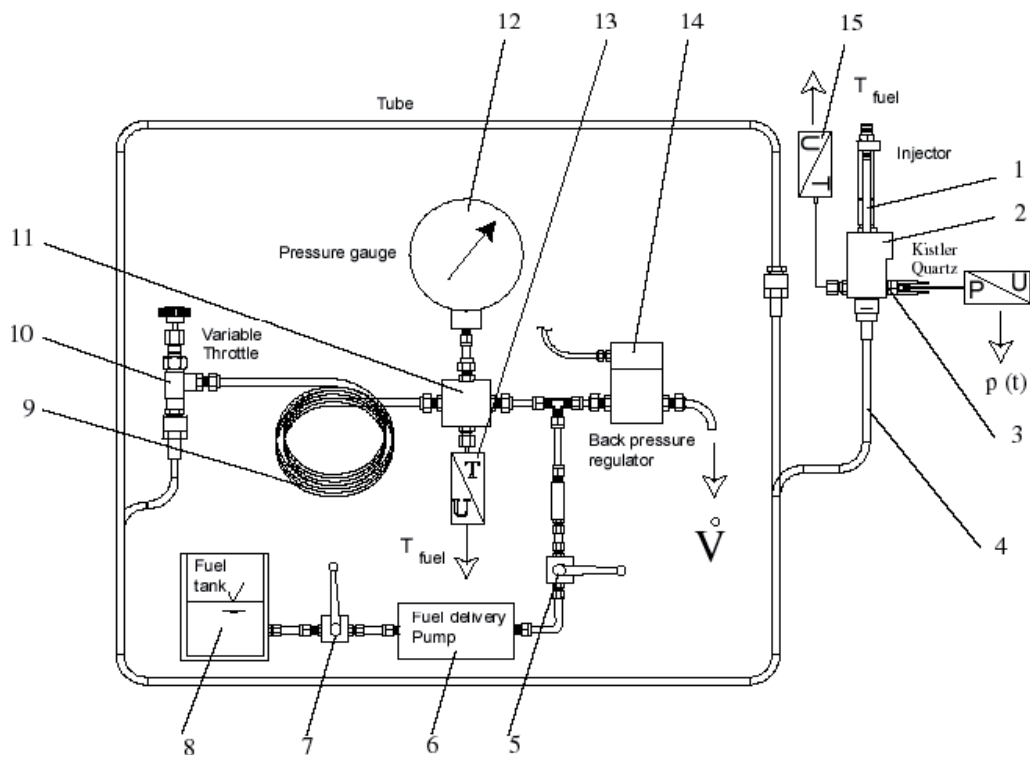

\begin{tabular}{|c|l|c|l|c|l|}
\hline 1 & Injector & 2 & Injector holder & 3 & Pressure sensor \\
\hline 4 & Rate meter tube & 5 & Stop cock & 6 & Feul delivery pump \\
\hline 7 & Stop cock & 8 & Fuel tank & 9 & Downstream tube \\
\hline 10 & Variable throttle & 11 & Cross piece & 12 & Pressure gauge \\
\hline 13 & Thermocouple & 14 & Back pressure regulator & 15 & Thermocouple \\
\hline
\end{tabular}

Figure 3.7: Sketch of the injection-rate-meter [98] 


\subsection{Numerical setup}

The RANS (Reynolds Averaged Navier-Stokes equations) are solved numerically for the gaseous phase using the AC-FluX code on an unstructured mesh by a finite volume approach. Turbulence is modeled by the widely used $k-\varepsilon$ model.

\subsubsection{Spray modeling}

The spray model used is the DDM (Discrete Droplet Model) as introduced in [99]. In this model the spray-equation proposed by [100] is approximated by a Monte-Carlo simulation where the droplet distribution function is sampled by virtual droplets so-called parcels [101]. For the coupling between the parcels and the RANS-equations, source terms are exchanged on the computational mesh with the appropriate underlying cell. Sub-models are available in the code for liquid atomization and droplet break-up and for droplet-droplet interaction, collision and coalescence and droplet evaporation. The modeling of these sub-processes however is not evident. Usually, the spray simulation includes all sub-models for that the spray model constants have to be adjusted. A very popular approach is to prescribe the initial mean droplet diameter and model the droplet (secondary) atomization process due to instabilities based on density- and velocity gradients between liquid and gaseous phase. Parcels are therefore initialized either by a Rosin-Rammler distribution function or by a mono-disperse distribution function with a mean value derived from its SMR (Sauter mean radius) distribution function. The parcel velocity direction distribution is randomly initialized over a given spray cone angle and the parcel velocity magnitude is derived from injection rate measurements. Secondary droplet break-up is modeled following Reitz and co-workers [102-105] where droplet break-up is addressed to KH (Kelvin-Helmholtz) and RT (Rayleigh-Taylor) instabilities. The collision model used here is the same as proposed by O'Rourke [106] with a few modifications. Following [102], only parcels that approach each other are considered for parcel-parcel interaction. Another modification is due to the fact that only parcels residing in the same underlying cell are considered for parcel-parcel interaction. Here, only parcels that reside in a sphere spanned by a given collision radius are considered for parcel-parcel interaction. Since the collision probability function is inverse proportional to the considered volume, a larger collision radius and therefore a higher collision frequency will not necessary lead to a larger collision probability. The transition between liquid and gaseous phase is due to the droplet evaporation which will be presented in detail in the next sub-section.

\subsubsection{Combustion model (RIF)}

The separation between the turbulent integral time-scales and the time-scale of chemistry is a major benefit of the flamelet approach. The diffusive transport in the flamelet space is independent of the Reynolds-number and only controlled by the scalar dissipation rate. Furthermore, the one-dimensional nature of the thin reaction zone allows using a detailed 
reaction mechanism. The complete flow domain is assigned by a single flamelet solution denoted as RIF (Representative Interactive Flamelet) - model. The coupling between the CFD solutions and the solution of Flamelet equations is shown in Fig. 3.8. In order to solve the flamelet equations the so called flamelet parameters, domain averaged pressure and conditional scalar dissipation rate, are provided by the CFD code.

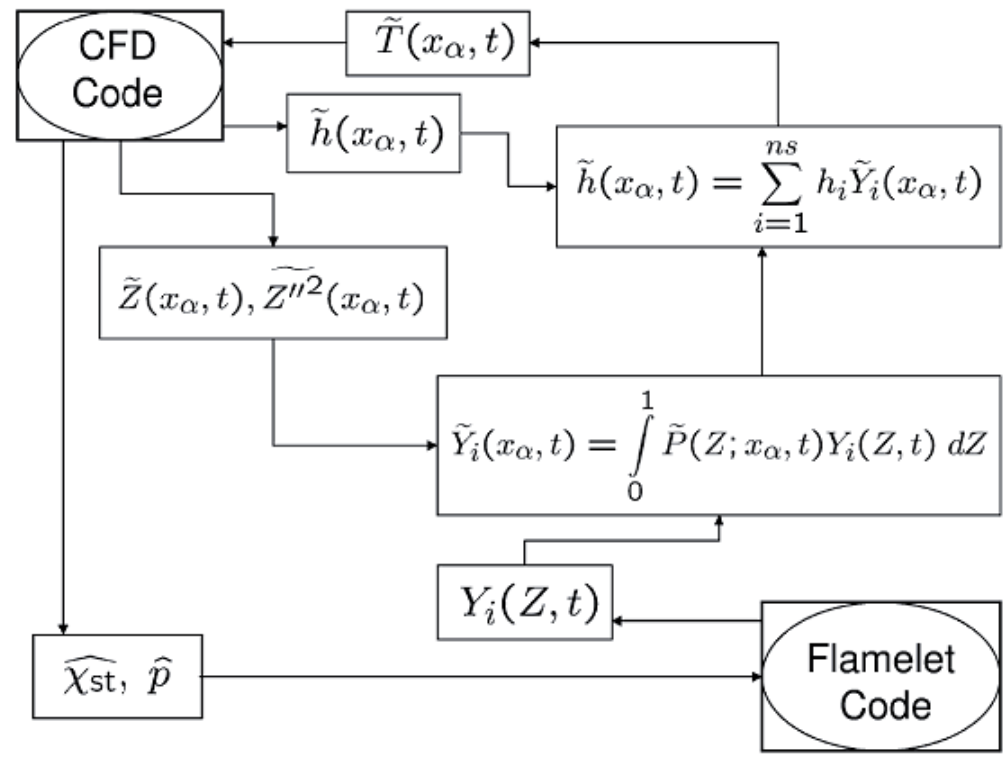

Figure 3.8: Interaction between CFD- and Flamelet-code

\subsubsection{Engine simulations}

Engine simulation is carried out on a sector mesh due to the symmetry of the injector located on the cylinder axis. For applied 7-hole nozzle, a sector angle of $51.4^{\circ}$ is applied due to the rotational symmetry $1 / 7^{\text {th }}$ of the bowl is considered. The swirl ratio was 1.5 for the engine simulations which was designed to be optimal for the reference nozzle. Periodic boundary conditions are applied at the side faces. The number of cells is 50,000. The computational grid at top dead center front and top face are removed for illustration. Valve recess or piston cut-outs are not included. The sector mesh is shown in Fig. 3.9. RIF-model was applied for combustion simulation. The comparison between the engine data for base line case and simulation data, that includes the analysis of pressure traces. The engine simulations were carried out by Dipl. -Ing. Michael Gauding at the Institute for Combustion Technology, RWTH-Aachen. 


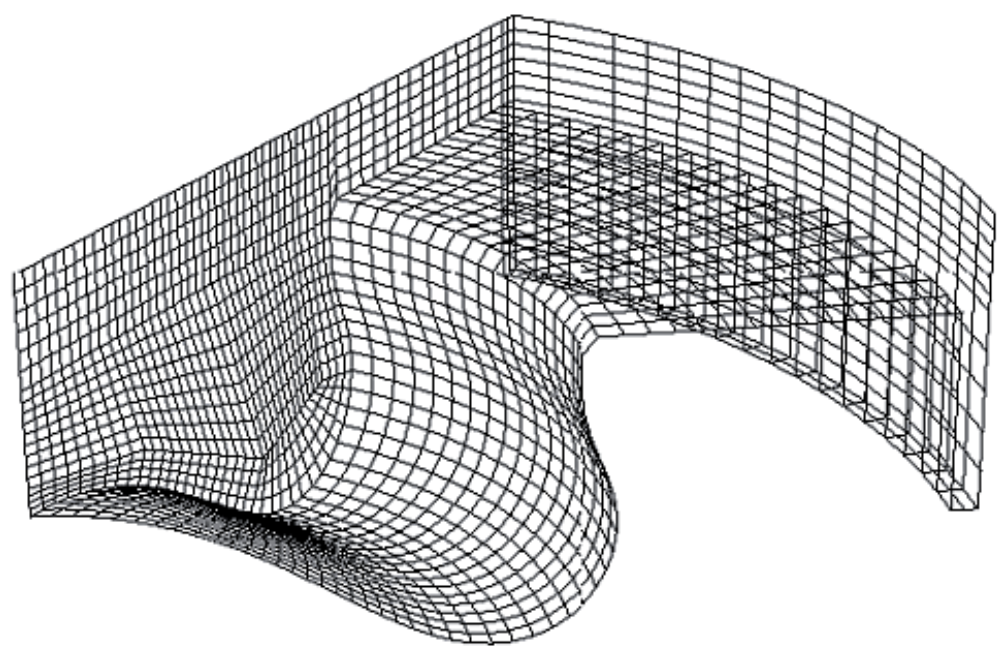

Figure 3.9: Sector mesh of Duramax engine 


\section{Results and Discussion}

Fig. 4.1 shows the flowchart of concepts for the cluster nozzle design for Diesel engine. During the first phase of cluster nozzle investigation, three cluster nozzles were designed according to numerical simulation results and fundamental study [107, 108] was conducted in high pressure vessel in engine like conditions. Also, the three cluster nozzles were tested in the engine [109, 110]. Emissions and performance properties were collected form the engine test. From these experiments, fundamental spray measurement, CFD simulation and engine measurement, we concluded that there was a problem with fuel targeting which is an important factor in diesel engine. In the second phase, nine more clusters were designed with discussions of the first results. Targeting angle and angle in-between two orifices were changed while overall concept of the nozzle was maintained [109]. Total eleven nozzles were tested including the conventional seven-hole nozzle and a cluster nozzle form first set of clusters which had shown the best results among the first three cluster nozzles for the 4 test points. Engine measurement was conducted with eleven nozzles first to find optimal rail pressure [111, 112]. Various rail pressures were tested at each test point and for each cluster nozzle. And optimal rail pressure was defined as the pressure which resulted in low emission level and fuel consumption together. To select proper cluster design, eleven nozzles were tested in the single cylinder engine at 4 test points form low load and low engine speed to high load and high engine speed [113]. Also the CFD simulation was conducted to compare with engine experiment and to understand the phenomena inside the combustion chamber. The results were combined and 4 cluster nozzles were selected as appropriate nozzles for further investigation. As swirl is also an important element which affects the combustion of diesel engine, it was necessary to test different swirl ratios and find the effects of swirl ratio on cluster nozzles. In this test, four selected clusters were tested for variation of swirl and were compared with the reference nozzle. Swirl is varied between 0.5, 1.5 and 3.0 of MSR (Mean Swirl Ratio) and the results were used to define the optimal swirl ratio for the cluster nozzles [114]. In the final phase of cluster nozzle investigation, a new piston bowl design was proposed for cluster nozzles. The new bowl geometry was modified using CFD simulation and it was considered also with the results of spray study and engine measurements to promote the character of cluster nozzles. Engine measurements were conducted with the new bowl geometry at four different test points. Various injection rail pressures were also tested together with three different steps of mean swirl ratio. Five nozzles including the reference nozzle were used for the engine experiments. From this investigation, it was possible to find the characters to take advantage of cluster nozzles [115]. Tab. 4.1 shows the list of the used nozzles for the each experiment. 
1. Characterization of Cluster Sprays

$1^{\text {st }}$ Design

3 Nozzles

Fundamental Spray Measurement

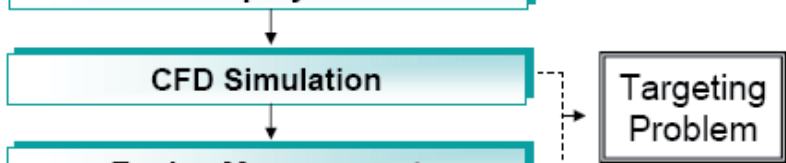

Engine Measurement

Test Points : • Part Load

- Full Load

Feed Back

\section{Evaluations and Improvements for Clusters}

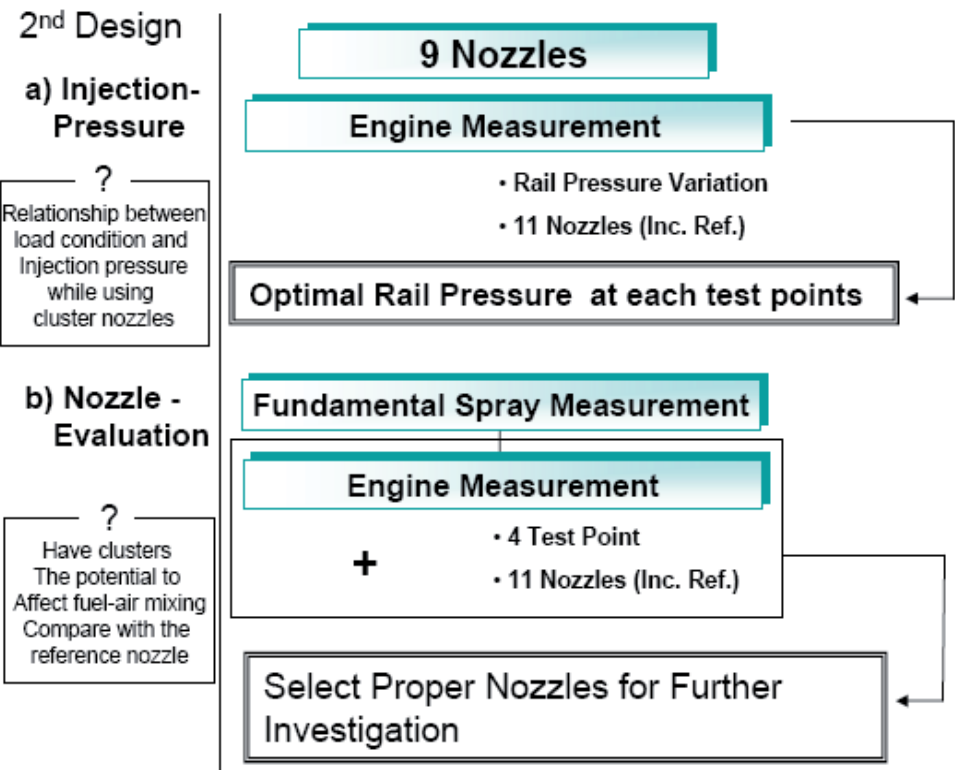


2. Evaluations and Improvements for Clusters (Continue)

c) Swirl Variation

$?$

Effect of swirl on cluster nozzle

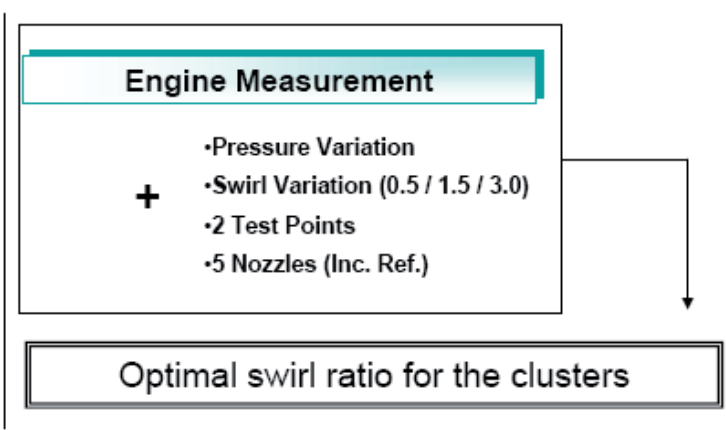

3. Optimizing Clusters with New Bowl Geometry

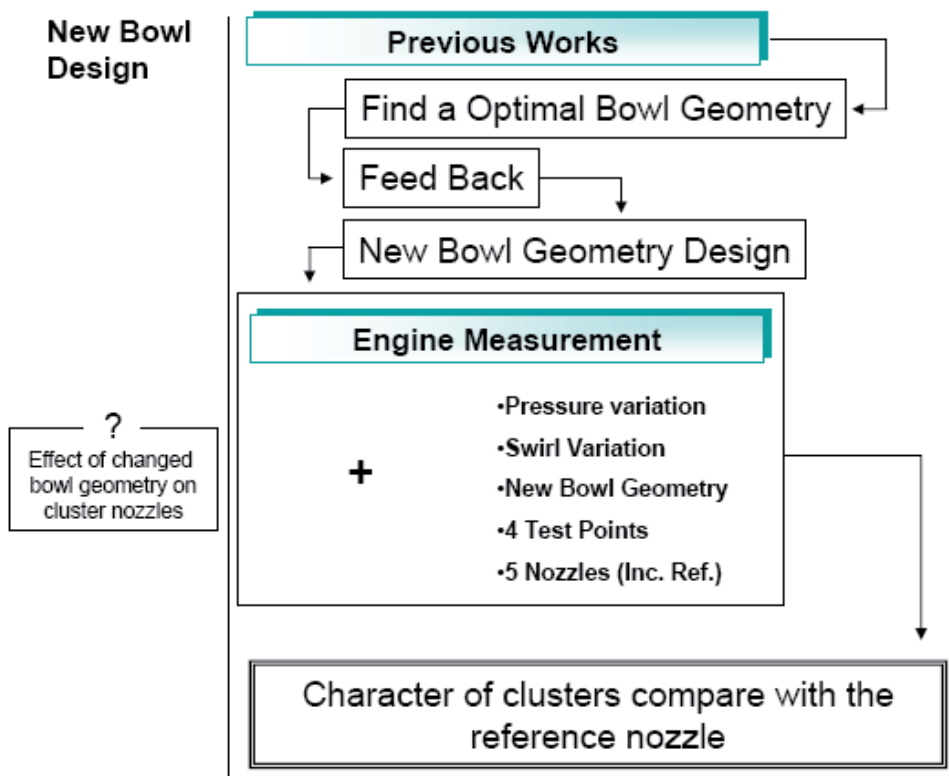

Figure 4.1: The flowchart of the concepts for the cluster nozzle 
Table 4.1: The list of used nozzles for the each experiment

\begin{tabular}{|l|c|c|c|c|c|}
\hline \multicolumn{1}{|c|}{ Nozzle } & $\begin{array}{c}\text { First set of } \\
\text { clusters } \\
\text { (Section 4.1) }\end{array}$ & $\begin{array}{c}\text { Optimizing } \\
\text { rail pressure } \\
\text { (Section 4.2) }\end{array}$ & $\begin{array}{c}\text { Evaluation } \\
\text { of nozzles } \\
\text { (Section 4.3) }\end{array}$ & $\begin{array}{c}\text { Effect of } \\
\text { Swirl } \\
\text { (Section 4.4) }\end{array}$ & $\begin{array}{c}\text { Modification } \\
\text { of Bowl } \\
\text { (Section 4.5) }\end{array}$ \\
\hline $7 \times 158$ & $\sqrt{ }$ & $\sqrt{ }$ & $\sqrt{ }$ & $\sqrt{ }$ & $\sqrt{ }$ \\
\hline $14 \times 140 / 140 \_20^{\circ}$ & $\sqrt{ }$ & & & & \\
\hline $14 \times 150 / 130 \_10^{\circ}$ & $\sqrt{ }$ & & $\sqrt{ }$ & & \\
\hline $14 \times 160 / 120 \_20^{\circ}$ & $\sqrt{ }$ & $\sqrt{ }$ & $\sqrt{ }$ & $\sqrt{ }$ & $\sqrt{ }$ \\
\hline $14 \times 158 / 158 \_10^{\circ}$ & & $\sqrt{ }$ & $\sqrt{ }$ & $\sqrt{ }$ & $\sqrt{ }$ \\
\hline $12 \times 158 / 158 \_10^{\circ}$ & & $\sqrt{ }$ & $\sqrt{ }$ & & \\
\hline $10 \times 158 / 158 \_10^{\circ}$ & & $\sqrt{ }$ & $\sqrt{ }$ & & \\
\hline $10 \times 158 / 158 \_0^{\circ}$ & & $\sqrt{ }$ & $\sqrt{ }$ & $\sqrt{ }$ & $\sqrt{ }$ \\
\hline $14 \times 158 / 138 \_10^{\circ}$ & & $\sqrt{ }$ & $\sqrt{ }$ & & \\
\hline $12 \times 158 / 138 \_10^{\circ}$ & & & $\sqrt{ }$ & & \\
\hline $10 \times 158 / 138 \_10^{\circ}$ & & & & &
\end{tabular}




\subsection{First set of cluster nozzles}

The cluster nozzles from the first set were tested using various experimental and numerical studies to understand the behavior of cluster nozzles. The results provided detailed understanding of the processes and helped in designing the second set of nozzles. The results of the first phase are discussed in the following sections.

\subsubsection{Injection rate measurements}

The injection rates for three clusters and the reference nozzle were measured with $630 \mu \mathrm{s}$ energizing time for $600 \mathrm{bar}$ injection pressure, which are shown in Fig. 4.2. The pressure inside the rate meter tube was 40bar. The clusters with high flow number have high injection rate than the reference nozzle. In this condition, injected fuel was $17.51 \mathrm{mg} / \mathrm{inj}$. for the reference nozzle, $18.65 \mathrm{mg} / \mathrm{inj}$. for Cluster $14 \mathrm{x} 150 / 130,18.51 \mathrm{mg} / \mathrm{inj}$. for Cluster $14 \times 160 / 120$ and $18.81 \mathrm{mg} / \mathrm{inj}$. for Cluster 14x140/140. Injection rate measurements were also carried out for all the nozzles using the injection durations used in engine experiments to determine the actual injected mass for the engine measurement and engine simulation.

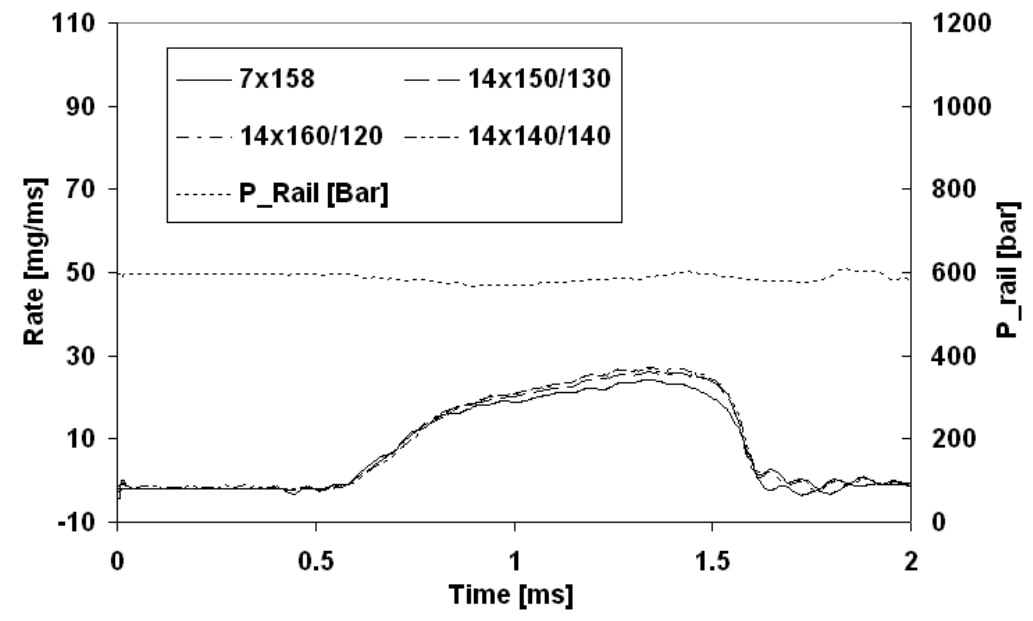

Figure 4.2: Injection rate for three clusters and the reference nozzle 


\subsubsection{Visualization results}

Three more clusters with 3 hole-pair orifices were designed for spray measurements to characterize the spray of clusters in high pressure chamber and the clusters were also named according to their geometry. The spray visualization measurements were carried out by Dr. -Ing. Adam Pawlowski at the Institute for Heat and Mass-Transfer (WSA), RWTH-Aachen.

The left image in Fig. 4.3 shows the light scattered by the fuel jet from Cluster 6x160/120 $1 \mathrm{~ms}$ after energizing the injector. The rail pressure has been $900 \mathrm{bar}$ and the total energizing time was $630 \mu \mathrm{s}$. Only the liquid phase is visible in the image, as the vapor phase scatters almost no light. The right image in Fig. 4.3 shows a back-lit schlieren image of the same injection event $15 \mu$ s later, taken by the same camera. As the liquid phase of the spray, which is bright in the left image, is optically very dense, practically no light from the back ground is transmitted. In fact the connected dark area in the image indicates the presence of liquid fuel. Strong intensity differences to the background as well as to the vapor phase are observed. The vapor phase is indicated by the presence of schlieren downstream of the liquid phase [116-118]
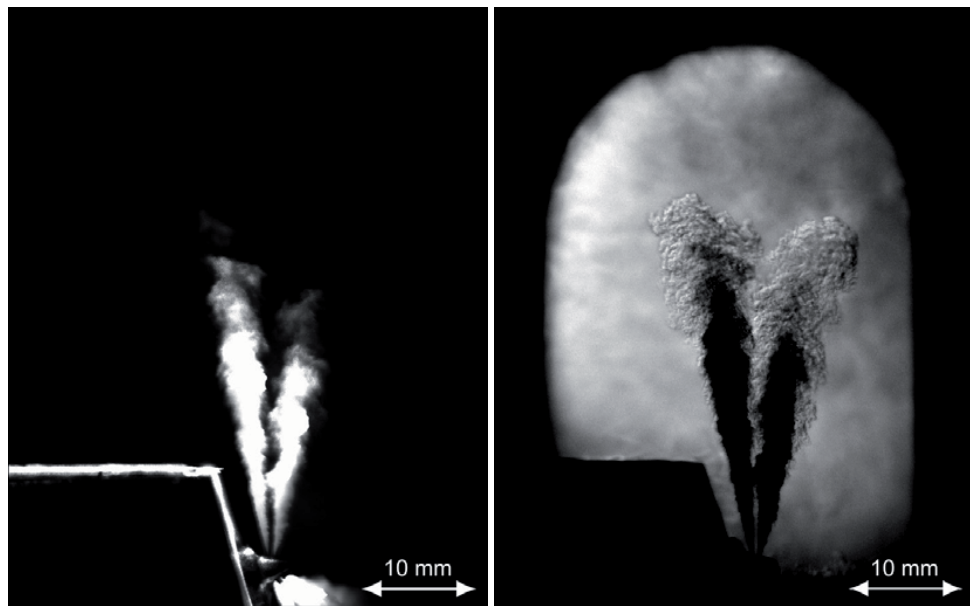

Figure 4.3: Scattering light (left) and schlieren (right, $15 \mu$ s later) image of the spray from Cluster 6x160/120 [6].

The comparisons of the vapor and liquid phase penetration of all four investigated nozzles are shown in Fig. 4.4 and 4.5. The conventional nozzle penetrates faster than the clusters. This is not only true for the vapor phase, but also for the liquid phase. This can be attributed to the larger dispersion of the cluster spray. For $600 \mathrm{bar}$, the penetration of the spray for the Cluster $6 \times 160 / 120$ is significantly delayed against the other sprays. 
About $1.2 \mathrm{~ms}$ after the start of the energizing of the injector, the spray with the horizontal cluster suddenly starts to disappear, whereas the spray for Cluster 6x160/120 remains practically stationary. This is no artifact of the image evaluation, but can be clearly seen in the raw images. Also this behavior is very repeatable. To clarify this, the standard deviation of the 20 evaluated images is also shown in Fig. 4.5. The difference in liquid penetration length between the sprays is significantly smaller than the standard deviation of this parameter. For a rail pressure of 900 bar, both sprays penetrate similarly during the beginning of the injection, but stabilize at first about $10 \mathrm{~mm}$ apart from each other. The spray closer to the nozzle tip remains shorter than the other until again about $1.2 \mathrm{ms,}$ when the penetration length of the other spray plume suddenly starts to decrease. At a rail pressure of $1350 \mathrm{bar}$, the differences between the spray plumes are much smaller than for the other two pressures, indicating a more stable condition. The reason for this behavior of Cluster $6 \times 160 / 120$ can be attributed to hydrodynamic instabilities in the internal nozzle flow [6].
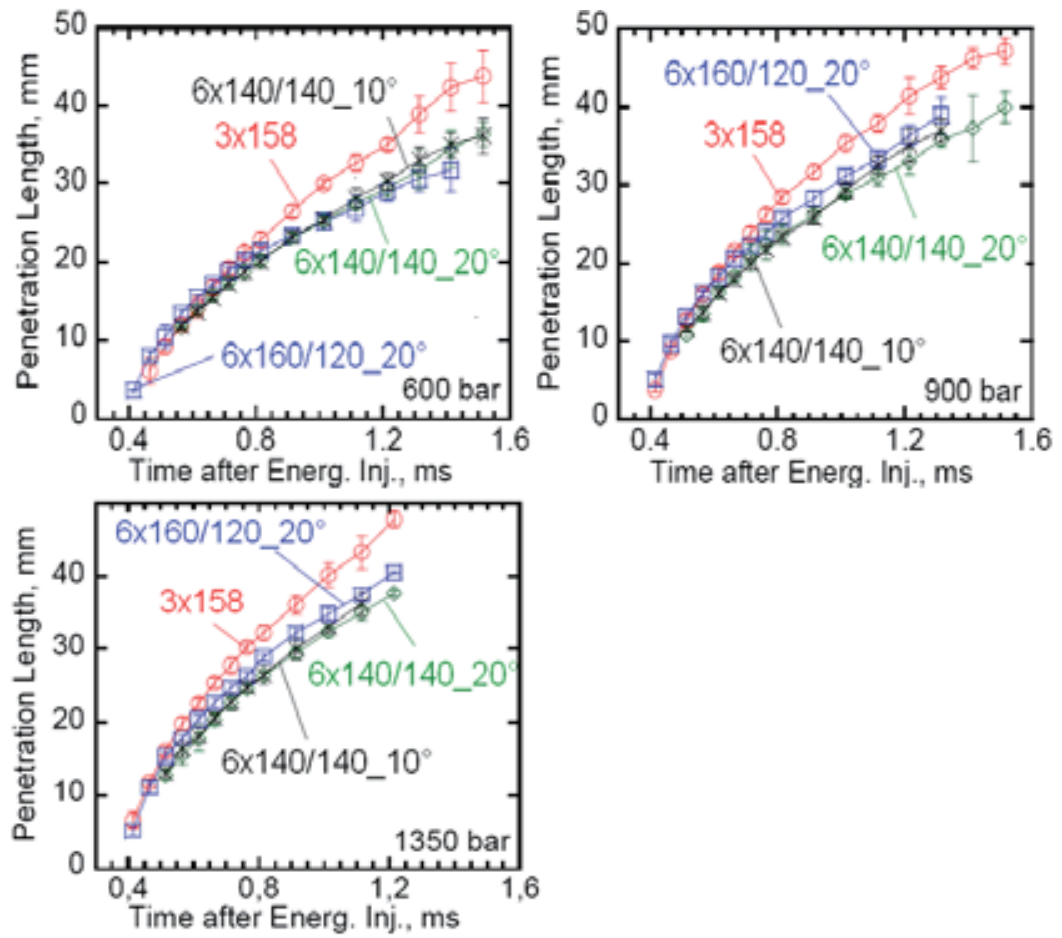

Figure 4.4: Comparison of vapor phase penetration 


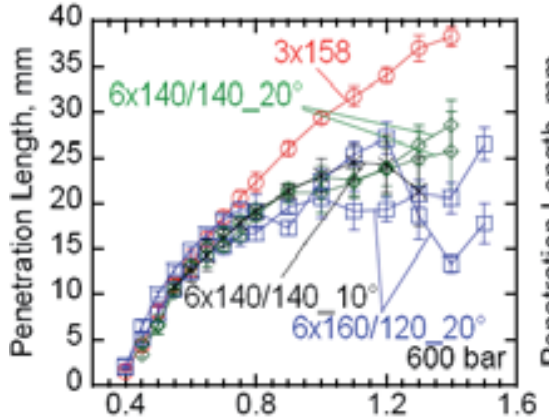

Time after Energ. Inj., ms

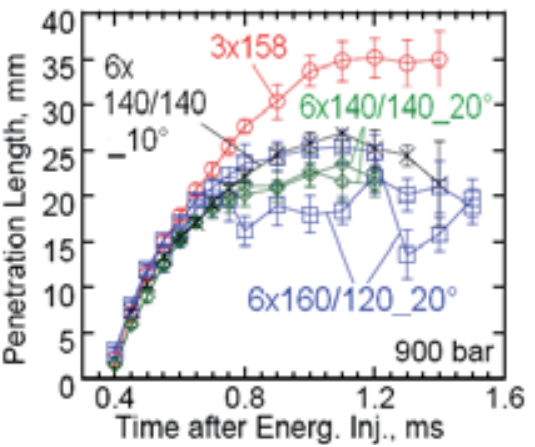

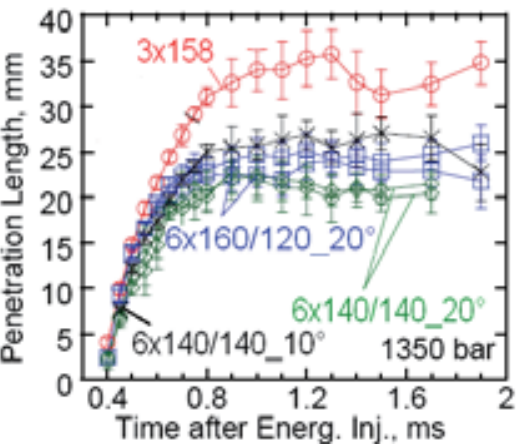

Time after Energ. Inj., ms

Figure 4.5: Comparison of liquid phase penetration

\subsubsection{Soot luminosity and LII measurements}

The soot luminosity and LII measurements were carried out by Dipl. -Ing. Peter Hottenbach at the Lehr und Forschungsgebiet Laser-Messverfahren in der Thermofluiddynamik (LTFD), RWTH-Aachen.

Fig. 4.6 shows the soot luminosity measurements and the corresponding LII measurements. The images are taken $2000 \mu \mathrm{s}$ after energizing the injector using an energizing time of $1200 \mu \mathrm{s}$. All images are averaged over 25 injections. The soot luminosity images of the reference nozzle show an established flame with the conventional shape. The LII measurements show that most of the soot is formed in a broad area around the spray axis as expected for conventional nozzles. Both cluster nozzles generate shorter penetration lengths of the flame compared to the reference nozzle. For both cluster nozzles, droplets can be observed close to the sooting region (at a height of nearly $20 \mathrm{~mm}$ ), due to Mie scattering in the images. The LII images for the $10^{\circ}$ cluster angle nozzle show a narrower soot distribution compared to the reference nozzle, 
except for the upper part, i.e., sooting region is mushroom-shaped. In the LII images of the $20^{\circ}$ cluster nozzles two separated soot distributions can be identified which are only slightly connected. Comparing signals of the different nozzles, the shape (and symmetry) of the soot distributions differ. Thus, a different fraction of the total soot mass is probed by the LII technique, since the measurements are only done in the central plane of the flames. Therefore, the total soot mass is lower for the cluster nozzles than that indicated by the LII results, when they are compared to the results of the reference nozzle. This is particularly true for the $20^{\circ}$ cluster nozzle. But it is impossible to calculate this factor precisely, because the exact 3-D shape is not known. Using the LII measurements, it can be estimated that at least in the early combustion phase the reference nozzle produces more soot in the central plane than both the cluster nozzles. Based on the LII data it can not be decided which cluster nozzle generates more soot. The line-of-sight luminosity data essentially corroborates that the reference nozzle generally produces more soot than the cluster nozzles [107].
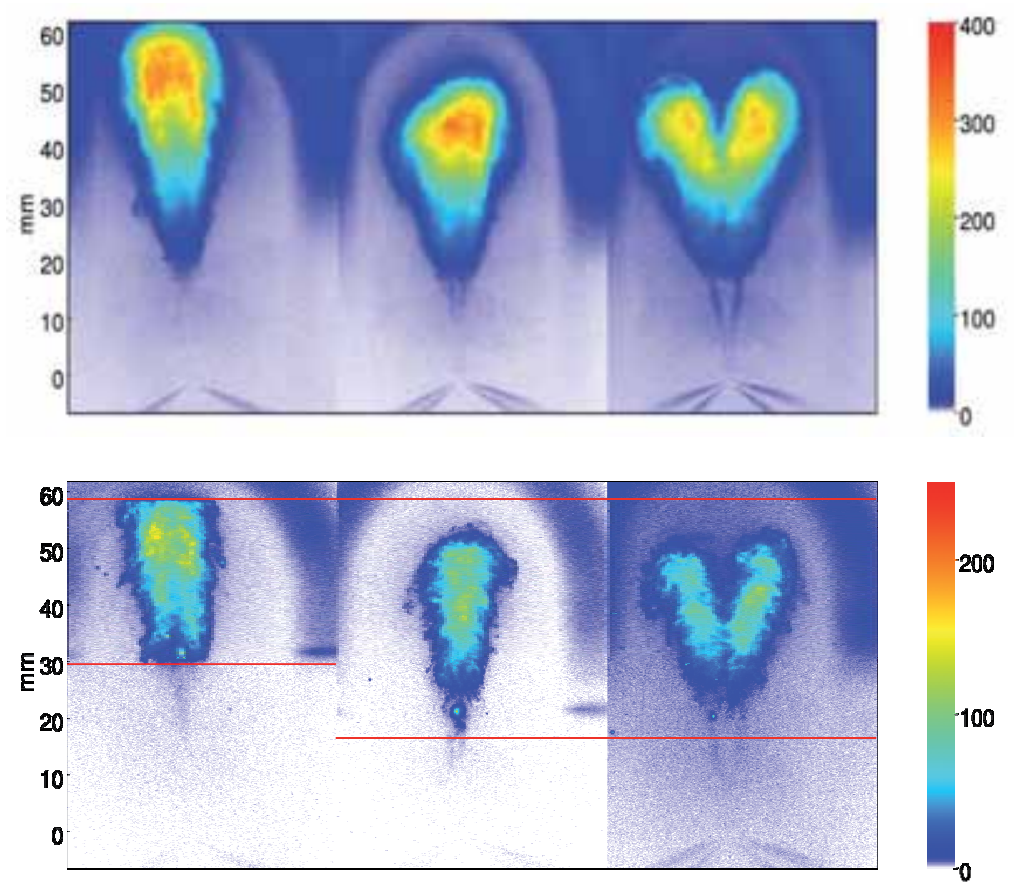

Figure 4.6: Soot luminosity images (top) LII images (bottom) of the reference nozzle (left), $10^{\circ}$ cluster nozzle (middle), $20^{\circ}$ cluster nozzle (right), rail pressure $=900 \mathrm{bar}, \mathrm{T}=$ $800 \mathrm{~K}, \mathrm{p}=50 \mathrm{bar}, 2000 \mu \mathrm{s}$ after energizing the injector 


\subsubsection{Numerical study}

Fig. 4.7 depicts the mixture fraction distributions in the horizontal and vertical injector cut-planes for the three investigated nozzles from the simulation. For the cluster $14 \times 160 / 120$ the vapor phase originating from the two orifices exhibits a separation. For the cluster $14 \times 150 / 130$ the vapor phase merges and behaves like a single spray. This leads to a higher gaseous penetration compared to $14 \times 160 / 120$. However, when compared to cluster $14 \times 160 / 120$, the cluster $14 \times 150 / 130$ exhibits a richer mixture in the horizontal cut plane. The larger cluster angle for cluster 14x160/120 increases the contact between the vapor phase and the bowl wall.

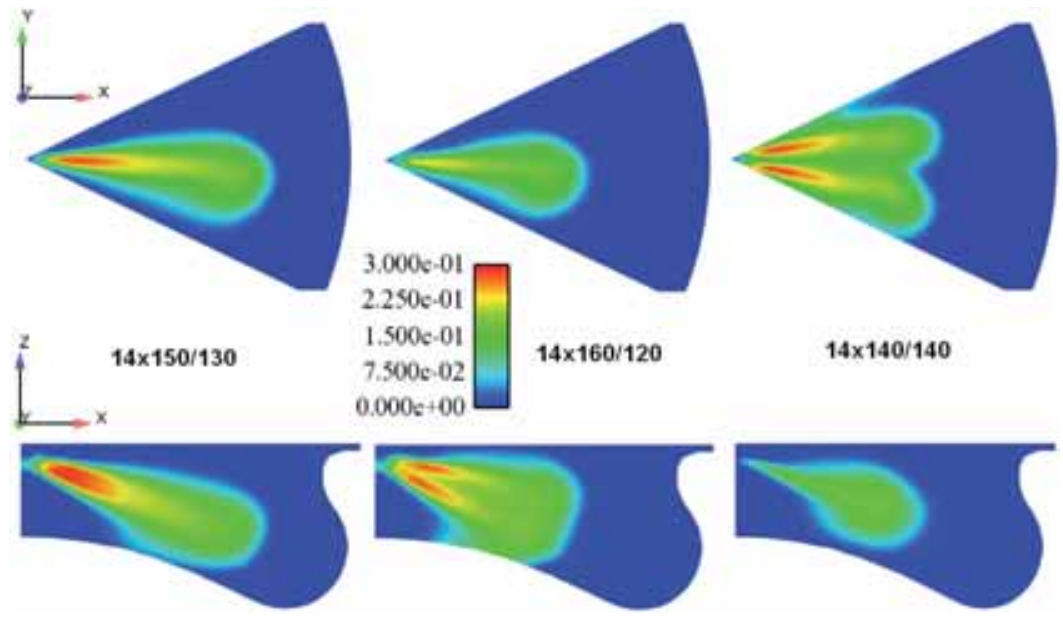

Figure 4.7: Mixture fraction distribution in cylinder for the three clusters for $6^{\circ} \mathrm{bTDC}$ SOI, 1400rpm, 800bar rail pressure, 5.5bar IMEP, $4.5 \mathrm{~g} / \mathrm{kg}$ fuel NOx

\subsubsection{Engine experiments}

The pressure traces and heat release curves for the three cluster nozzles are shown for part load for an SOI of $12^{\circ}$ bTDC (before Top Dead Center) in Fig. 4.8(a). Fig. 4.8(b) compares the pressure curves from experiments and numerical simulations for the three clusters. The cluster $14 \times 160 / 120$ has the highest peak pressure and heat release rate, while the start of combustion was found to be similar for all the nozzles. The simulation results match well with the data from the experiments. 
a)

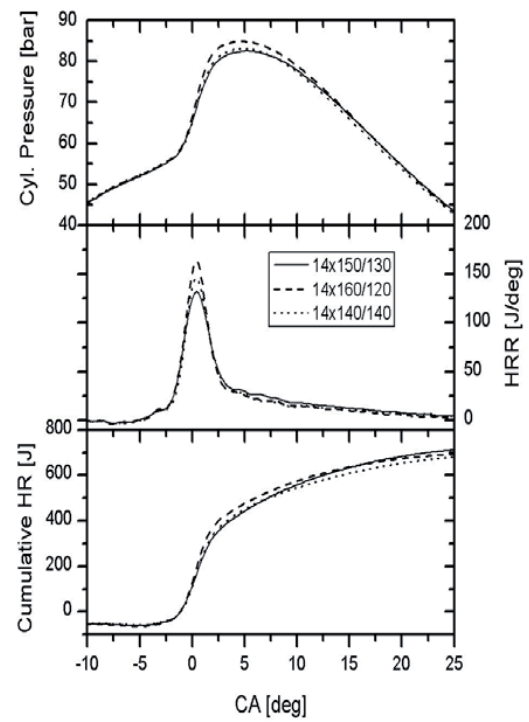

b)

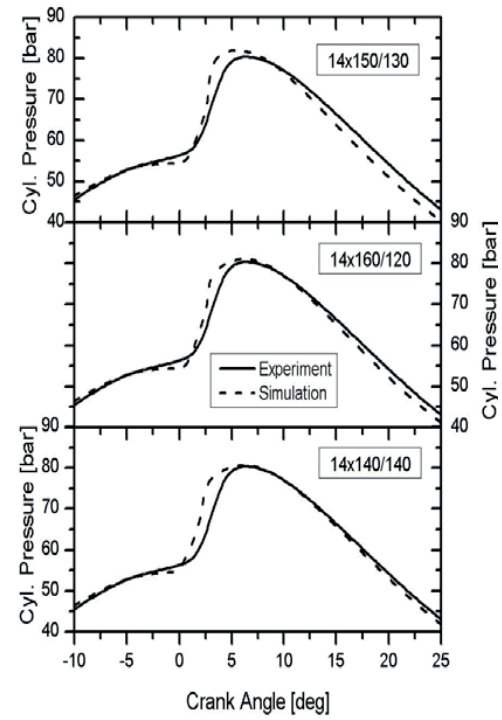

Figure 4.8: Pressure, Heat Release and Cumulative heat release for the three clusters (a), and comparison with simulation data (b).

Smoke- $\mathrm{NO}_{\mathrm{x}}$ and Hydrocarbon- $\mathrm{NO}_{\mathrm{x}}$ tradeoffs are shown in Fig. 4.9 for different SOI. The cluster 14x160/120 had better results for smoke than the reference nozzle for early start of injection points. All the clusters had higher smoke than the reference nozzle for conventional injection timings. A minimum smoke number is found around $25^{\circ} \mathrm{CA}$ bTDC using cluster $14 \times 160 / 120$. Smoke mostly depends on the mixing process and fuel rich regions close to the wall. The sprays from the clusters having a narrower centerline angle lose momentum because of improper targeting under conventional injection timings, which worsens the mixing process and increases soot formation. $\mathrm{HC}$ for all the clusters were lower than those for the reference nozzle for early injection timings but were found to be similar to the reference nozzle for conventional injection timings. At early injection timings, the fuel vapor spreads along the curved interior of the combustion chamber wall, and then turns towards the cylinder center for the clusters due to a narrower spray cone angle. Thus, the mixture does not disperse to the squish area. A reduction of air-fuel mixture in the volume above the squish area leads to a reduction of the air-fuel mixture dispersing to the top land area of the piston, which is the main cause of $\mathrm{HC}$ emission. This reduces $\mathrm{HC}$. The results indicate that low $\mathrm{NO}_{\mathrm{x}}$ combustion is possible for lean mixtures, even when the injection timing is $28^{\circ} \mathrm{CA}$ bTDC, while low $\mathrm{HC}$ combustion is possible by preventing the dispersion of the air-fuel mixture to a squish area. 

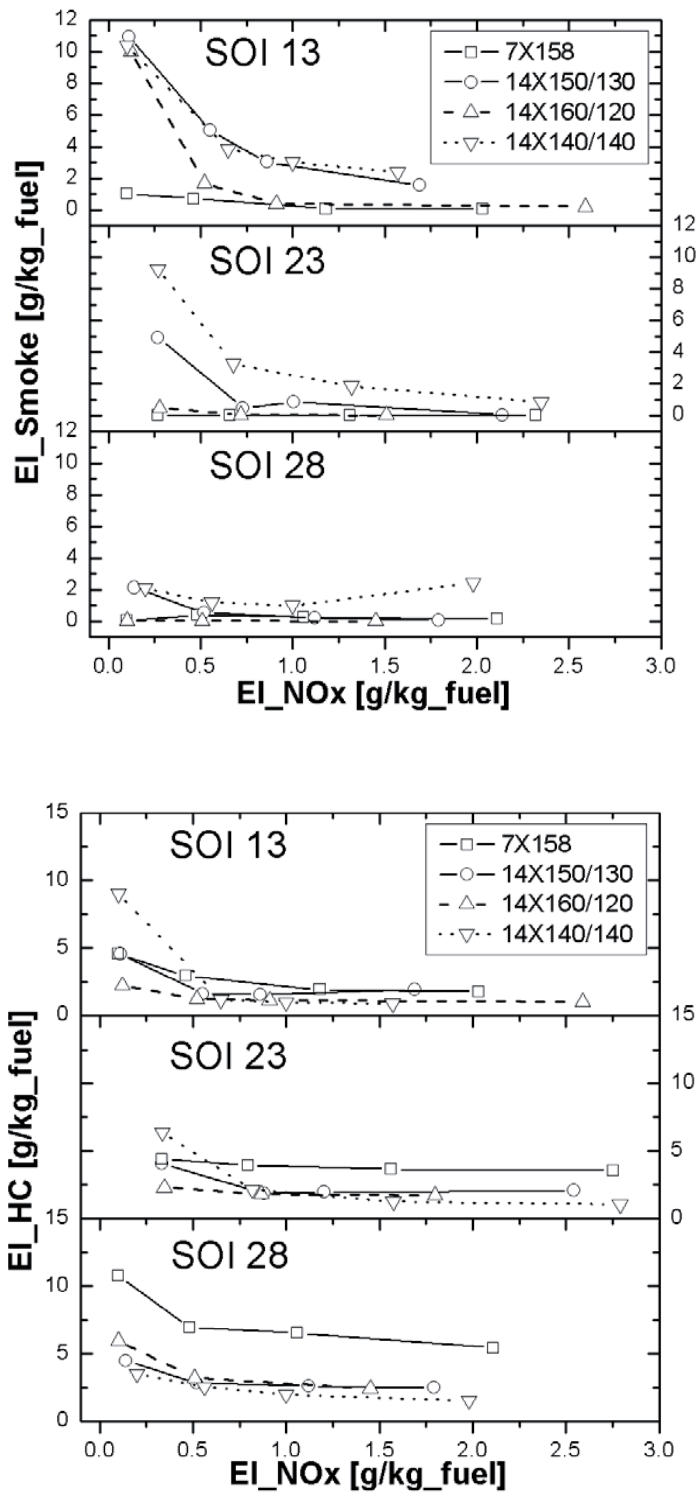

Figure 4.9: Smoke- $\mathrm{NO}_{\mathrm{x}}$ and Hydrocarbon- $\mathrm{NO}_{\mathrm{x}}$ Tradeoff: 1400rpm, 5.5bar IMEP 
The results of the spray measurement in the combustion vessel show a potential improvement for soot emissions for all the clusters, because the regions of clusters where high soot concentrations occur were narrower than for the reference nozzle. But the engine experiments for high load operation show a different trend. Among the three clusters, Cluster $14 \times 160 / 120$ shows the lowest soot, but it is still higher than the conventional nozzle. The anomaly between the relative trends of soot emissions for early injection under part load condition and conventional timings under high load condition was found to be caused by improper targeting.
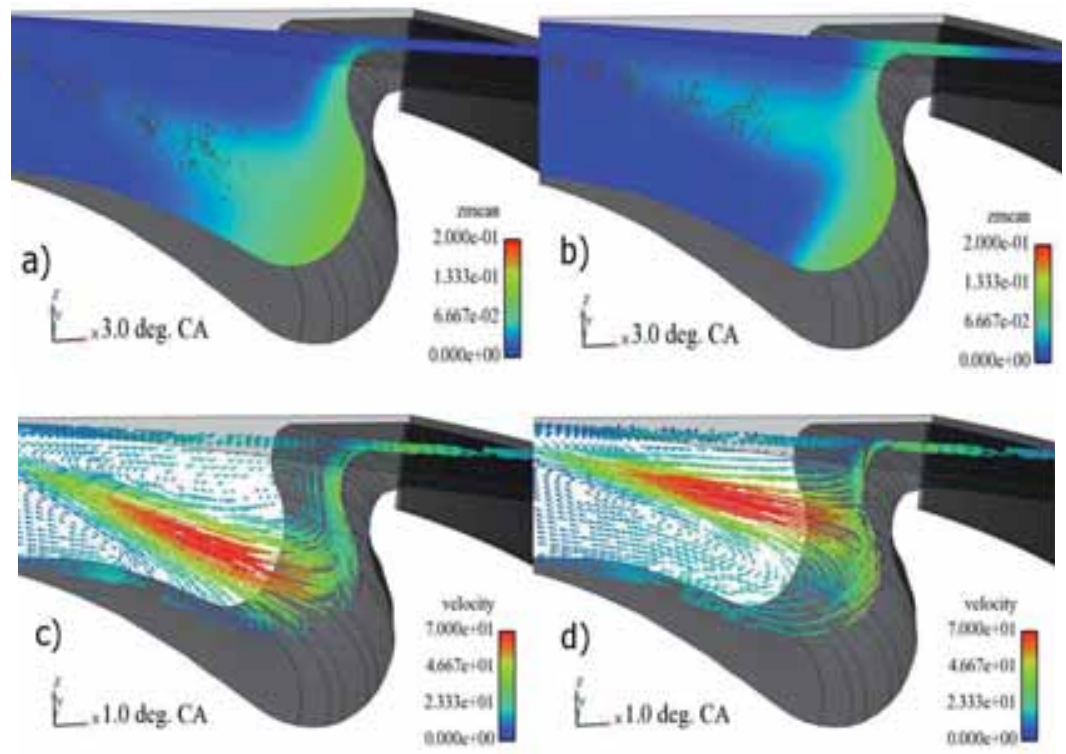

Figure 4.10: Mixture Fraction field for Spray cone angle of $140^{\circ}$ (a), $158^{\circ}$ (b) and Velocity distribution for Spray cone angle of $140^{\circ}$ (c) and $158^{\circ}$ (d), SOI $6^{\circ}$ bTDC

Fig. 4.10 explains the issue of targeting. Here we see results of simulations for two conventional nozzles with spray cone angles of $140^{\circ}$ in Fig. 4.10 (a) and (c) similar to the clusters of the first set and $158^{\circ}$ in Fig. 4.10(b) and (d) similar to the reference nozzle. The simulation is done for a conventional SOI $\left(6^{\circ} \mathrm{bTDC}\right)$. It is evident that the spray from the $140^{\circ}$ nozzle loses momentum close to the piston wall in Fig. 4.10(c) and leaves more amount of rich mixture there in Fig. 4.10(a), whereas the spray from the $158^{\circ}$ nozzle turns towards the center of the bowl in Fig. 4.10(d) and doesn't leave much of rich mixture near the wall. For earlier injection timings the spray from the cluster nozzles also turns towards the center of the bowl as described above. 


\subsubsection{Summary}

The cluster nozzles exhibit a smaller penetration for the flame than the conventional nozzle. The $20^{\circ}$ nozzle shows two separated soot "kernels" while the $10^{\circ}$ cluster shows only a single one with lower intensity than the conventional nozzle. The LII measurements demonstrate that the total soot mass generated by both the cluster nozzles is smaller than that in the case of the reference nozzle, at least in the early combustion phase. The first set of clusters which were designed with a smaller spray cone angle keeping in mind early injection operations, demonstrate the soot reduction potential of cluster nozzles under early injection conditions. But, the disadvantage due to improper targeting overweighs the advantage of the cluster concept under conventional timings. Simulations confirm the findings of the experiments and hint towards improvements in targeting. 


\subsection{Second set of clusters and optimization of injection pressure}

A total of six $10^{\circ}$ horizontal and vertical clusters with 5, 6 and 7 hole-pair orifice were investigated with different injection pressures under part load condition (TP1) and high load condition (TP2) and the results were compared with a reference nozzle. The clusters tend to produce higher smoke than the reference nozzle for low injection pressures under conventional injection timing because the spray from the clusters with a shorter spray tip penetration loses momentum near the piston bowl. But clusters with high pressure injection have improved smoke emissions as better fuel atomization and evaporation are achieved, while holding momentum near piston bowl and maintaining the penetration of the spray. Injection pressure was varied to find low smoke emission and better fuel consumption for each test point and an optimal injection pressure for each condition, such as PCCI condition and conventional injection timing under TP1 and TP2, was selected through the results of this investigation.

\subsubsection{Pressure and heat release}

Ignition delay in the case of the cluster nozzles is generally shorter than that in the case of the conventional nozzle. The initial rate of heat release is also higher for the cluster nozzles. The combustion period is shortened. With the higher heat release during the premixed phase, the clusters normally have a higher combustion temperature and correspondingly show an increase in $\mathrm{NO}_{\mathrm{x}}$ emissions. Therefore they required higher EGR rate than the reference nozzle to keep the same emission index of $\mathrm{NO}_{\mathrm{x}}$. The clusters were designed with different orifice diameter to keep the same flow number, the Cluster 10x158/138 has a slightly lower flow number than the other clusters. The differences between the cluster nozzles with respect to their different configurations and different hole-diameters are also apparent from the pressure and heat release curves shown below.

\subsubsection{Low load condition (TP1)}

Fig. 4.11 shows the pressures and heat releases of the horizontal clusters with 5, 6 and 7 hole-pairs and the reference nozzle by 1400rpm and 4.5bar IMEP under TP1. Even though the clusters had a higher EGR rate to keep the same emission index of $\mathrm{NO}_{\mathrm{x}}$, they showed shorter ignition delay than the reference nozzle. The combustion periods of the clusters were also shorter than the reference nozzle. The clusters except the 5 hole-pair cluster show higher heat release rates than the reference nozzle. The clusters with small orifices and high fuel delivery have better atomization and evaporation. Among the clusters, the 7 hole-pair cluster has highest heat release rate and the 5 hole-pair cluster shows the lowest heat release rate. The vertical clusters with 5, 6 and 7 hole-pairs and the reference nozzles are compared in Fig. 4.12. The trends of pressure and heat release rate were similar to the trends for the horizontal clusters. 


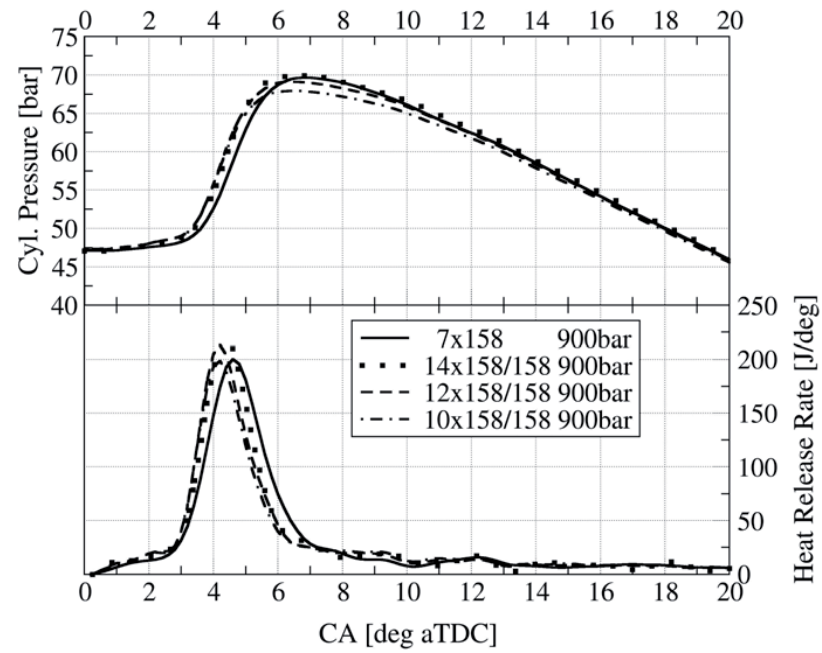

Figure 4.11: Pressure and heat release for horizontal clusters under TP1: $-6^{\circ} \mathrm{CA}$ aTDC SOI, 1400rpm, 4.5bar IMEP, $4.0 \mathrm{~g} / \mathrm{kg}$ fuel $\mathrm{NOx}$

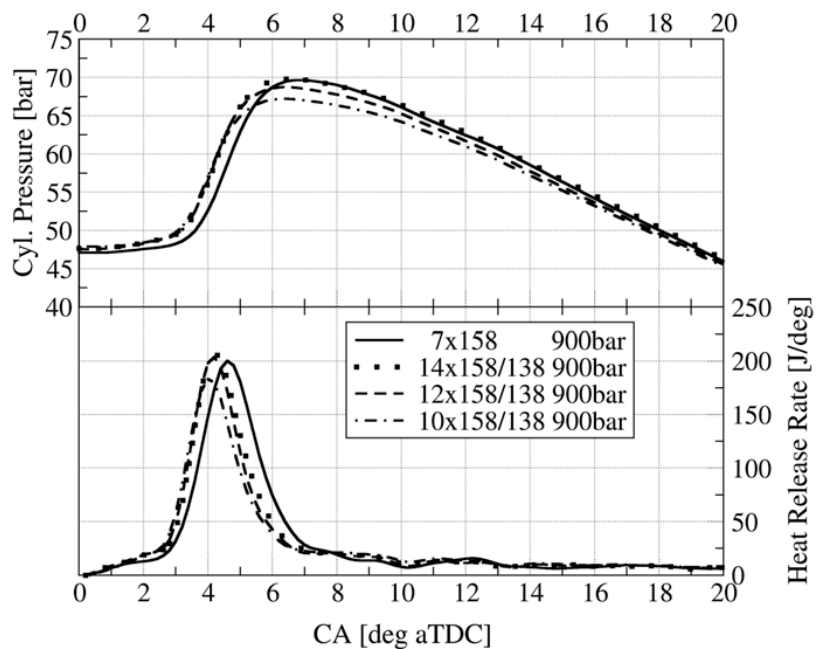

Figure 4.12: Pressure and heat release for vertical clusters under TP1: $-6^{\circ} \mathrm{CA}$ aTDC SOI 


\subsubsection{High load condition}

Fig. 4.13 shows the pressure and heat release rates for the horizontal clusters with 5, 6 and 7 hole-pairs and the reference nozzle by 1400rpm and 10.5bar IMEP under TP2. The clusters have ignition delays similar to the reference nozzle but the heat release rates of the clusters with better evaporation are higher than the reference nozzle during premixed combustion. A lower rate of heat release for the clusters than the reference nozzle during mixing controlled combustion phase indicates that a large number of the droplets were already consumed during premixed combustion phase for the clusters. The 5 hole-pair cluster has the lowest heat release rate. The vertical clusters and the reference nozzle are compared in Fig. 4.14. The trends of pressure and heat release rates are similar to the results for the horizontal clusters. Heat release rates for clusters being higher during the premixed combustion and lower during the mixing controlled combustion.

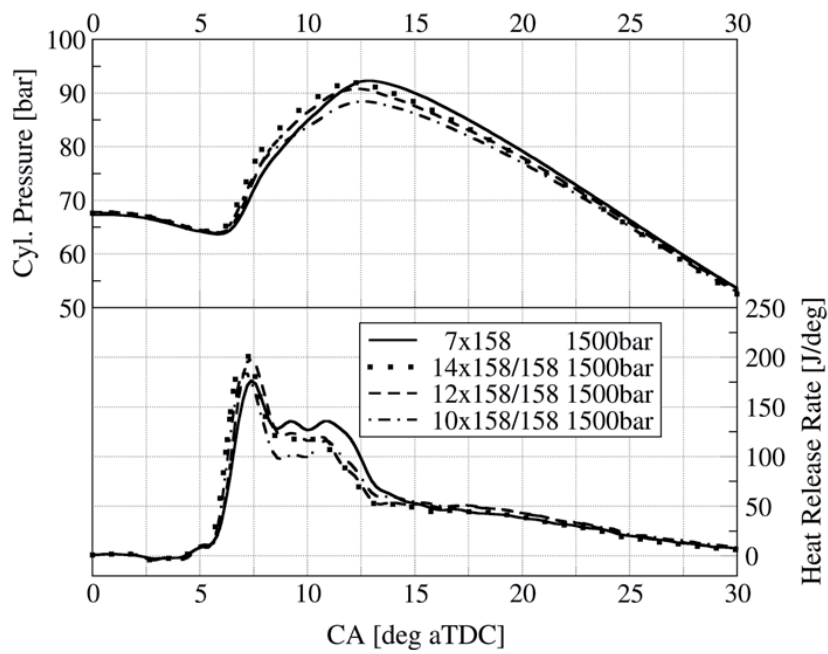

Figure 4.13: Pressure and heat release for horizontal clusters under TP2: $0^{\circ} \mathrm{CA}$ aTDC SOI, 1400rpm, 10.5bar IMEP, $4.5 \mathrm{~g} / \mathrm{kg}$ fuel NOx 


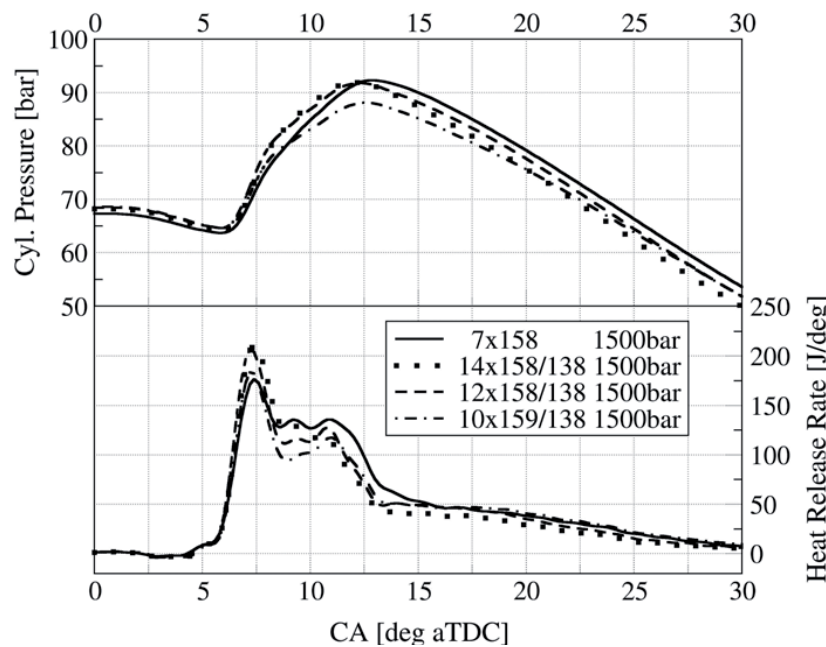

Figure 4.14: Pressure and heat release for vertical clusters under TP2: $0^{\circ} \mathrm{CA}$ aTDC SOI

\subsubsection{Variation of rail pressure}

Fig. 4.15 shows the pressure traces, heat release rates and cumulative heat release curves for the Cluster $14 \times 158 / 158$ and the reference nozzle with 600 bar and 900bar rail pressure. The cluster shows short ignition delay and combustion duration similar to previous figures. The ignition delays and the combustion duration of both the nozzles were reduced by high injection pressure. The peak pressure and maximum heat release rate were increased by higher injection pressure.

The cluster was also compared with the reference nozzle under TP2 in Fig. 4.16. The cluster with higher injection pressure has the earliest ignition in this case. Ignition delay was reduced with higher injection pressure or using smaller orifice nozzle. With higher injection pressure, the premixed combustion duration as well as the rate of heat release during that period is increased while the mixing controlled combustion duration is shortened with high injection pressure. The overall combustion duration is reduced with higher injection pressure. It is notable that in this case the ignition delay as well as the initial rate of heat release is almost identical for the conventional nozzle with 1500bar and the cluster nozzle with 1200 bar. 


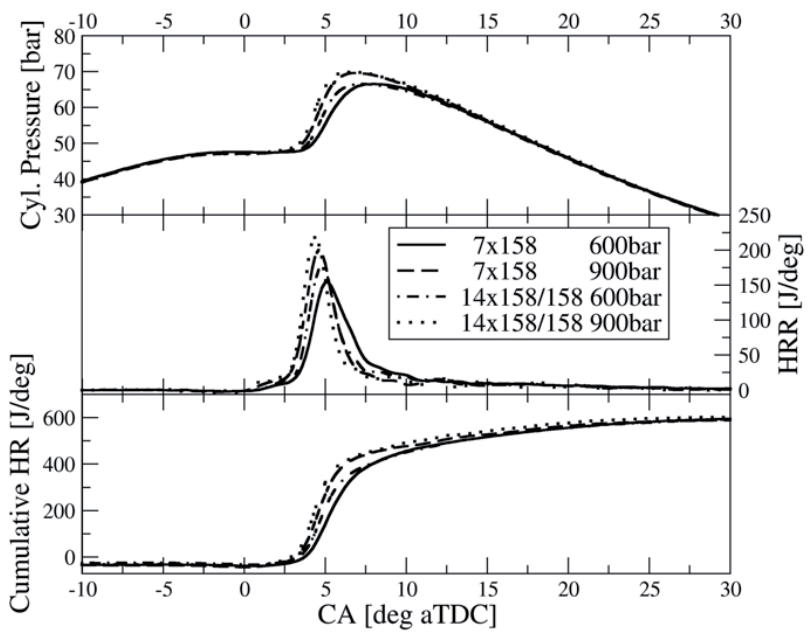

Figure 4.15: Pressure and heat release for Cluster $14 \times 158 / 158$ and the reference nozzle under TP1: $-6^{\circ} \mathrm{CA}$ aTDC SOI, 600bar and 900bar rail pressures

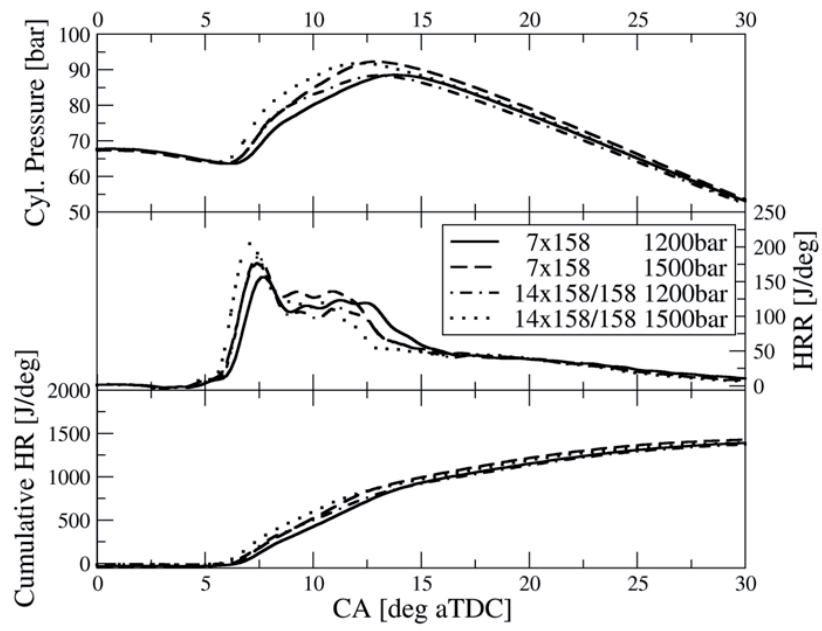

Figure 4.16: Pressure and heat release for Cluster $14 \times 158 / 158$ and the reference nozzle under TP2: $0^{\circ} \mathrm{CA}$ aTDC SOI, $1200 \mathrm{bar}$ and $1500 \mathrm{bar}$ rail pressures 


\subsubsection{Emissions and fuel consumption}

\subsubsection{Variation of injection pressure}

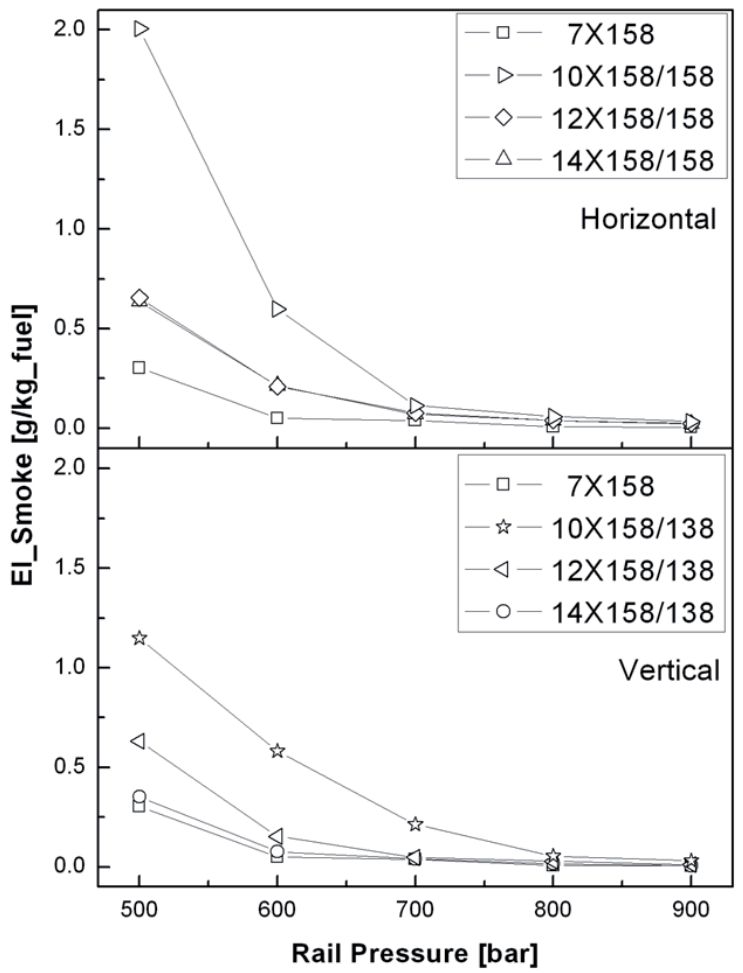

Figure 4.17: Smoke emissions with different injection pressures for TP1: $-5^{\circ} \mathrm{CA}$ aTDC SOI, 1400rpm, 4.5bar IMEP, $4.0 \mathrm{~g} / \mathrm{kg}$ fuel NOx

Fig. 4.17 shows smoke emissions for different rail pressures at an SOI of $-5^{\circ} \mathrm{CA}$ aTDC under TP1. The clusters show extremely high smoke for lower rail pressure under conventional injection timing. Among the compared clusters, the 7 hole-pair clusters show lower smoke than other clusters, but it is still higher than the reference nozzle. Since the atomization characteristics of the 7 hole-pair clusters are better than the reference nozzle, this behavior can only be explained by the shorter spray tip penetration. It is evident that the use of small-orifice nozzle is not sufficient to reduce the smoke 
levels for the clusters down to the level for reference nozzle. It is also necessary to increase the rail pressure for the purpose. The smoke emissions of the clusters were reduced down to similar smoke level of the reference nozzle by increasing the rail pressure. The reduction in smoke emissions at higher injection pressures is mainly due to the improved homogeneity of the charge. Another factor that might have contributed to the drop in smoke emission is reduction of the fraction of the fuel injected in to the flame. As noted above, the injection velocity increases the lift-off which allows more air to be entrained into the spray before the fuel reaches combustion zones.

\subsubsection{Low load condition (TP1)}

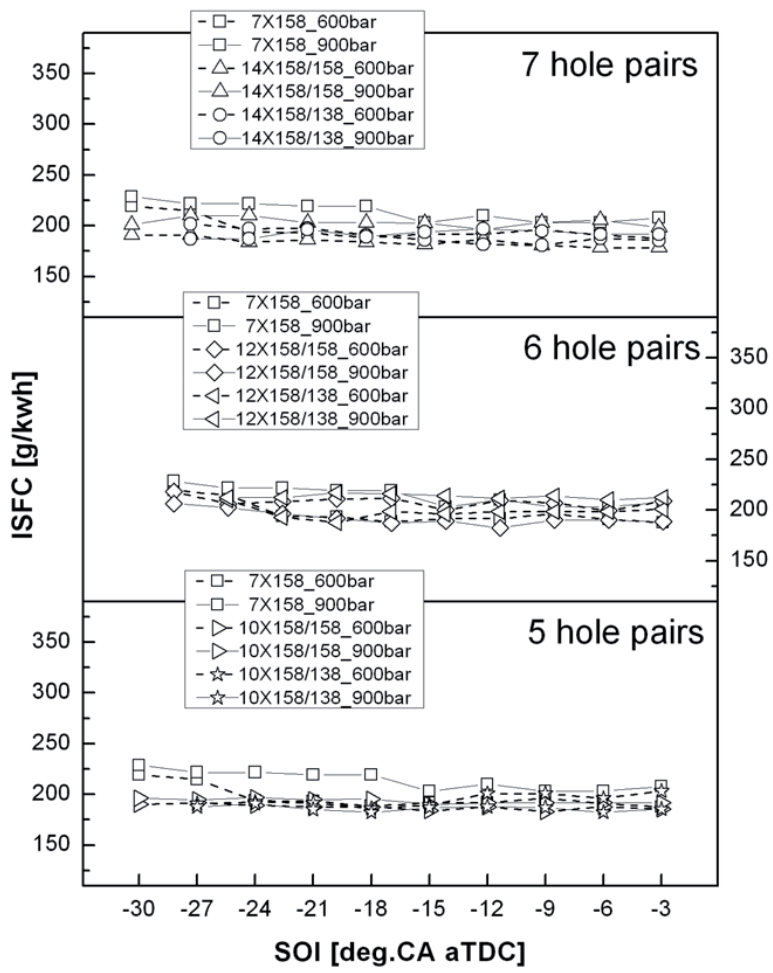

Figure 4.18: ISFC for TP1: 600bar and 900bar rail pressures, 1400rpm, 4.5bar IMEP, $4.0 \mathrm{~g} / \mathrm{kg}$ fuel $\mathrm{NOx}$ 
The Clusters were used to investigate effects of rail pressure for different SOI under low load condition and the results were compared with the reference nozzle. The size of the orifice and spray tip penetration should be the important parameters for TP1 because a small mass of fuel was injected in the chamber with low temperature and low pressure. Here the clusters should have an advantage with long ignition delay at early injection timing, but they tend to reduce spray tip penetration and the spray makes a rich zone. High injection pressures are required for the clusters to improve smoke emissions through the increase in the premixed combustion fraction. An increase of injection pressure with small injected quantity brings negative results for HC and ISFC under TP1. The smoke forms in the rich unburned-fuel-containing core of the fuel sprays, within the flame region, where the fuel vapor is heated by mixing with hot burned gases. When a small quantity of fuel is injected with high injection pressure in chamber of low temperature and low pressure, the smoke is reduced by reduced rich zones in the fuel jet. But the dilution has a negative impact on heat release which causes a higher ISFC. HC originates in regions where the flame quenches either close to the walls or where excessive dilution with air prevents the combustion process. In this case, the excessive dilution of spray is a more probable cause for higher $\mathrm{HC}$ emissions.

The results of ISFC using 5, 6 and 7 hole-pair clusters are shown for a variation of SOI in Fig. 4.18. The clusters have better fuel consumption than the reference nozzle for all injection timings. ISFC with 900 bar rail pressure is generally higher than 600 bar rail pressure. These are effects from the dilution of spray and increase in unburned HC emissions.

In low load conditions, $\mathrm{HC}$ emissions are also of major concern, because $\mathrm{HC}$ emissions are usually higher when the combustion temperature is low. The HC emissions of 5, 6 and 7 hole-pair clusters are measured for a variation of SOI under TP1 and the results are compared with the reference nozzle in Fig. 4.19. The HC emissions of all the nozzles were higher at early and late injection timings. At early injection timings more fuel reaches piston top and combustion chamber walls due to higher dilution and long ignition delays. At late injection timings combustion occurs past TDC when the expansion has already begun and the temperature starts reducing. More fuel close to chamber walls and lower temperature of combustion are both contributors to higher $\mathrm{HC}$ emissions. The reference nozzle with a longer spray tip penetration and larger orifices shows higher HC than cluster nozzles.

Of the compared cluster configurations, the vertical clusters have relatively lower HC than the horizontal clusters. This is perhaps due to the fact that horizontal clusters inject more fuel towards the top part of the piston than the vertical clusters, because of the vertical clusters having two spray cones with one of them narrower than the spray cone for horizontal clusters. It may also be helped by the fact that a spray with slightly narrower spray-cone angle takes a little longer to touch the piston wall in a reentrant type combustion chamber than a spray with conventional spray-cone angle. There is no common trend for change in injection pressure but $\mathrm{HC}$ emissions are worse with high pressure injection in most of the cases. The injection pressure has to be limited to keep $\mathrm{HC}$ emissions and the fuel consumption at acceptable levels under part load condition. 


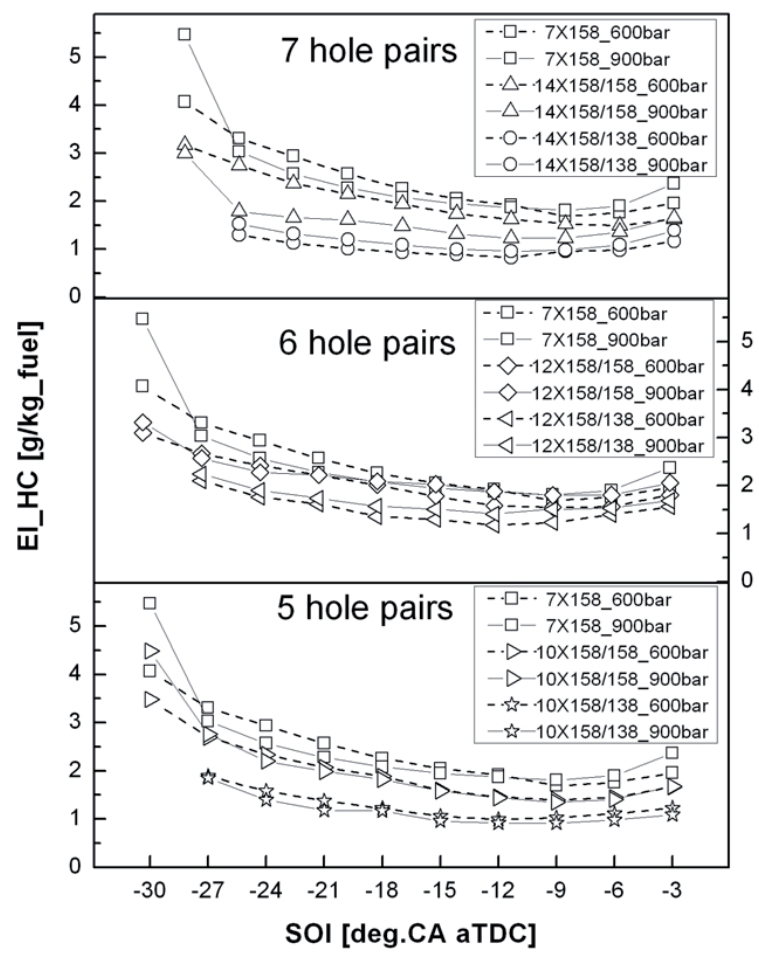

Figure 4.19: $\mathrm{HC}$ emissions for TP1: 600bar and 900bar rail pressures, 1400rpm, 4.5bar IMEP, $4.0 \mathrm{~g} / \mathrm{kg}$ fuel $\mathrm{NOx}$

Fig. 4.20 shows smoke emissions of 5, 6 and 7 hole-pair clusters with different rail pressures for a variation of SOI. For the clusters the smoke emission with low injection pressure is lower than the reference nozzle under early injection timings but it becomes much higher than the reference nozzle under conventional injection timing for TP1. The sprays from the clusters have a shorter spray tip penetration and can not entrain more air than the reference nozzle with shorter ignition delay as in the case of conventional timings. But the clusters show improved smoke emissions with higher injection pressure. With the increase of injection pressure, the clusters show a potential to reduce, to some extent, the adverse effects on spatial distribution of spray caused by better atomization.

For 600bar rail pressure, the horizontal clusters have higher smoke than the vertical clusters at conventional injection timings. The horizontal clusters make rich zones in chamber because the ignition delays for the conventional injection timings with relatively 
higher temperature and pressure are shorter than the ignition delay for early and late injection timings and the distances between the tips of the spray from adjacent holegroups in the horizontal configuration are also very small for short spray penetrations. The Cluster 10x158/138, which was specially designed with smaller flow number, also shows high smoke levels. It required longer injection duration than the other clusters to inject the similar amount of fuel to keep constant IMEP. Also remarkable is that the reference nozzle with 900 bar injection pressure shows higher smoke than with $600 \mathrm{bar}$ injection pressure for conventional injection timings. The increase in spray tip penetration with higher injection pressure makes richer mixture near the piston walls for the reference nozzle. However, the horizontal clusters and a vertical cluster (Cluster 10x158/138) showed substantial improvement in smoke emissions for higher injection pressure. It seems that unlike the reference nozzle, their spray tip penetration is inadequate for $600 \mathrm{bar}$ and is improved for 900 bar. For high injection pressure the clusters show lower smoke than the reference nozzle for TP1.

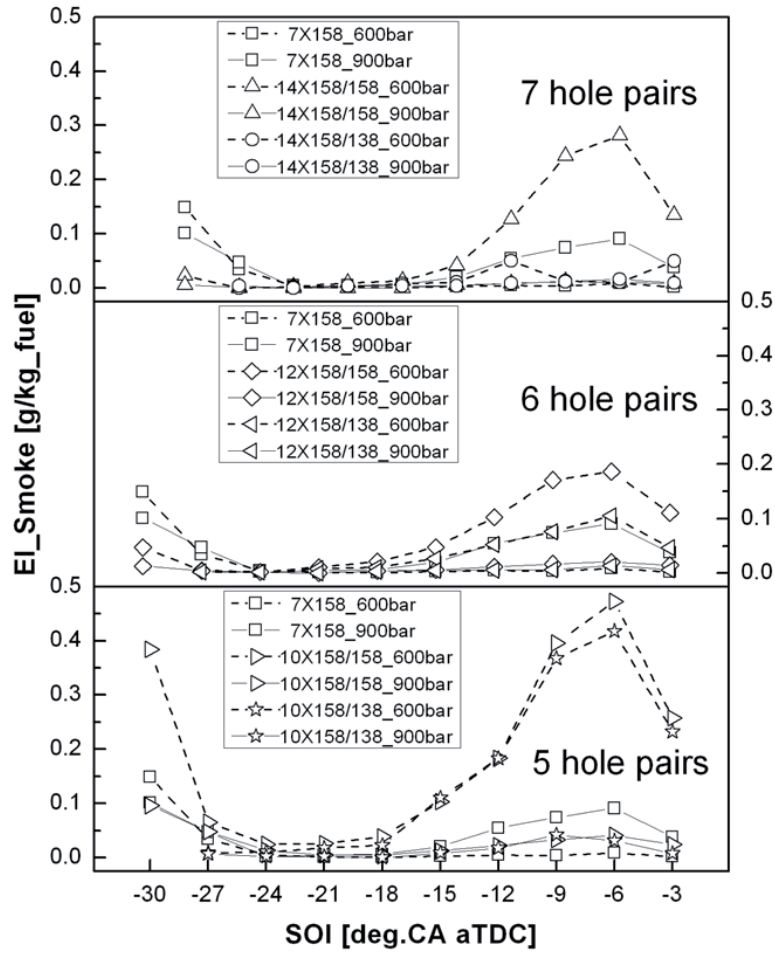

Figure 4.20: Smoke emissions for TP1: 600bar and 900bar rail pressures, 1400rpm, $4.5 \mathrm{bar}$ IMEP, $4.0 \mathrm{~g} / \mathrm{kg}$ fuel NOx 


\subsubsection{High load condition (TP2)}

The nozzles were also used to investigate effects of rail pressure for different SOI under high load condition. The injection timing under high load is limited by intense diesel knock. For this reason, the injection timings were varied between $-10^{\circ} \mathrm{CA}$ aTDC and $+4^{\circ} \mathrm{CA}$ aTDC. Also High injection pressures are required for the clusters to improve smoke emissions and thus the nozzles were tested with $1200 \mathrm{bar}$ rail pressure, which was suggested by GM for the reference nozzle under this condition, and 1500bar rail pressure. It was expected that an increase of injection pressure would reduce the smoke by reduced rich zones in the fuel jet.

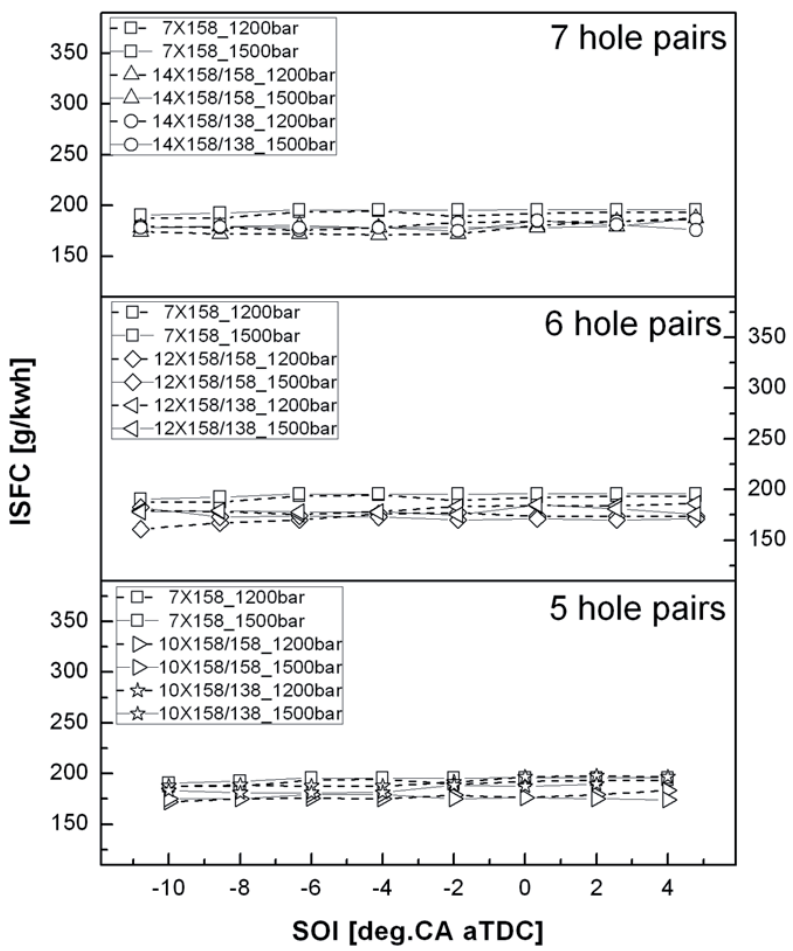

Figure 4.21: ISFC for TP2: 1200bar and 1500bar rail pressures, 1400rpm, 10.5bar IMEP, $4.5 \mathrm{~g} / \mathrm{kg}$ fuel $\mathrm{NOx}$ 
The results of ISFC using 5, 6 and 7 hole-pairs clusters are shown for the variation of SOI in Fig. 4.21. The clusters except Cluster 10x158/138 have better fuel consumption than the reference nozzle in all injection timings for TP2. The Cluster 10x158/138 with lower flow number required longer injection timing than other clusters and the combustion period is lengthened. But the cluster with high pressure improves the fuel consumption.

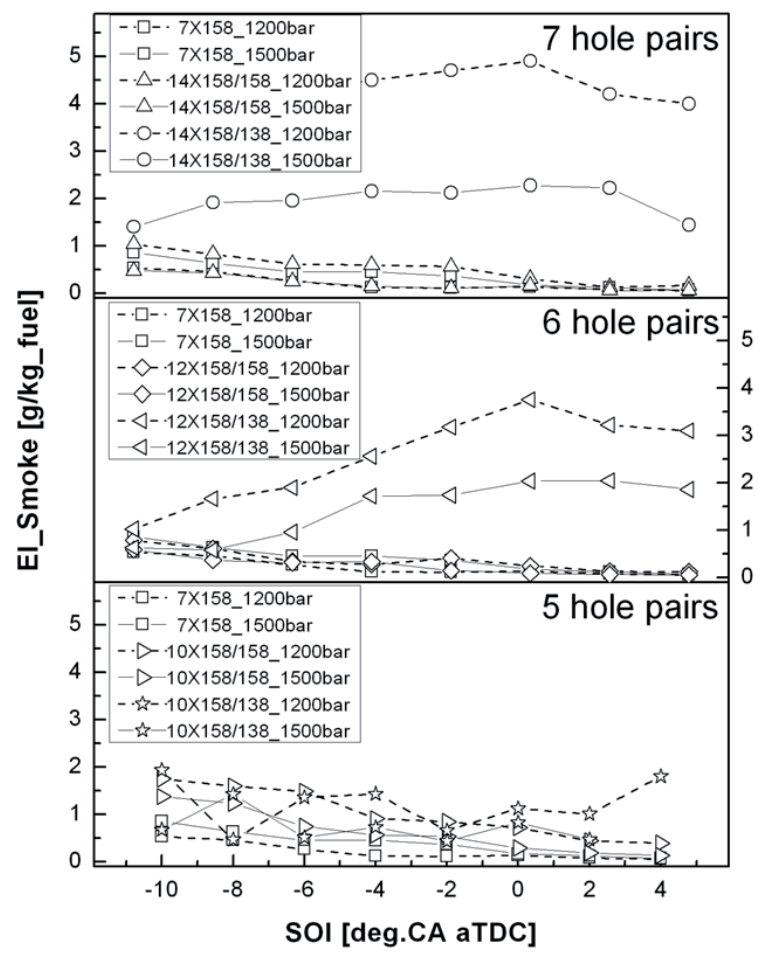

Figure 4.22: Smoke emissions for TP2: 1200bar and 1500bar rail pressures, 1400rpm, 10.5 bar IMEP, $4.5 \mathrm{~g} / \mathrm{kg}$ fuel $\mathrm{NOx}$

The results of smoke emissions for 5, 6 and 7 hole-pair clusters are shown in Fig. 4.22. Of the compared cluster configurations, the vertical clusters have relatively higher smoke emission than the horizontal clusters and the reference nozzle. The horizontal clusters, which were designed with $158^{\circ}$ spray cone angle, same as the reference nozzle, have better spray targeting and mixture formation near the piston bowl. A combination of the clusters with small orifices and high pressure injection can achieve lean combustion with the development of faster wall jets producing more turbulence and better mixing. As the 
spray reaches the piston walls, the vapor spreads over a larger surface area, moves further along the wall towards the bottom of the bowl and radially inward to the center of the bowl. This improves the mixing of the fuel with the bulk of the air in the bowl. The horizontal clusters with high pressure injection show lower smoke than the vertical clusters and the reference nozzle.

\subsubsection{Summary}

A combination of high pressure injection and cluster nozzles is one of the alternative hardware configurations to achieve lean combustion. Despite the experiments being performed with a wide piston bowl without optimized swirl level, some clusters with high injection pressure have lower smoke level than the reference nozzle. However, the cluster nozzles required relatively higher injection pressures to achieve low smoke emission and better fuel consumption. Based on these results injection pressures were determined for further experiments, namely 600bar injection pressure for PCCI condition under TP1, $900 \mathrm{bar}$ for conventional injection timing under TP1 and 1500bar for TP2. 


\subsection{Evaluation of cluster nozzles}

Using the optimal rail pressures determined for TP1 and TP2 the engine experiments were performed to evaluate the clusters with respect to each other and in comparison to the reference nozzle. They were also tested under TP3 and TP4 using 1800 and 2000bar rail pressure respectively. The results are discussed in detail in the following sections.

\subsubsection{PCCI condition (TP1)}

The results are discussed for an early injection timing of $-27^{\circ} \mathrm{CA}$ aTDC with $600 \mathrm{bar}$ rail pressure for different EGR rates. The results for smoke, $\mathrm{HC}$ and fuel consumption for 7 hole-pair clusters are shown in Fig. 4.23. The two vertical clusters with $10^{\circ}$ and $20^{\circ}$ included angle and one horizontal cluster with $10^{\circ}$ included angle were investigated for TP1.

The clusters having small orifices are regarded as a promising approach to lower fuel consumption because the sprays from clusters have a greater mass of entrained ambient gas and more mass of fuel vapor compared to the reference nozzle. The ISFC of the clusters is lower than the reference nozzle except for the Cluster 14x160/120_20 ${ }^{\circ}$, which has wider angle between orifices. Due to the smaller dispersion and a much stronger interaction between the jets, the $10^{\circ}$ cluster nozzles are expected to deliver a faster penetration than the $20^{\circ}$ cluster configuration, providing better mixing for part load conditions. The clusters show an improvement for $\mathrm{HC}$, because the reference nozzle having longer spray tip penetration than the 7 hole-pair clusters causes more fuel in proximity of the cylinder liner and combustion chamber walls, where flame quenching occurs. Lower soot emissions for the lower oxygen concentration conditions, which have substantially lower flame temperatures, suggest that $\mathrm{NO}_{\mathrm{x}}$ and soot can potentially be simultaneously reduced with small orifices and exhaust gas recirculation. The 7 hole-pair clusters show improvements over the conventional nozzle for TP1 at early injection timings.

The ISFC, $\mathrm{HC}$ and smoke levels stay almost the same with different $\mathrm{NO}_{\mathrm{x}}$ levels. It seems that a change in $\mathrm{NO}_{\mathrm{x}}$, which is achieved by a change in EGR, has no effect on ISFC, HC and smoke, which is different from what is seen with conventional injection timings. There are two opposing effects of increasing the EGR which is already high for early injection strategy. The first one is the dilution of oxygen with high EGR, which increases ISFC, HC and smoke emissions and the second one is a longer ignition delay with higher EGR (ignition closer to TDC), which decreases them. Due to the two opposing effects no clear tradeoff was found for ISFC, $\mathrm{HC}$ and smoke with respect to $\mathrm{NO}_{\mathrm{x}}$ for early injection timings under part load conditions. 


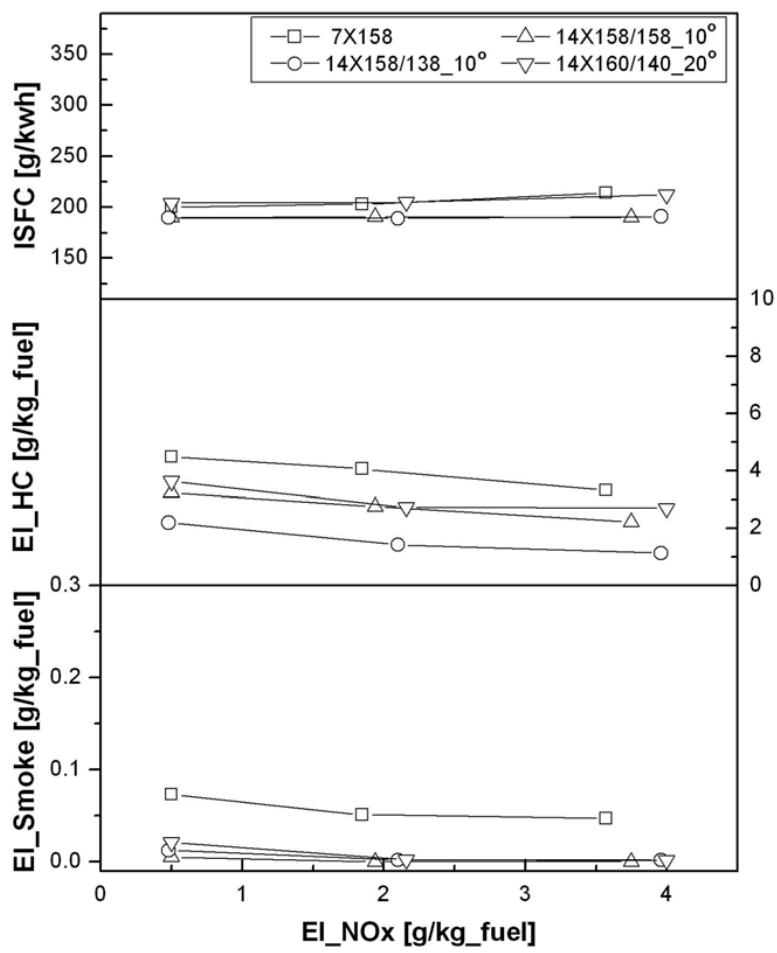

Figure 4.23: 7 hole-pair clusters for $\mathrm{TP} 1$ : $-27^{\circ} \mathrm{CA}$ aTDC SOI, 1400rpm, 600bar rail pressure, 4.5bar IMEP

The results for 5 hole-pair clusters are shown in Fig. 4.24. Among the 5 hole-pair clusters are two horizontal clusters, one with parallel orifices and the other with a $10^{\circ}$ diverging angle between the orifices, and three vertical clusters with diverging included angles of $5^{\circ}, 10^{\circ}$ and $20^{\circ}$ between the two orifices. The 5 hole-pair clusters were designed with larger orifices than the 7 hole-pair clusters to keep the same flow number.

The 5 hole-pair clusters have relatively better fuel consumption than the reference nozzle. The tradeoffs of emissions for individual clusters are similar to the results with 7 holepairs clusters, though some clusters have worse emission results than the reference nozzle. The clusters with a narrower included angle (Cluster $14 \times 158 / 1580^{\circ}$ and Cluster $14 \times 158 / 1485^{\circ}$ ) have more $\mathrm{HC}$ emission than the reference nozzle. Both these nozzles have almost similar or even longer spray tip penetration than the reference nozzle $[6,108]$, resulting in more fuel adhering to the cylinder liner thus increasing the amount of fuel 
present in the zones where flame quenching happens. The spray tip penetration and ignition delay for low load and low engine speed are longer than those for the high load condition because of the lower boost pressure and intake temperature. The clusters with wider included angles show smaller HC emissions than the reference nozzle.

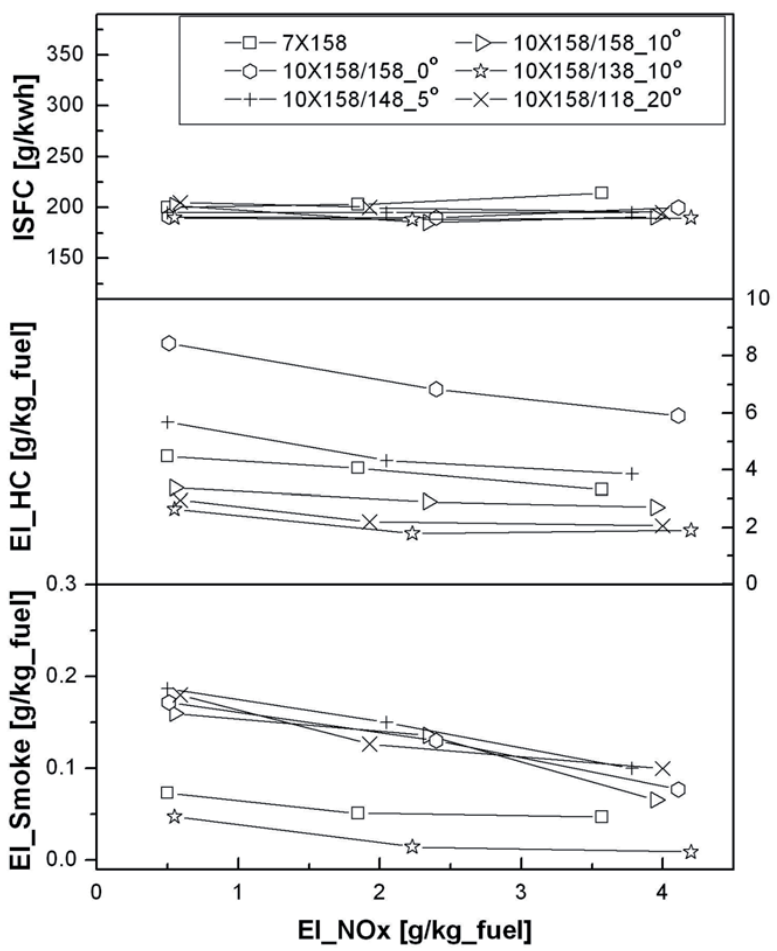

Figure 4.24: 5 hole-pair clusters for $\mathrm{TP} 1:-27^{\circ} \mathrm{CA}$ aTDC SOI, 1400rpm, 600bar rail pressure, 4.5bar IMEP

Only Cluster $10 \times 158 / 138 \_10^{\circ}$, which had a smaller flow number and thus relatively a smaller orifice diameter, showed lower smoke than the reference nozzle, while all others showed considerably higher smoke. Cluster 10x158/148_5 $5^{\circ}$ showed the highest smoke levels for TP1. The orifice diameter for the individual orifices of 5 hole-pair nozzles $(0.123 \mathrm{~mm})$ is slightly smaller than the reference nozzle $(0.135 \mathrm{~mm})$. But the interaction between two jets of a hole-pair suppresses ambient gas entrainment and evaporation compared to a single orifice of the size same as one orifice of the pair [87], making the spray characteristics of a hole pair similar to those of a larger orifice. Moreover, a lesser 
number of orifice-groups worsens the fuel distribution in the combustion chamber and thus increases soot. The size of orifice is a very important parameter for smoke emission in lean mixture conditions such as in PCCI. Better performance of the 5 hole-pair cluster with smaller orifices hints that for a 5 hole-pair nozzle with the same flow number, the orifices are not small enough to be beneficial over slightly larger single orifices of 7-hole conventional nozzles.

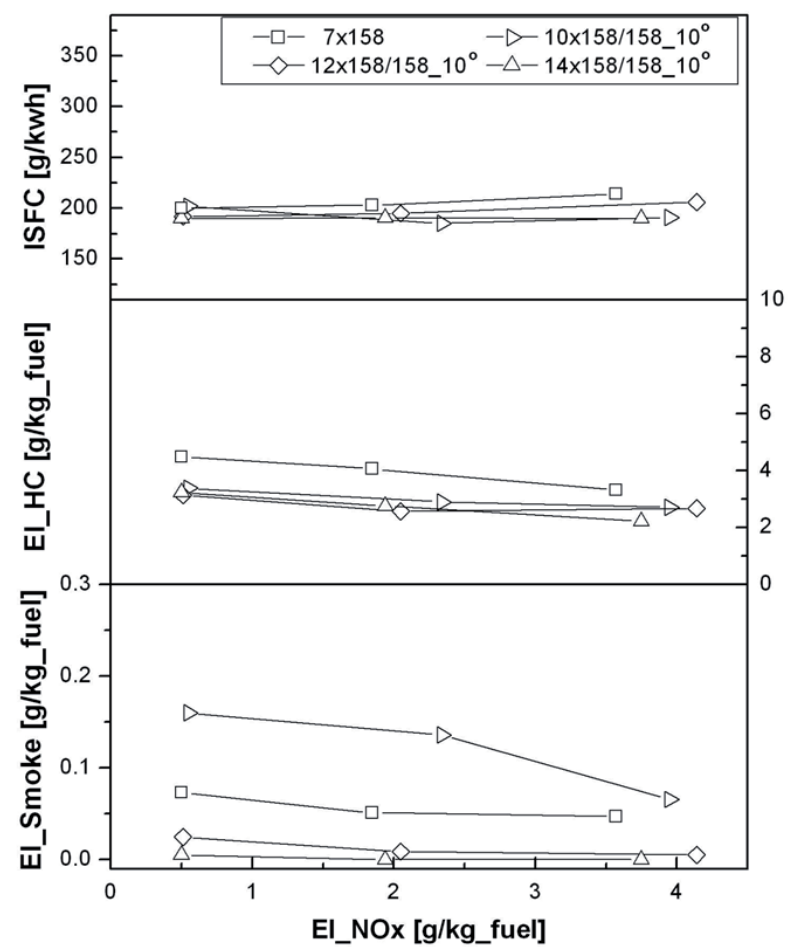

Figure 4.25: Horizontal clusters for $\mathrm{TP} 1$ : $-27^{\circ} \mathrm{CA}$ aTDC SOI, $1400 \mathrm{rpm}$, 600bar rail pressure, 4.5bar IMEP

The horizontal clusters with 5, 6 and 7 hole-pairs are compared in Fig. 4.25. The fuel was injected in relatively lower temperature and pressure at early injection timing with long ignition delay. The Clusters show better fuel consumption and lower $\mathrm{HC}$ emission than the reference nozzle. However, the 5 hole-pair cluster has more smoke than the reference nozzle, while the others perform better. Among the three clusters, the 7 hole-pair cluster having relatively smaller orifices shows better fuel consumption and lower HC- and 
smoke emissions. As the number of holes increases, the diameter of orifices decreases to keep the same flow number. The reduction of the orifice size is regarded as an approach to facilitate better fuel atomization and evaporation and the clusters with short spray tip penetration and better mixture formation have advantage in $\mathrm{HC}$ emission in this condition.

\subsubsection{Low engine speed and high load condition (TP2)}

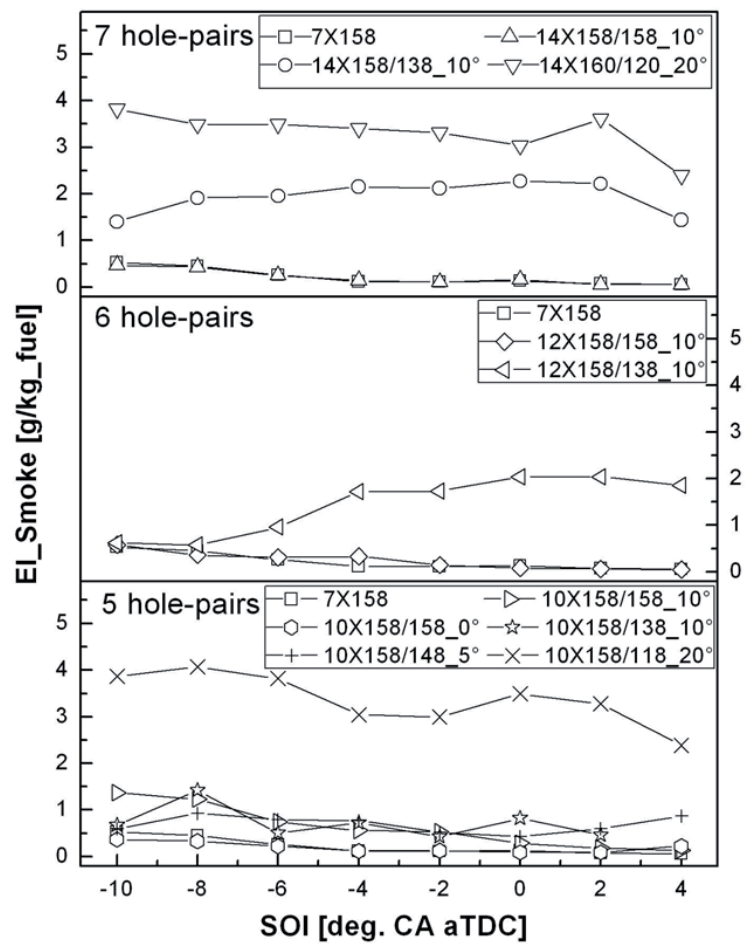

Figure 4.26: Smoke emissions for 5,6 and 7 hole-pair clusters under TP2: 1400rpm, $1500 \mathrm{bar}$ rail pressure, $10.5 \mathrm{bar}$ IMEP, $4.5 \mathrm{~g} / \mathrm{kg}$ fuel $\mathrm{NOx}$

TP2 is an operating condition in low engine speed under high load. PCCI operation under high load is limited by intense diesel knock. It is necessary to switch from PCCI to conventional combustion under high load and to find a solution for the problem with high smoke level under high load condition. With the use of smaller orifice nozzles, lesser fuel adheres to the wall because the distance the fuel spray reaches is shortened. This is 
considered to be caused by a low penetrating force due to smaller droplet sizes in the spray, and by an evaporation-prone characteristic due to a larger surface area to droplet weight ratio [92]. Only the smoke emissions are compared because the $\mathrm{HC}$ and $\mathrm{CO}$ are not of major concern in this condition. Moreover the performance of all the nozzles with respect to $\mathrm{HC}$ and $\mathrm{CO}$ was quite similar. The size of the orifices, spray targeting and spray tip penetration should be the important parameters for TP2 because a lot of fuel was injected in this condition while the engine speed was relatively lower, the spray tip penetrations were long enough to see the effect of spray targeting. The closely-placed orifices help to hold the momentum, maintaining the penetration of the spray.

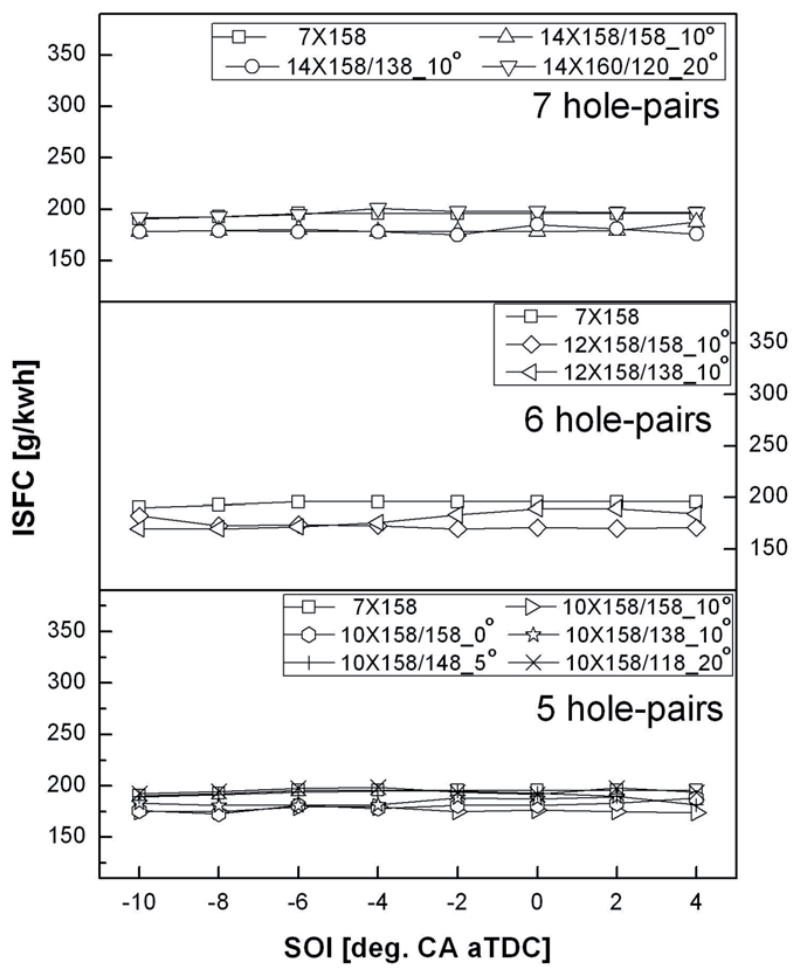

Figure 4.27: ISFC for 5, 6 and 7 hole-pair clusters under TP2: 1400rpm, 1500bar rail pressure, 10.5 bar IMEP, $4.5 \mathrm{~g} / \mathrm{kg}$ fuel NOx

The results for smoke emissions for 5, 6 and 7 hole-pair clusters are shown in Fig. 4.26. Of the compared cluster configurations, the horizontal clusters (Cluster 14x158/158_10 , 
Cluster $12 \times 158 / 15810^{\circ}$, Cluster $10 \times 158 / 1580^{\circ}$ ) have lower smoke emission than the vertical clusters and the reference nozzle. The horizontal clusters, which were designed with $158^{\circ}$ spray cone angle, same as the reference nozzle, have better spray targeting and mixture formation near the piston bowl. The spray of horizontal clusters is injected towards the top part of the piston bowl from where it is guided along the bowl surface towards the center of the bowl. In this way sufficient air can be entrained during the mixing and combustion process, and thus the burning rate is accelerated. But the results of horizontal clusters do not show significantly lower soot levels compared to the reference nozzle. The clusters with small orifices improve the fuel atomization and evaporation, but because of the shorter penetrations compared to the reference nozzles, their sprays lose the momentum faster, when used in a wide piston bowl. There exists a trade-off between the fuel evaporation improvement and keeping the spray penetration in the application of cluster nozzles. With the increase of separation between the sprays, the ratio of vapor phase with respect to liquid phase increases, however, the penetration distance is restrained. The vertical clusters show relatively higher smoke emissions. It seems that the two sprays, one directed towards the top part of the bowl and the other towards the middle or the bottom part of the bowl, guided against each other by the bowl contour, merge with each other and make a rich zone near the piston wall. This might be a source of higher smoke emissions for the vertical clusters. This is also supported by the results shown in section 4.1.5. This can explain the increase in smoke emissions with an increase in the included angle between the orifices for TP2. Fig. 4.27 shows the ISFC results for TP2. The trends are similar to the results for TP1. The clusters have better fuel consumption than the reference nozzle.

\subsubsection{High engine speed and medium load condition (TP3) and full load condition (TP4)}

The clusters were also investigated under medium and full load condition in high engine speed. The size of the orifices and the included angle of the cluster should be the determining factors in TP3 and TP4, because of the spray tip penetration being smaller and the ignition delay being shorter than the low load conditions, owing to the higher boost pressure and temperature. The clusters with smaller orifices and larger includedangle between the orifices have better fuel atomization and evaporation and lower fuel consumption and greater mass of ambient gas entrained and more mass of fuel vapor in short times compared to the reference nozzle. Here again only the smoke emissions were compared because the $\mathrm{HC}$ and $\mathrm{CO}$ are not a major concern for these operating conditions and were found to be within acceptable range for all the nozzles. The trends for ISFC were very similar to those shown for TP2 therefore they are not being shown for TP 3 and TP4. The results for smoke emissions using 5, 6 and 7 hole-pair clusters in TP3 and TP4 are shown in Fig. 4.28 and 4.29.

Only one horizontal cluster (Cluster $14 \times 158 / 158 \_10^{\circ}$ ) and a vertical cluster (Cluster $14 \times 160 / 120 \_20^{\circ}$ ) showed smoke levels similar to the reference nozzle. Both of them are 7 hole-pair nozzles, thus have smaller orifices than the other nozzles. All the other clusters have shown higher smoke levels for TP3 and TP4. All the 7 hole-pair clusters 
have relatively lower smoke than the other clusters for both TP3 and TP4. Of the compared cluster configurations, the horizontal clusters also have relatively lower smoke than the corresponding vertical clusters for TP4. The included angle between two orifices affects also the smoke emission. The clusters with wider cluster angles have relatively lower smoke than the clusters with the narrower included angles. The $10^{\circ}$ horizontal and $20^{\circ}$ vertical 7 hole-pair clusters perform better than the reference nozzle for TP 3 and the $10^{\circ}$ horizontal 7 hole-pair cluster is the only one performing better than the reference nozzle for TP4.

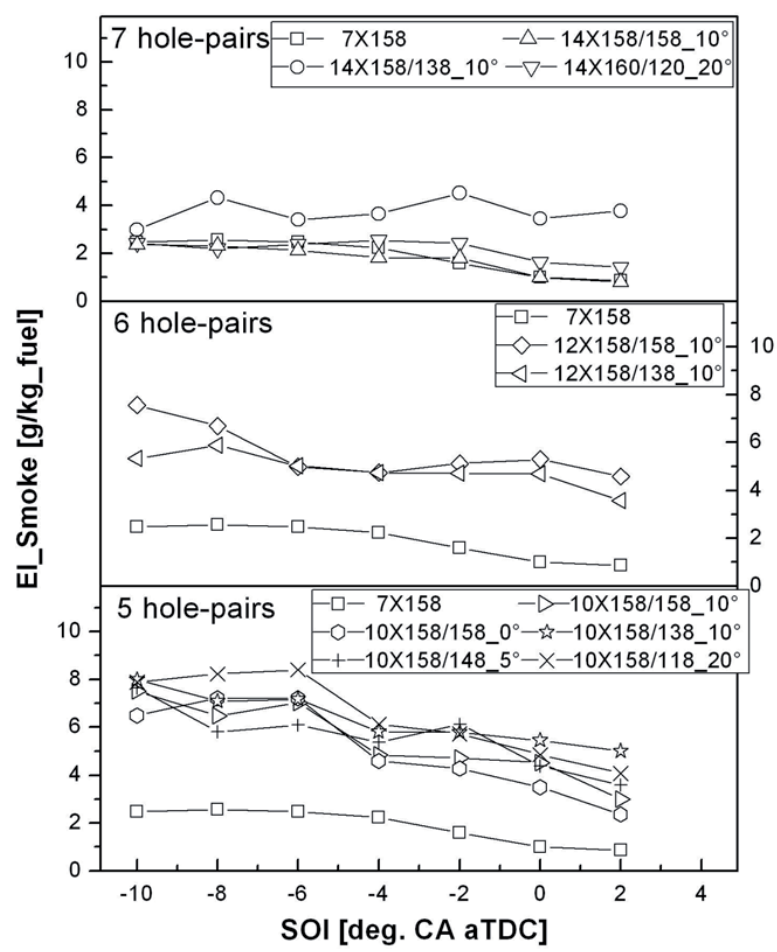

Figure 4.28: Smoke emission for 5, 6 and 7 hole-pair clusters under TP3: 2800rpm, 1800 bar rail pressure, 10.2 bar IMEP, $4.5 \mathrm{~g} / \mathrm{kg}$ fuel $\mathrm{NOx}$ 


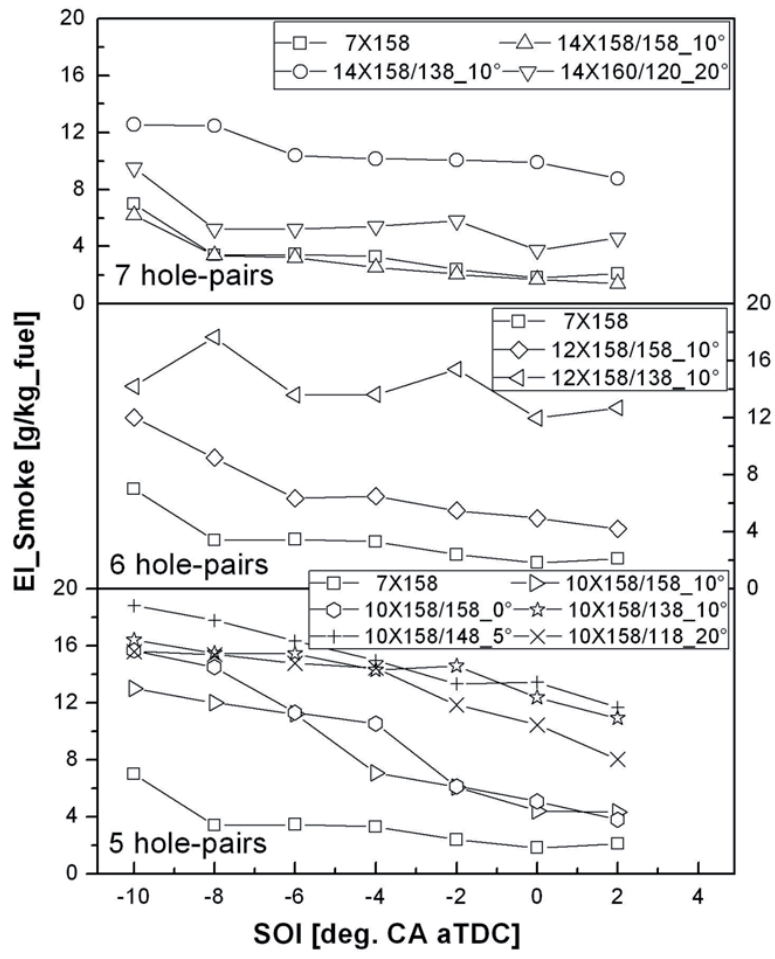

Figure 4.29: Smoke emission for 5, 6 and 7 hole-pair clusters under TP4: 2800rpm, $2000 \mathrm{bar}$ rail pressure, $15.2 \mathrm{bar} \mathrm{IMEP}, 5.0 \mathrm{~g} / \mathrm{kg}$ fuel NOx

\subsubsection{Summary}

The investigated cluster nozzles are evaluated by comparison with the reference nozzle for emissions and fuel consumption. Some clusters are regarded as better than conventional nozzle for part load operation. While the results confirm the above notion, they also show that some cluster configurations can improve upon the conventional nozzles in high load conditions also. But Clusters have generally higher smoke emissions than the reference nozzle under high speed and high load condition. Cluster $14 \times 158 / 158 \_10^{\circ}$ has lowest smoke level in all test points, despite the experiments being performed with a wide piston bowl without optimized swirl level. However, the investigation did not address the effects of jet-wall or jet-jet interactions, which occur in engines, or the effects of swirl. To make the use of clusters in a diesel engine feasible, a significant redesign of the typical in-cylinder geometry is required to promote efficient air utilization. 


\subsection{Effects of swirl ratio for cluster nozzles}

Since the swirl level used in the previous part was designed to be optimal for the reference nozzle, it was thought that it might not be optimal for the cluster nozzle. Therefore to ascertain the effect of swirl on the performance of cluster nozzles, four clusters (Cluster 10x158/158, Cluster 10x158/138, Cluster 14x158/158 and Cluster $14 \times 158 / 138$ ) were tested with three different levels of swirl and the results were compared with the reference nozzle.

The swirl ratio was varied by partially blocking one of the intake ports by using specially designed gaskets. The cylinder head has two helical intake ports, a high (swirl port) and a low swirl port (direct port). In order to obtain a lower swirl ratio, a gasket was installed keeping the direct port completely open, while partially blocking the swirl port. The original gasket was used for the designed swirl ratio by keeping both the ports completely open. A higher swirl ratio was obtained by using the other gasket to partially block the direct port, while keeping the swirl port completely open. The swirl ratios for the three configurations were measured to be $0.5,1.5$ and 3.0 of MSR. The results are discussed in the following sections.

\subsubsection{Emissions and fuel consumption}

\subsubsection{Variation of injection pressure}

The nozzles were compared with 3 different swirl ratios. Under low speed and low load condition, the engine was operated with low mass-flow-rate of the air with low intake pressure. In this condition, the injection pressure is more important parameter for air-fuel mixing than swirl.

Fig. 4.30 shows smoke emissions for different rail pressures and variable swirl ratio at SOI of $-5^{\circ} \mathrm{CA}$ aTDC under TP1. The clusters except the Cluster $14 \times 158 / 138$ show extremely high smoke for lower rail pressures and 7 hole-pair clusters show lower smoke than 5 hole-pair clusters. The smoke emissions for low injection pressure show different levels with different swirl ratios. For $0.5 \mathrm{MSR}$ they are generally at a lower level than at other swirl levels. Swirl reduces the penetration of the spray and spreads out the spray more rapidly [1]. These effects are positive for air-fuel mixing under medium and high load condition but they could have a negative effect for the low engine speed and low load conditions because the particulate emissions increase due to concentration of hot products in the center of cylinder with decreasing spray tip penetration and an overlap between adjacent sprays with the spread of the spray [8,9]. However, the smoke emissions of the clusters for all the three swirl ratios were reduced down to the levels similar to the reference nozzle by increasing the rail pressure. The reduction in smoke emissions at higher injection pressures is mainly due to the improved homogeneity of the charge. 


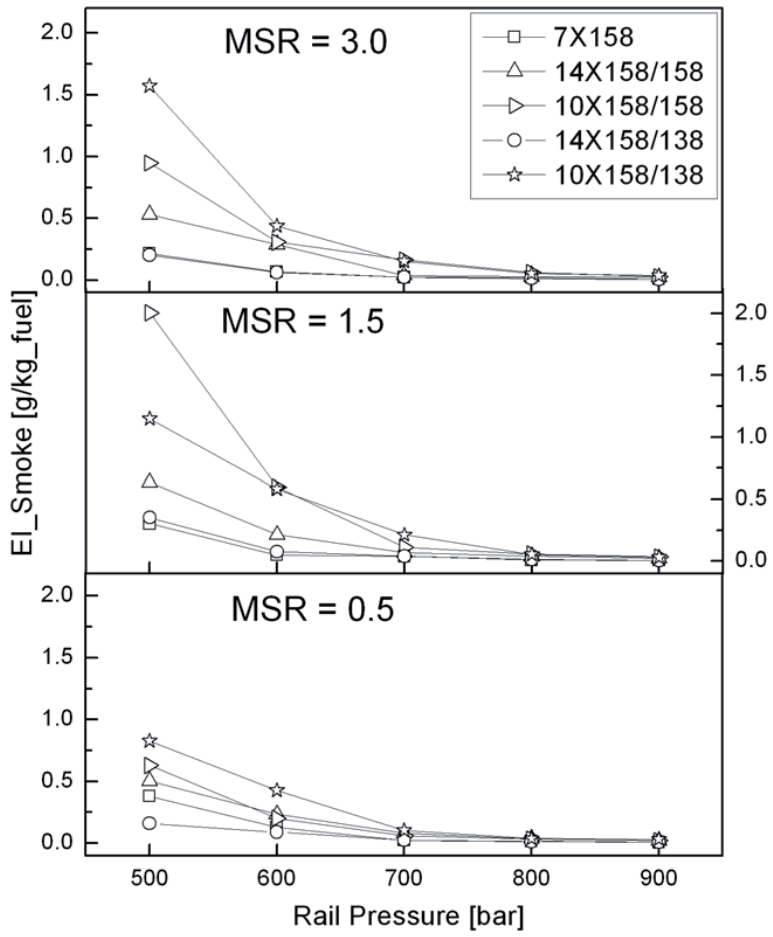

Figure 4.30: Smoke emission for variable swirls and different rail pressures for TP1: $-5^{\circ} \mathrm{CA}$ aTDC SOI, 1400rpm, 4.5bar IMEP, $4.5 \mathrm{~g} / \mathrm{kg}$ fuel NOx

\subsubsection{PCCI condition (TP1)}

In PCCI condition, a small mass of fuel was injected in the chamber with low temperature and low pressure at an early injection timing. It requires a large amount of cooled EGR to delay the ignition timing. Spray should have enough tip penetration since the ignition delay is extended. In these cases, swirl can help to improve air-fuel mixing but very low or high levels of swirl could have negative effects on $\mathrm{HC}$ emissions and ISFC. The results are discussed for an early injection timing of $-27^{\circ} \mathrm{CA}$ aTDC with $600 \mathrm{bar}$ rail pressure for different EGR rates under TP1.

The results with variable swirl for fuel consumption are shown in Fig. 4.31. The ISFC for the clusters is generally lower than the reference nozzle and the trends are also similar for all the swirl levels. The clusters except Cluster 10x158/158 have lower ISFC with MSR 
of 1.5 than other swirl levels. Fig. 4.32 shows the results of $\mathrm{HC}$ emissions. The clusters have lower $\mathrm{HC}$ emissions than the reference nozzle in all conditions and all levels of swirl. Comparing the clusters, Cluster 10x158/158 has higher HC than the other clusters. The spray tip penetration should be one of the important parameters for $\mathrm{HC}$ emission under PCCI conditions. All nozzles also have lower HC emissions with MSR of 1.5 than other swirl levels. The optimal swirl ratio is required for lower $\mathrm{HC}$ emission and ISFC in PCCI conditions.

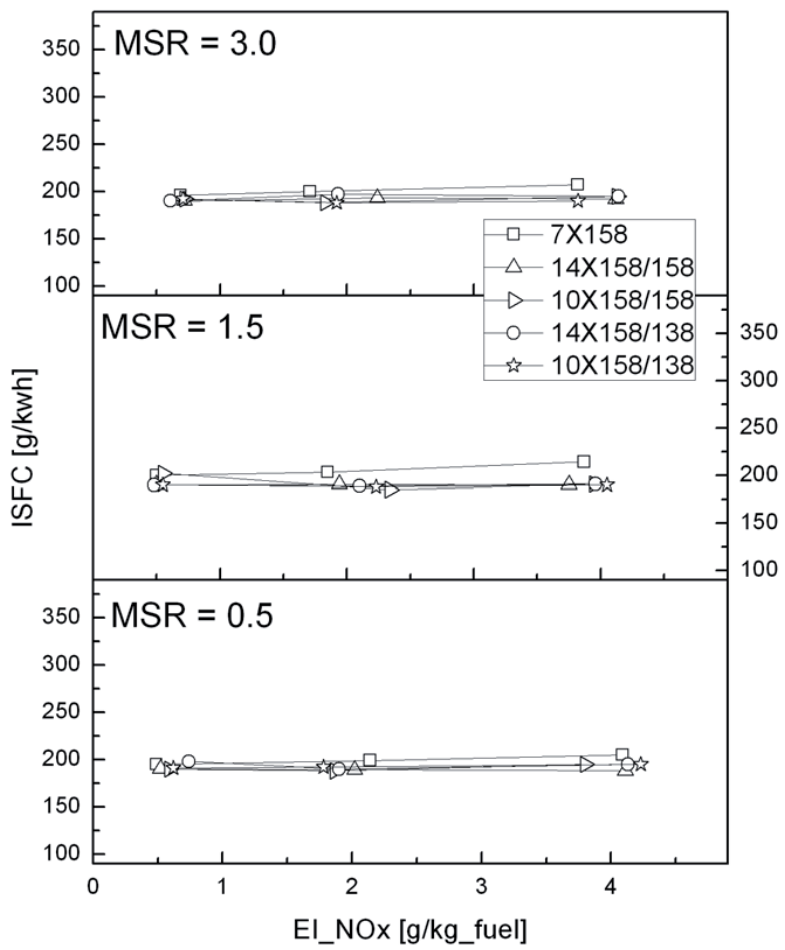

Figure 4.31: ISFC for variable swirls under PCCI: $-27^{\circ} \mathrm{CA}$ aTDC SOI, $1400 \mathrm{rpm}, 600 \mathrm{bar}$ rail pressure, 4.5 bar IMEP 


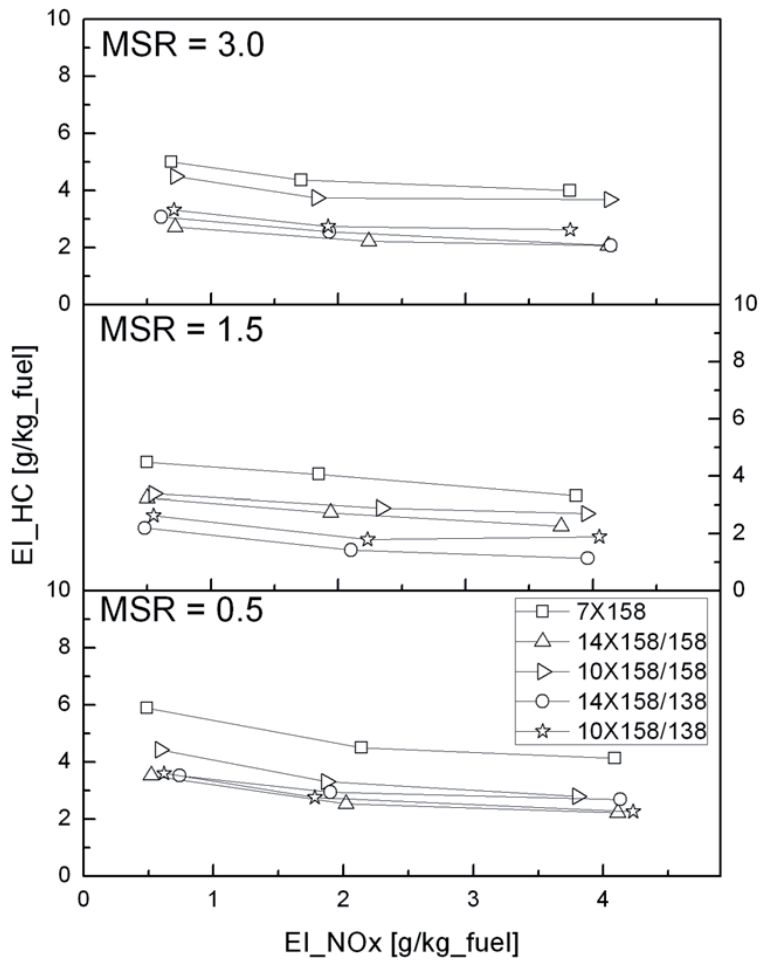

Figure 4.32: $\mathrm{HC}$ emissions for variable swirls under PCCI: $-27^{\circ} \mathrm{CA}$ aTDC SOI, $1400 \mathrm{rpm}$, 600 bar rail pressure, 4.5 bar IMEP

The results of smoke emissions are shown in Fig. 4.33. The small orifice nozzle can help in improving the air-fuel mixing in lean mixture conditions such as in PCCI. Cluster 10x158/158 has higher smoke emissions in all conditions than the reference nozzle while the other clusters have lower smoke emissions than the reference nozzle. This is due to the influence of the orifice diameter on soot formation. The improvement in fuel-air mixing with small orifices helps in reduction of the formation of soot. Comparing the results between different swirl levels, it is seen that the smoke emissions are lower with MSR of 3.0 than other swirl levels. The reference nozzle and Cluster 10x158/138 show improvement in smoke emissions with an increase in swirl ratio. The 7 hole-pair clusters show lower smoke than other nozzles for all cases. The results show the usage of clusters to be advantageous and show improvements in the soot-NOx trade-off in PCCI conditions. 


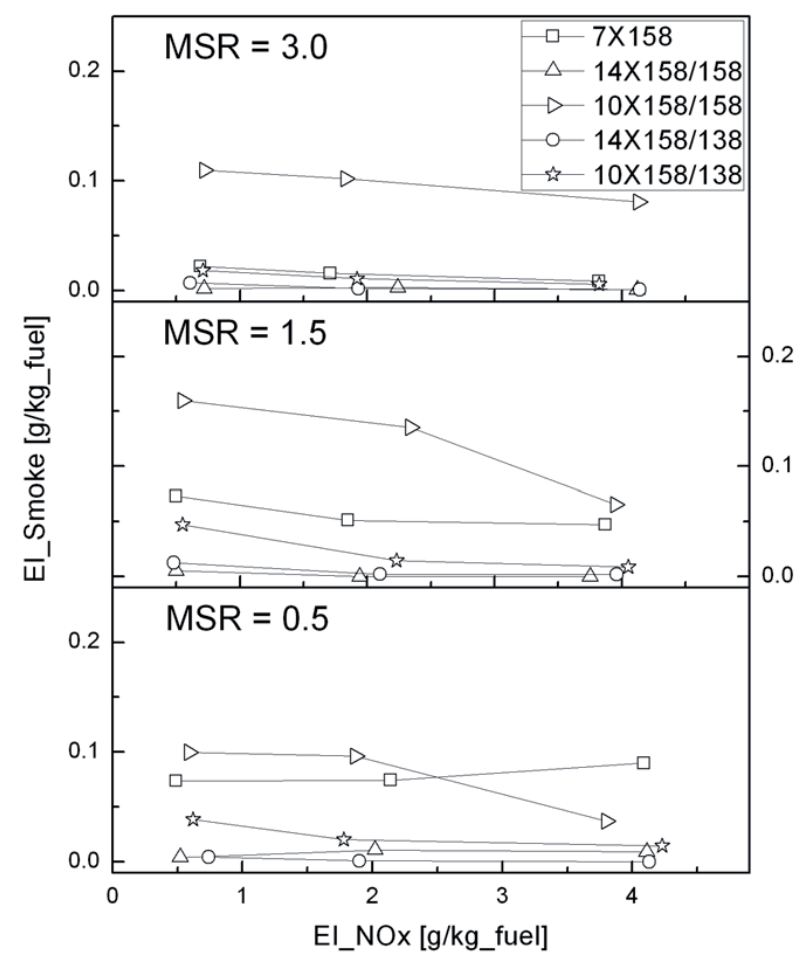

Figure 4.33: Smoke emissions for variable swirls under PCCI: $-27^{\circ} \mathrm{CA}$ aTDC SOI, 1400rpm, 600bar rail pressure, 4.5bar IMEP

\subsubsection{Low load condition (TP1)}

The nozzles were tested with different swirl levels for different SOI under low load condition. A small mass of fuel is injected in the chamber with low temperature and low pressure under TP1. When a small quantity of fuel is injected with high injection-pressure in chamber of low temperature and low pressure, the spray is lean and reduces the formation of soot. But a very lean mixture could also have a negative impact on heat release which causes a higher ISFC and the excessive dilution of spray is a cause for higher HC emissions.

The results of ISFC and HC emissions are shown in Fig. 4.34 and Fig. 4.35. The clusters have generally better fuel consumption than the reference nozzle with the different swirls for all the injection timings under TP1. At early and late injection timings, $\mathrm{HC}$ emissions 
increase due to relatively lower temperature of combustion and more fuel reaching the quenching regions. The $\mathrm{HC}$ emissions are slightly lower for conventional injection timings. The reference nozzle, having a longer spray tip penetration and larger orifices shows higher HC than the cluster nozzles with all swirl levels for all injection timings. The variation of swirl shows no improvement for HC emissions. All nozzles have lower $\mathrm{HC}$ emissions with 1.5 MSR.

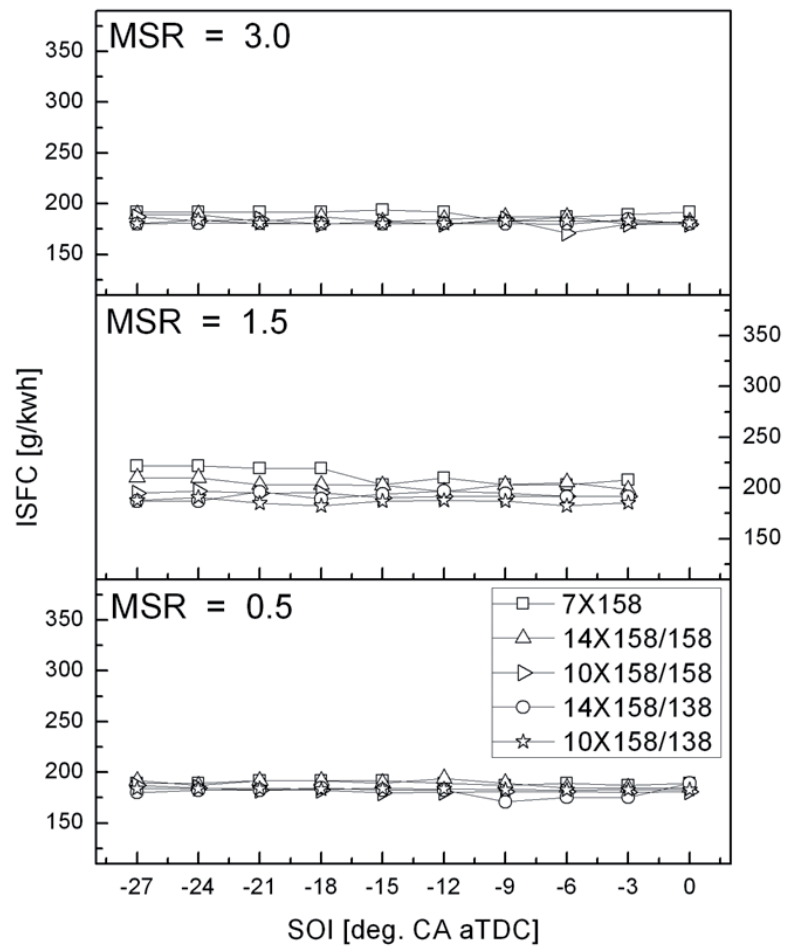

Figure 4.34: ISFC for variable swirls under TP1: 1400rpm, 900bar rail pressure, 4.5bar IMEP, $4.0 \mathrm{~g} / \mathrm{kg}$ fuel $\mathrm{NOx}$ 


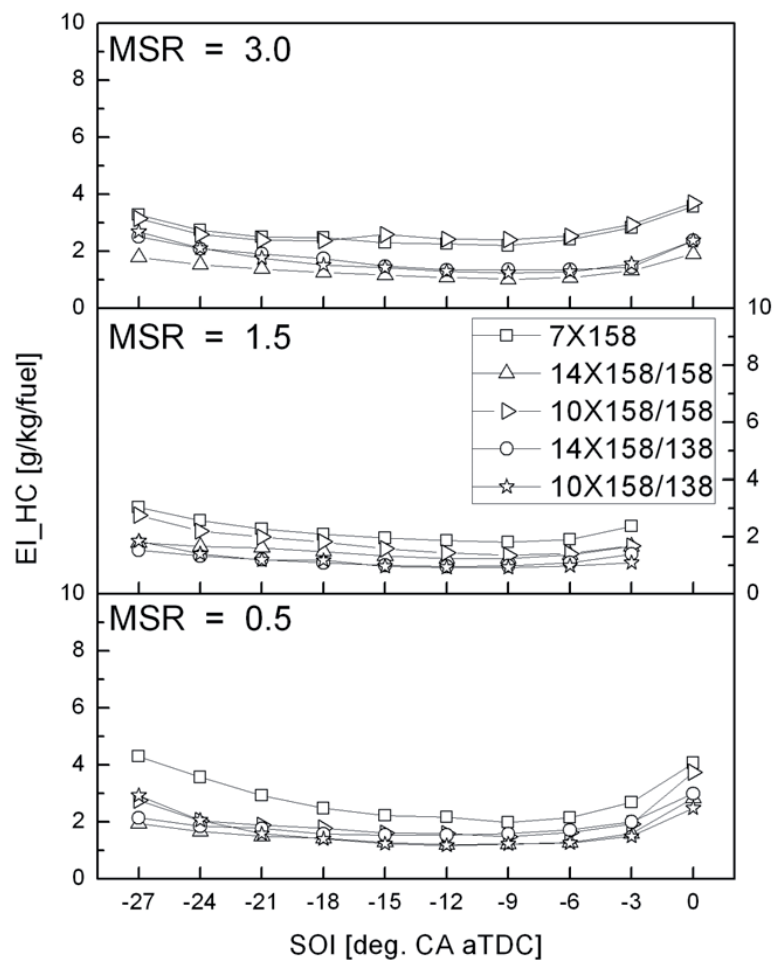

Figure 4.35: $\mathrm{HC}$ emissions for variable swirls under TP1: 1400rpm, 900bar rail pressure, $4.5 \mathrm{bar}$ IMEP, $4.0 \mathrm{~g} / \mathrm{kg}$ fuel NOx

Fig. 4.36 shows smoke emissions with different swirl ratios for a variation of SOI. The clusters have generally lower smoke at early injection timings than the reference nozzle. But 5 hole-pair clusters show higher while 7 hole-pair clusters show similar smoke levels under conventional injection timing for TP1. The smoke emissions are slightly reduced by increasing of swirl ratio at the early injection timing but the effects of swirl are not strong for smoke emissions with the nozzles at the conventional injection timing. Extremely high swirl and excessive injection pressure could result in higher emission levels and worsened fuel consumption rate due to dilution of fuel at part load condition. 


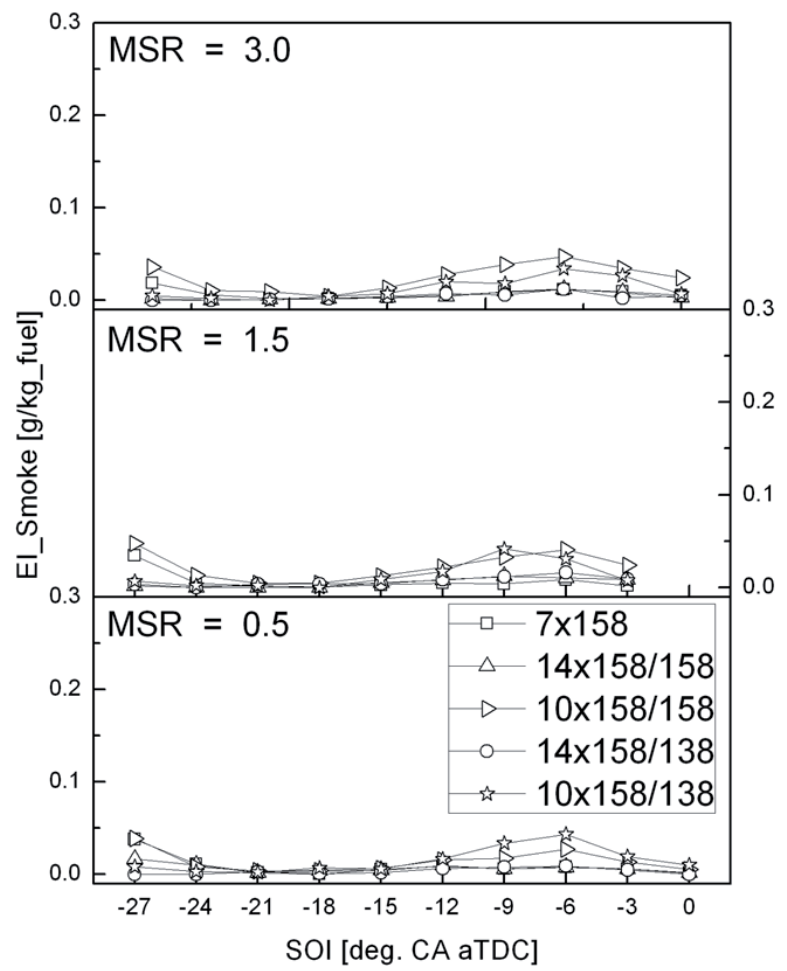

Figure 4.36: Smoke emissions for variable swirls under TP1: 1400rpm, 900bar rail pressure, $4.5 \mathrm{bar}$ IMEP, $4.0 \mathrm{~g} / \mathrm{kg}$ fuel $\mathrm{NOx}$

\subsubsection{High load condition (TP2)}

The nozzles were also investigated for effects of swirl with different SOI under TP2. The injection pressure was 1500 bar and the injection timings were varied form $-10^{\circ} \mathrm{CA}$ aTDC to $+4^{\circ} \mathrm{CA}$ aTDC on step $2^{\circ}$. Due to the longer spray tip penetrations under TP2, spray targeting is expected to have considerable influence on air-fuel mixing. The results of ISFC and HC emissions are shown in Fig. 4.37 and 4.38. The clusters have slightly lower fuel consumption than the reference nozzle with 1.5 MSR for all injection timings while they are similar with other swirl levels. The performance of all the nozzles with respect to $\mathrm{HC}$ emissions was quite similar which were generally low. 


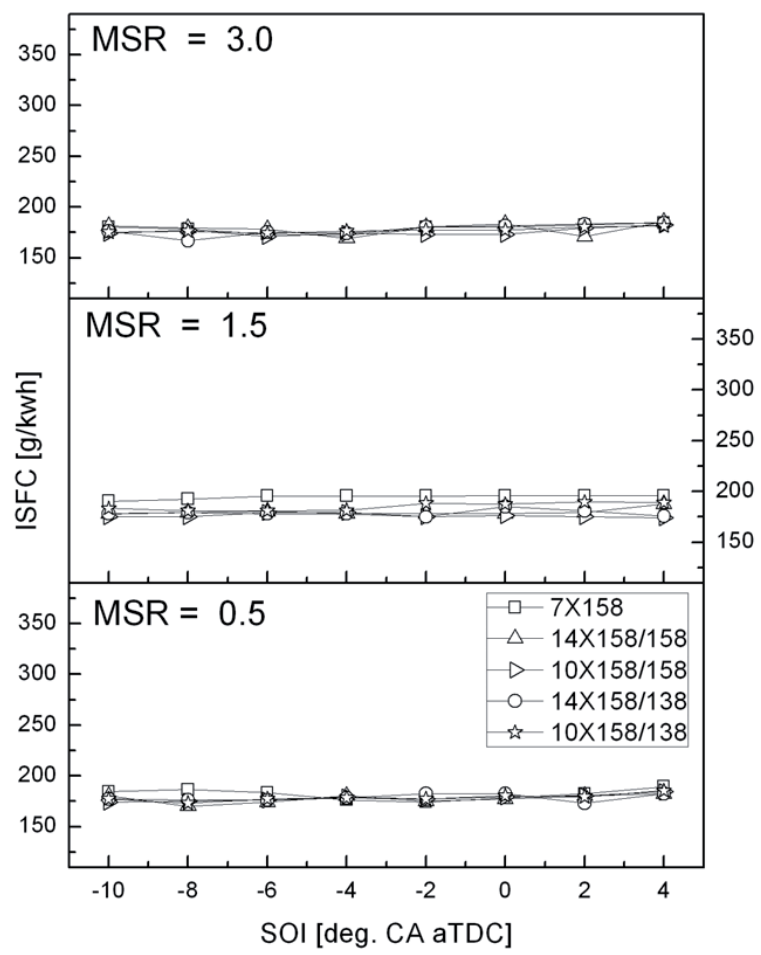

Figure 4.37: ISFC for variable swirls under TP2: 1400rpm, 1500bar rail pressure, 10.5bar IMEP, $4.5 \mathrm{~g} / \mathrm{kg}$ fuel $\mathrm{NOx}$ 


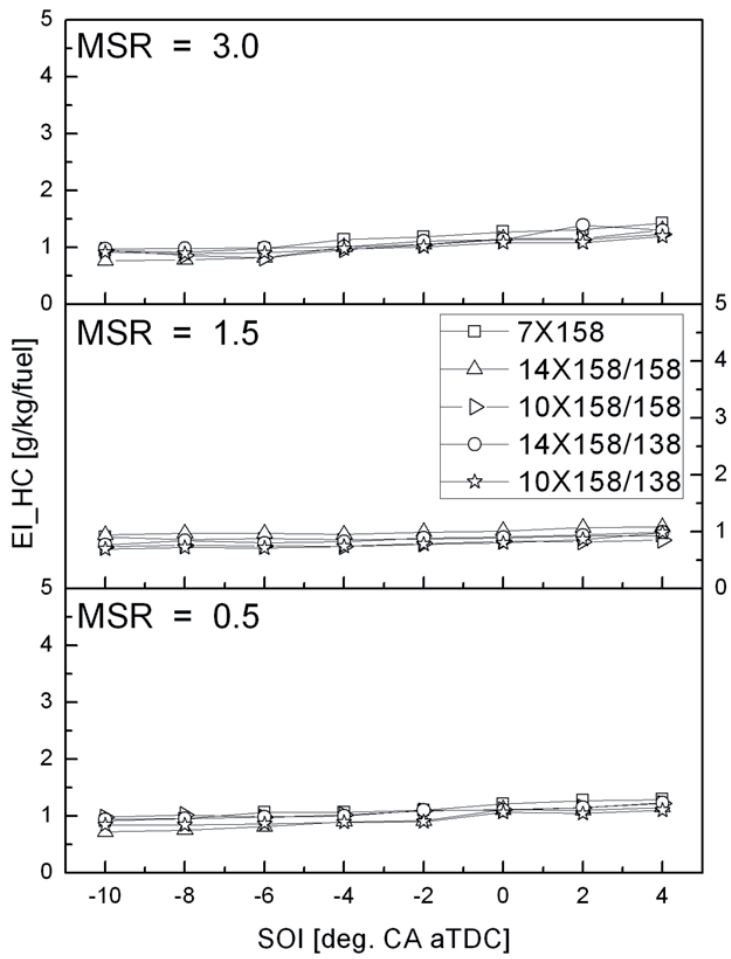

Figure 4.38: $\mathrm{HC}$ emissions for variable swirls under TP2: 1400rpm, 1500bar rail pressure, 10.5 bar IMEP, $4.5 \mathrm{~g} / \mathrm{kg}$ fuel NOx

Fig. 4.39 shows the results of smoke emissions. Except Cluster $14 \times 158 / 158$, the other clusters have higher smoke emissions than the reference nozzle. It is believed that the clusters with small orifices improve the fuel atomization and evaporation, but because of the shorter penetrations compared to the reference nozzles, their sprays lose the momentum faster, when used in a wide piston bowl. Of the compared cluster configurations, the vertical clusters have relatively higher smoke emission than the horizontal clusters and the reference nozzle. These are impacts of the spray motion and air-fuel mixing near the piston. The smoke emissions were generally reduced by increasing the swirl ratio. The smoke emissions of all nozzles are strongly reduced by increasing the swirl from 0.5 MSR to 1.5 MSR but just a small improvement in smoke emissions is seen by further increasing the swirl to 3.0 MSR. The smoke emissions are mainly the net result between production and oxidation of soot particles, and it is difficult to assess what the final effect of swirl on this pollutant is. The additional mixing induced 
by swirl provides the spray with more oxygen, which results in a leaning effect that reduces soot production and increases soot oxidation during expansion [15].

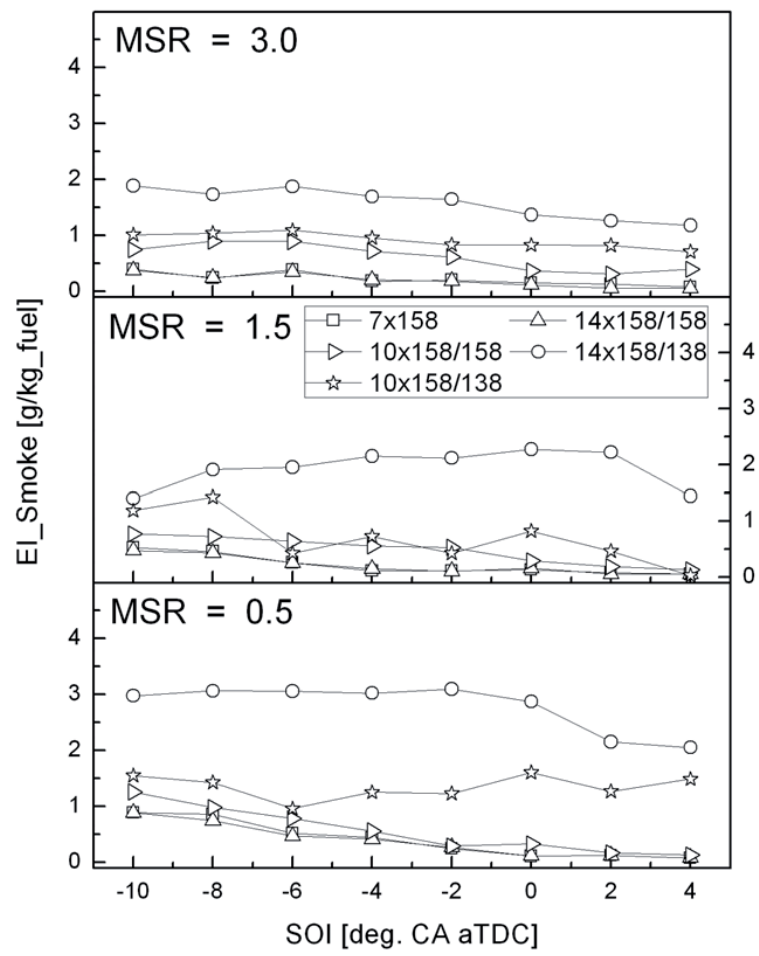

Figure 4.39: Smoke emissions for variable swirls under TP2: 1400rpm, 1500bar rail pressure, 10.5 bar IMEP, $4.5 \mathrm{~g} / \mathrm{kg}$ fuel NOx

\subsubsection{Comparison of a cluster with the conventional nozzle for effect of swirl}

The reference nozzle and Cluster 14x158/158 were also used to investigate effect of swirl for different SOI under low and high load conditions. The results are shown in Fig. 4.40 and 4.41. Swirl generally has a positive effect on the air-fuel mixing under high load conditions by increasing the contact between injected fuel and air.

Under part load condition, there are no strong effects of swirl for smoke emissions using both nozzles since a small quantity of fuel is injected with relative high injection pressure 
in chamber of low temperature and low pressure, the smoke is just reduced by increasing the swirl at early injection timings. Under high load condition the smoke emissions are reduced by increasing the swirl level from 0.5 MSR to 1.5 MSR but no improvement in smoke emissions is seen by further increasing the swirl to 3.0 MSR. The increase in swirl enhances the air-fuel mixing process, inducing a faster distribution of fuel and accelerating flame propagation $[10,14]$. This causes a more intense premixed combustion phase and consequently a faster increment of in-cylinder pressure during the early stages of the combustion process. The differences in smoke levels are larger at conventional injection timings than the late injection timings because the ignition delay is relatively shorter at conventional timings. At late injection timings which have a relatively longer ignition delay, the 3 swirl levels show similar smoke levels. Swirl is very important for air-fuel mixing with short ignition delay, but overswirl can also have negative results for $\mathrm{HC}$ emissions and fuel consumption in such conditions.

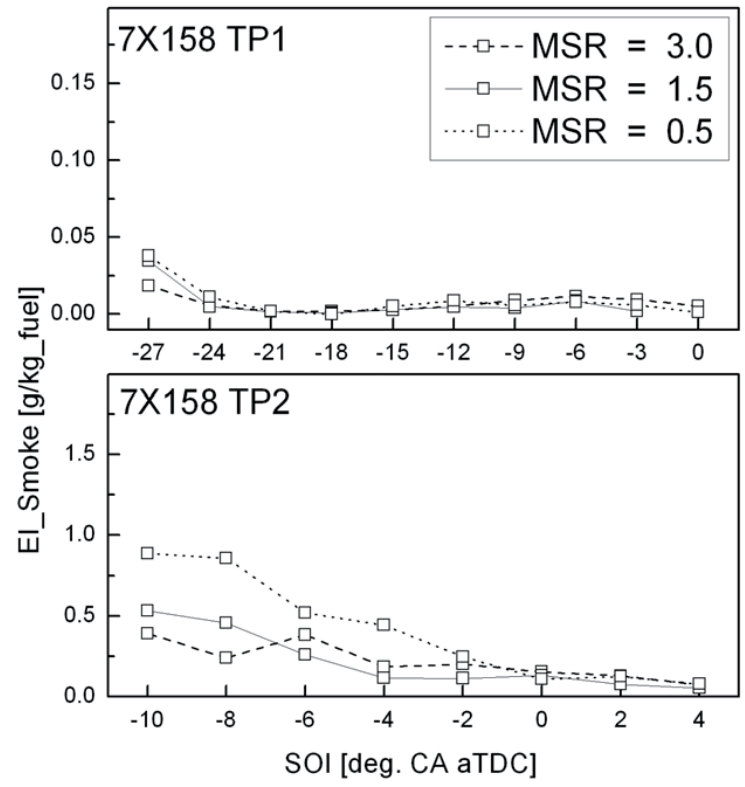

Figure 4.40: The smoke emissions of the reference nozzle with variable swirls under TP1 and TP2 


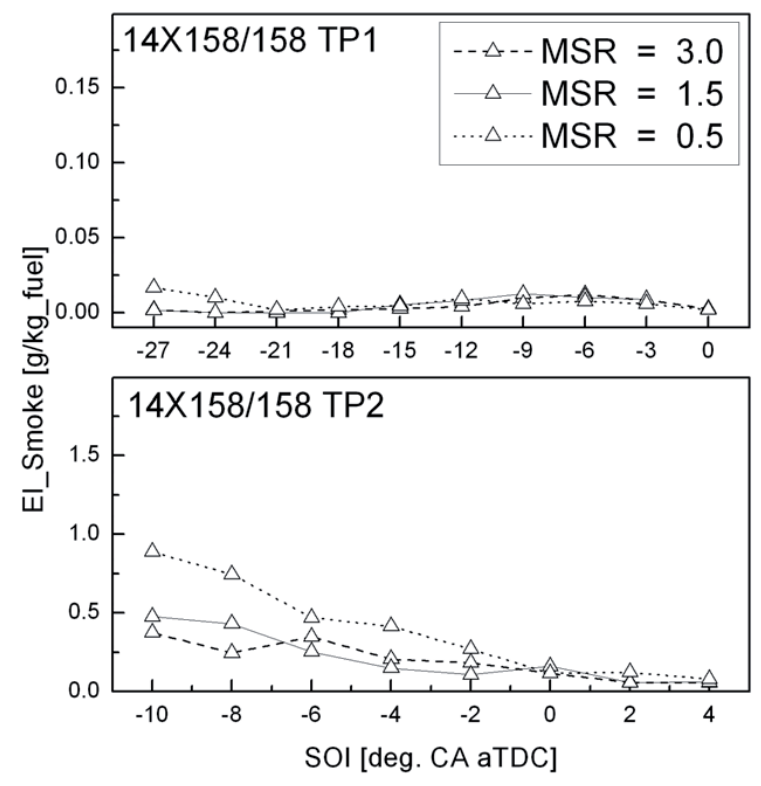

Figure 4.41: The smoke emissions of Cluster $14 \times 158 / 158$ with variable swirls under TP1 and TP2

\subsubsection{Summary}

The effect of swirl is generally stronger at high (full) load conditions where injection, mixing and combustion should be done in a very short period than the low load condition. The smoke emissions are reduced by increasing the swirl level from 0.5 MSR to 1.5 MSR but no improvement in smoke emissions is seen by further increasing the swirl to 3.0 MSR. Based on the results for emissions and fuel consumption, an MSR of 1.5 seems to be close to the optimal swirl level for the cluster nozzles and the reference nozzle in this engine. 


\subsection{Modified bowl geometry for cluster nozzles}

A new combustion chamber was designed with a smaller diameter and deeper bowl. It was expected to improve air-fuel mixing by better spray guidance. Four clusters (Cluster 10x158/158, Cluster 10x158/138, 14x158/158 and 14x158/138) were investigated for a variation of injection timings under 4 different test points in the original piston bowl and the new bowl and the results are compared with a conventional nozzle. Cluster $14 \times 158 / 158$ with the best results for smoke emissions in the first set of tests was also tested for 3 different swirl ratios and 2 different nozzle tip protrusion lengths with the new bowl.

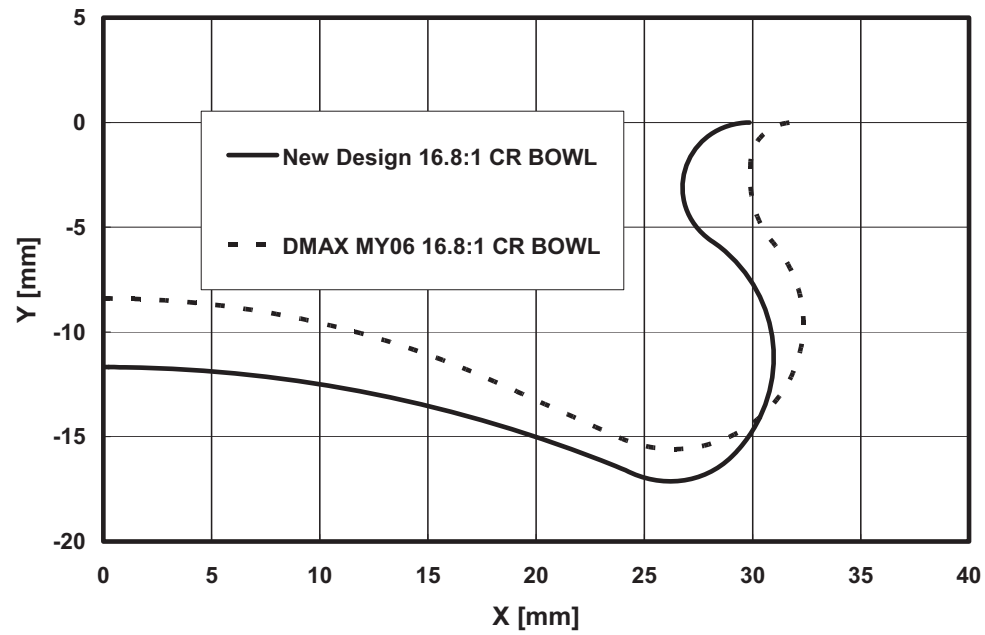

Figure 4.42: Sketches for MY06 by General Motors and a new modified piston bowl

The piston bowl for MY06 by General Motors and a new modified piston bowl were used for the experiments. Fig. 4.42 shows a sketch of both the bowl geometries. The new combustion chamber is designed to enhance air-fuel mixing in the diffusion combustion region for the clusters. The new combustion bowl is characterized by a smaller diameter and a deeper bowl with larger toroidal radius. The new bowl is also the re-entrant type with $53.6 \mathrm{~mm}$ throat diameter and $17.2 \mathrm{~mm}$ maximum depth (original chamber has $59.8 \mathrm{~mm}$ throat diameter and $15.6 \mathrm{~mm}$ maximum depth). The volume of new piston bowl is the same as the original bowl to keep the same compression ratio of 16.8. In fundamental spray measurements, the cluster with $10^{\circ}$ included angle was found to have about $3 \mathrm{~mm}$ shorter spray tip penetration than that of the reference nozzle under typical engine operating conditions i.e. $800 \mathrm{bar}$ rail pressure and $500 \mu \mathrm{s}$ energizing time. Therefore a smaller bowl radius was chosen. The central pip is also designed deeper for 
the vertical clusters because the cluster with larger included angle increases the contact between the vapor phase and the bottom of bowl wall. The toroidal radius is also increased for the better air-fuel mixing for the clusters.

\subsubsection{The comparison between the original bowl and the new bowl}

\subsubsection{Variation of injection pressure}

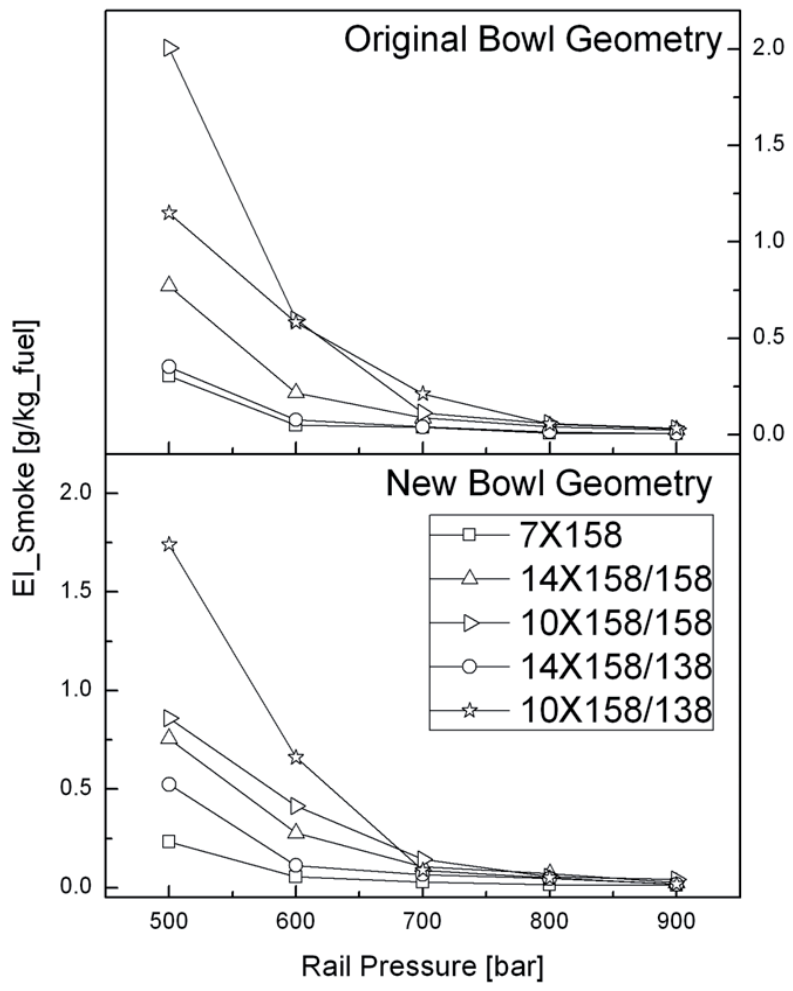

Figure 4.43: Smoke emissions with different rail pressures and two bowls for TP1: $-5^{\circ}$ CA aTDC SOI, 1400rpm, 4.5bar IMEP, $4.0 \mathrm{~g} / \mathrm{kg}$ fuel NOx

Fig. 4.43 shows smoke emissions for different rail pressures and the two bowl geometries at SOI of $-5^{\circ} \mathrm{CA}$ aTDC for TP1. With both of the bowls, the clusters show extremely high smoke for lower rail pressures under conventional injection timing, but the smoke 
emissions were reduced down to levels similar to that of the reference nozzle by increasing the rail pressure. Among the compared clusters, the 7 hole-pair clusters with relatively smaller orifices show lower smoke than the 5 hole-pair clusters. The results for the original bowl are compared with those for the new bowl. There is no strong effect of the bowl geometry for TP1 and the results are very similar for both the bowl geometries. In this operating condition, only a small mass of fuel is injected in the chamber, so the spray-spray interactions are more important than the spray-wall interactions.

\subsubsection{PCCI condition (TP1)}

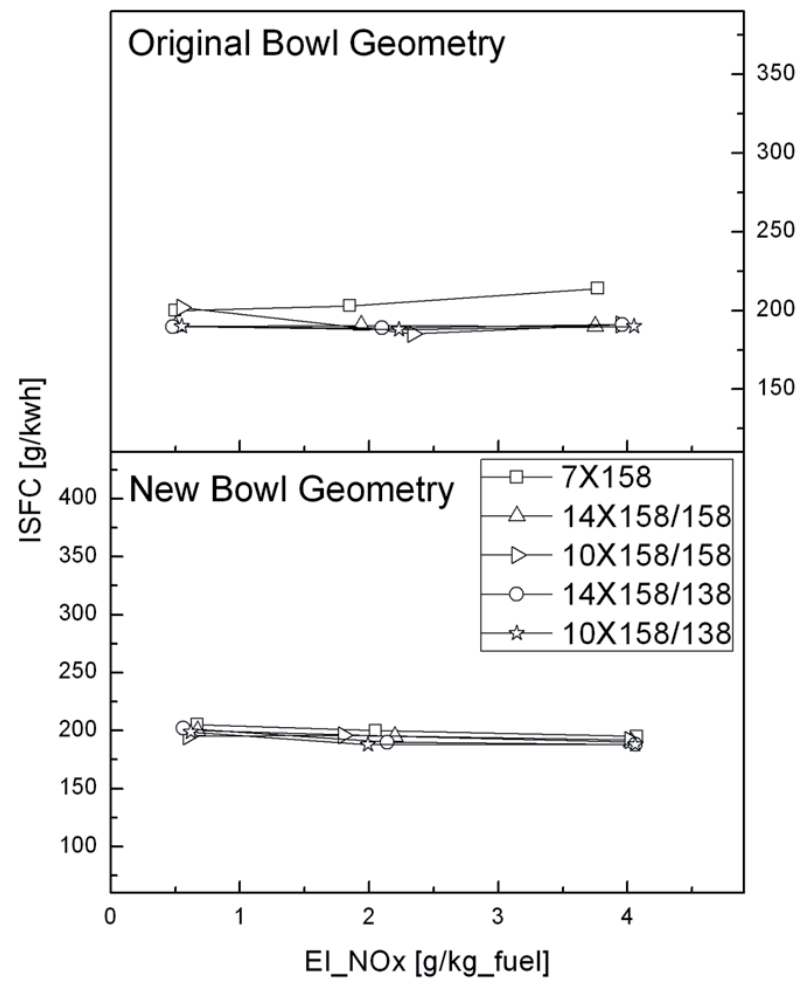

Figure 4.44: ISFC with two bowls for TP1: $-27^{\circ} \mathrm{CA}$ aTDC SOI, $1400 \mathrm{rpm}$, 600bar rail pressure, 4.5bar IMEP 
The results are discussed for an early injection timing of $-27^{\circ} \mathrm{CA}$ aTDC with $600 \mathrm{bar}$ rail pressure for different $\mathrm{NO}_{\mathrm{x}}$ emission levels under TP1. The results for fuel consumption and $\mathrm{HC}$ for the same conditions are shown in Fig. 4.44 and 4.45. The ISFC of the clusters is generally lower than the reference nozzle for both the piston bowl geometries. The clusters also have lower HC emissions than the reference nozzle in PCCI condition and the trends of $\mathrm{HC}$ emission for the nozzles are similar for both the bowl geometries. Comparing the two bowl geometries, all the nozzles have higher $\mathrm{HC}$ with the new bowl. The new bowl has a smaller diameter so the spray can reach the low temperature quenching areas faster, thus more fuel reaches close to the combustion chamber walls.

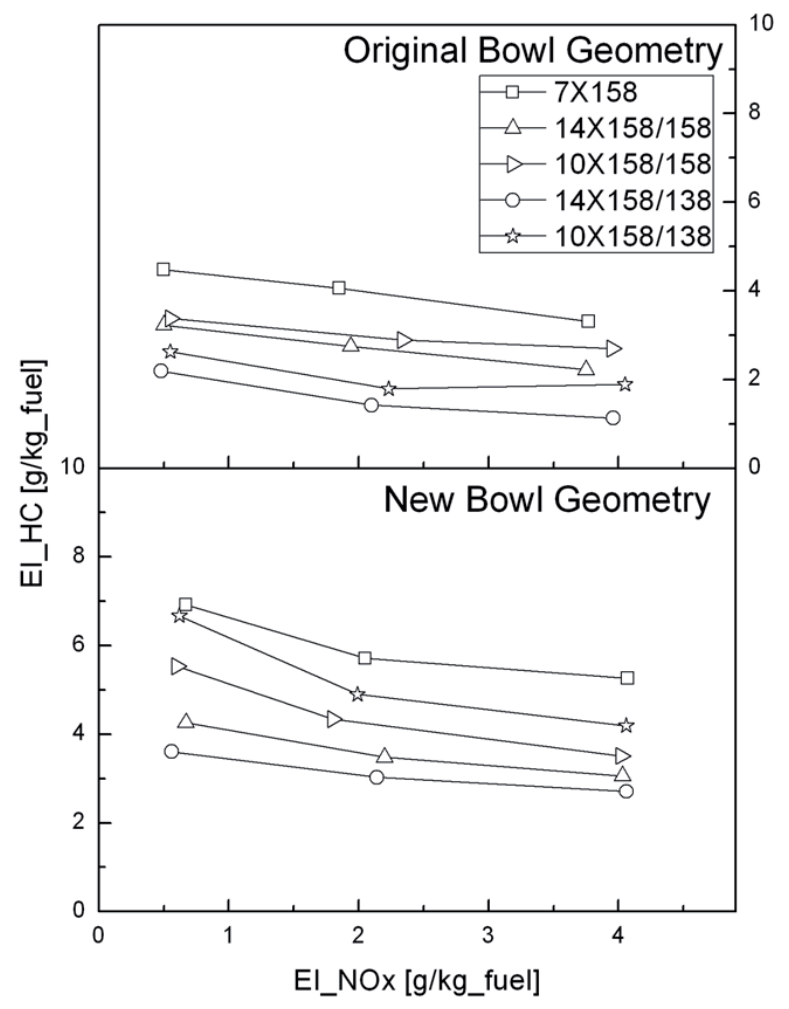

Figure 4.45: $\mathrm{HC}$ emissions with two bowls for TP1: $-27^{\circ} \mathrm{CA}$ aTDC SOI, 1400rpm, 600 bar rail pressure, 4.5 bar IMEP

Fig. 4.46 shows the results of smoke emissions. Except for the Cluster 10x158/158 which was designed with relatively bigger orifice diameter, all the clusters show lower smoke than the reference nozzle. The results for smoke emissions are similar for both of the 
bowl geometries, for all the nozzles except the reference nozzle and the Cluster 10x158/158. The reference nozzle and the Cluster 10x158/158 having relatively longer spray tip penetration, because a strong increase in the smoke levels with the new bowl. The 7 hole-pair clusters show lower smoke than other nozzles. The increase in spray-wall interaction with the reduction of the bowl-diameter should be the reason behind these observations.

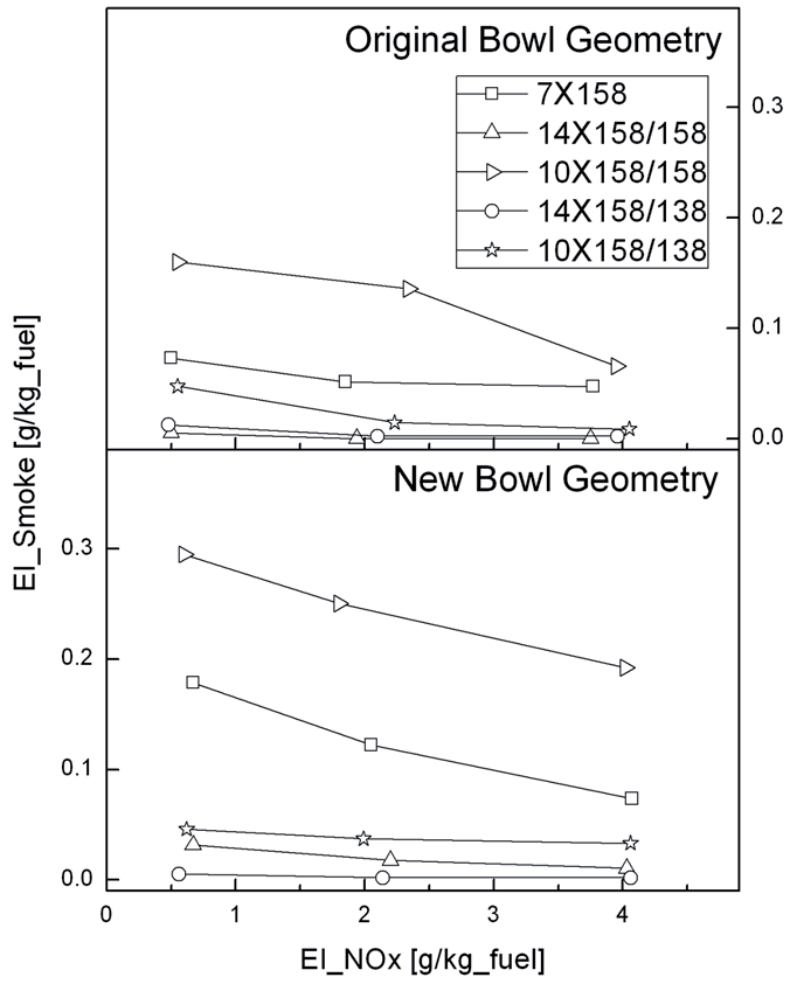

Figure 4.46: Smoke emissions with two bowls for TP1: $-27^{\circ} \mathrm{CA}$ aTDC SOI, $1400 \mathrm{rpm}$, 600bar rail pressure, 4.5bar IMEP

\subsubsection{Low engine speed and high load condition (TP2)}

The Clusters were investigated in two chambers with different bowl geometries for different SOI under high load condition and the results were compared with the reference nozzle. The injection timings were varied between $-10^{\circ} \mathrm{CA}$ aTDC and $+4{ }^{\circ} \mathrm{CA}$ aTDC and the fuel was injected with $1500 \mathrm{bar}$ rail pressure. The main purpose of this part of the 
study was to find a solution for the problem of high smoke levels under high load condition.

The results of HC and ISFC using 5 and 7 hole-pairs clusters are shown in Fig. 4.47 and 4.48. They were compared with the reference nozzle. The clusters have better fuel consumption in both of the bowls than the reference nozzle. The HC emissions for all nozzles are generally low because the engine in diesel combustion is operated with high boost pressure at low equivalence ratios under high load condition. The Clusters have relatively lower HC than the reference nozzle in both of the bowls for TP2. The difference of $\mathrm{HC}$ emissions between the clusters and the reference nozzle in the new bowl is higher than the difference in the original bowl. The $\mathrm{HC}$ emissions for the reference nozzle were increased with the new bowl geometry.

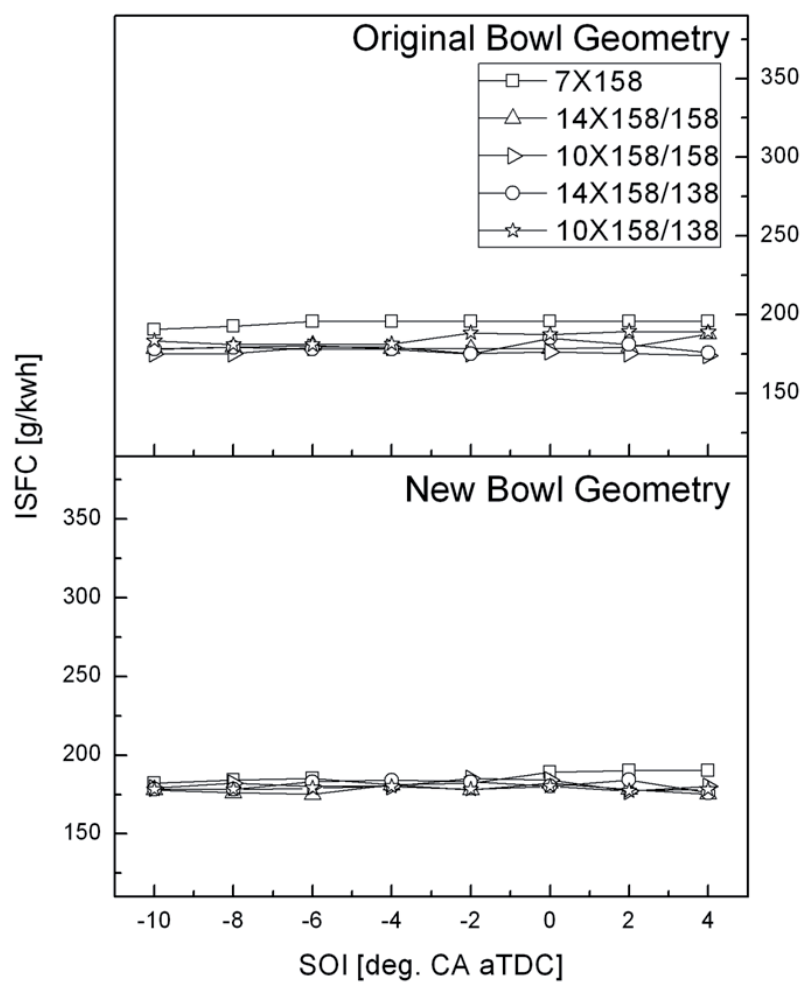

Figure 4.47: ISFC with two bowls for TP2: 1400rpm, 1500bar rail pressure, 10.5 bar IMEP, $4.5 \mathrm{~g} / \mathrm{kg}$ fuel $\mathrm{NOx}$ 


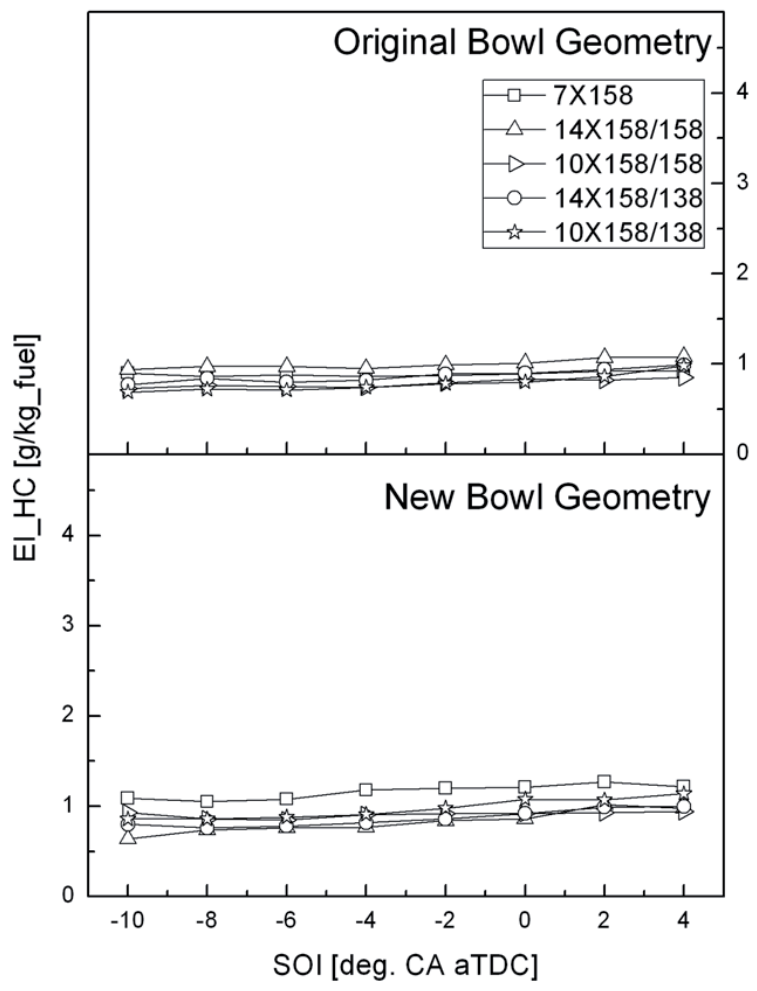

Figure 4.48: $\mathrm{HC}$ emission with two bowls for TP2: 1400rpm, 1500bar rail pressure, $10.5 \mathrm{bar}$ IMEP, $4.5 \mathrm{~g} / \mathrm{kg}$ fuel NOx

The results of smoke emissions for 5 and 7 hole-pair clusters are shown in Fig. 4.49. The Cluster 14x158/158 shows lower smoke than the reference nozzle while the other clusters show higher smoke than the reference nozzle. Comparing the cluster configurations, the vertical clusters have relatively higher smoke emissions than the horizontal clusters and the reference nozzle with both of the bowl geometries. The cluster $14 \times 158 / 158$ shows almost same levels of smoke for both the bowls, while the other nozzles show higher smoke levels for the new bowl geometry. It is expected that the new bowl having a smaller diameter should be less suitable for the 5 hole-pair clusters and the reference nozzle as they have longer spray penetration lengths than the 7 hole-pair clusters. The increase in smoke for the 7 hole-pair vertical cluster is more apparent for the two extreme SOI points, while the change for intermediate SOI points is not as prominent as for the 5 hole-pair clusters or the reference nozzle. 


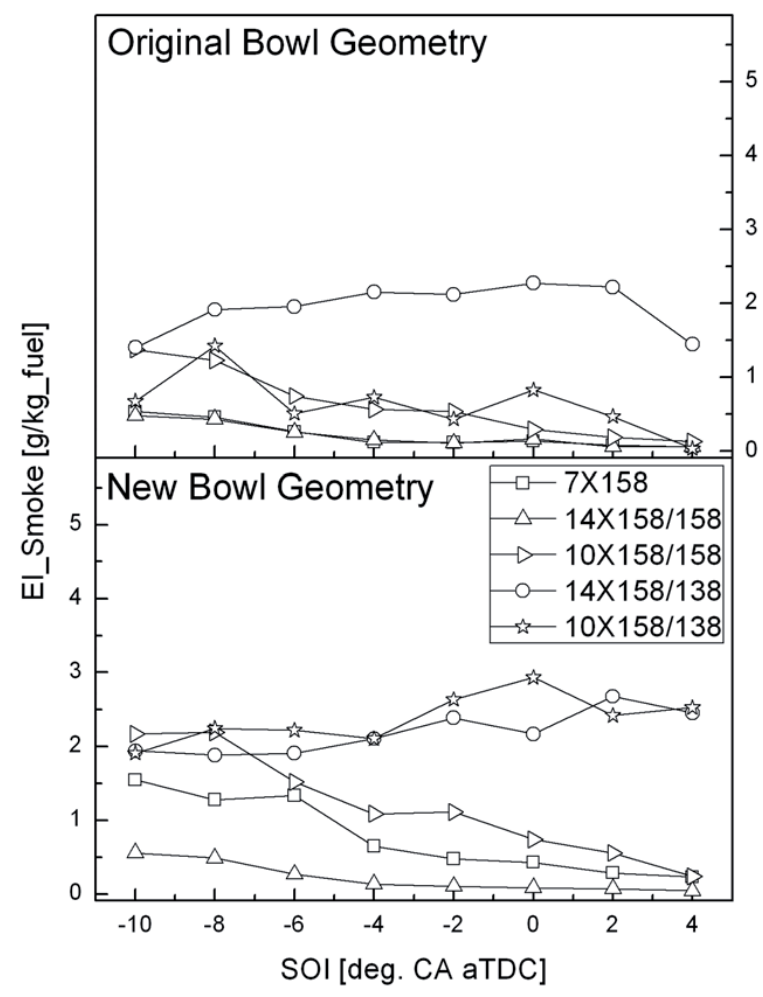

Figure 4.49: Smoke emissions with two bowls for TP2: 1400rpm, 1500bar rail pressure, 10.5 bar IMEP, $4.5 \mathrm{~g} / \mathrm{kg}$ fuel $\mathrm{NOx}$

\subsubsection{High engine speed and medium load condition (TP3) and full load condition (TP4)}

The clusters were also investigated under medium and full load condition with high engine speed. The size of the orifices and the spray targeting should be the determining factors in TP3 and TP4, because of short ignition delay, owing to the higher boost pressure and high engine speed. Lower $\mathrm{HC}$ emissions are expected with low equivalence ratios for medium and full load conditions and thus only the smoke emissions were compared for these operation conditions. The trends for ISFC were very similar as shown for TP2 therefore they are also not being shown for TP3 and TP4. The results for smoke emissions using 5 and 7 hole-pair clusters in TP3 and TP4 are shown in Fig. 4.50 and 4.51. Only one horizontal cluster (Cluster $14 \times 158 / 158 \_10^{\circ}$ ) has shown smoke levels 
similar to the reference nozzle while the other clusters have shown higher smoke than the reference nozzle for TP3 and TP4 with both of the bowl geometries. Of the compared clusters with the number of hole-pairs and cluster configurations, the 7 hole-pair clusters have relatively lower smoke than the other clusters and the horizontal clusters also have relatively lower smoke than the corresponding vertical clusters for TP4. The clusters have also shown improvement in smoke emissions with the new bowl. As it is well known, the correct targeting is an important parameter for the air-fuel mixing in a smaller diameter chamber such as re-entrant bowl type. It strongly depends on engine speed, injection system and combustion chamber diameter. The new bowl design considers for the shorter spray tip penetration of the clusters. The clusters with small orifice have improved emissions using high injection pressure, as better fuel atomization and evaporation are achieved. The new piston bowl with a smaller throat diameter and a larger toroidal radius helps in redirecting the spray along the bowl-wall back towards the center of the bowl.

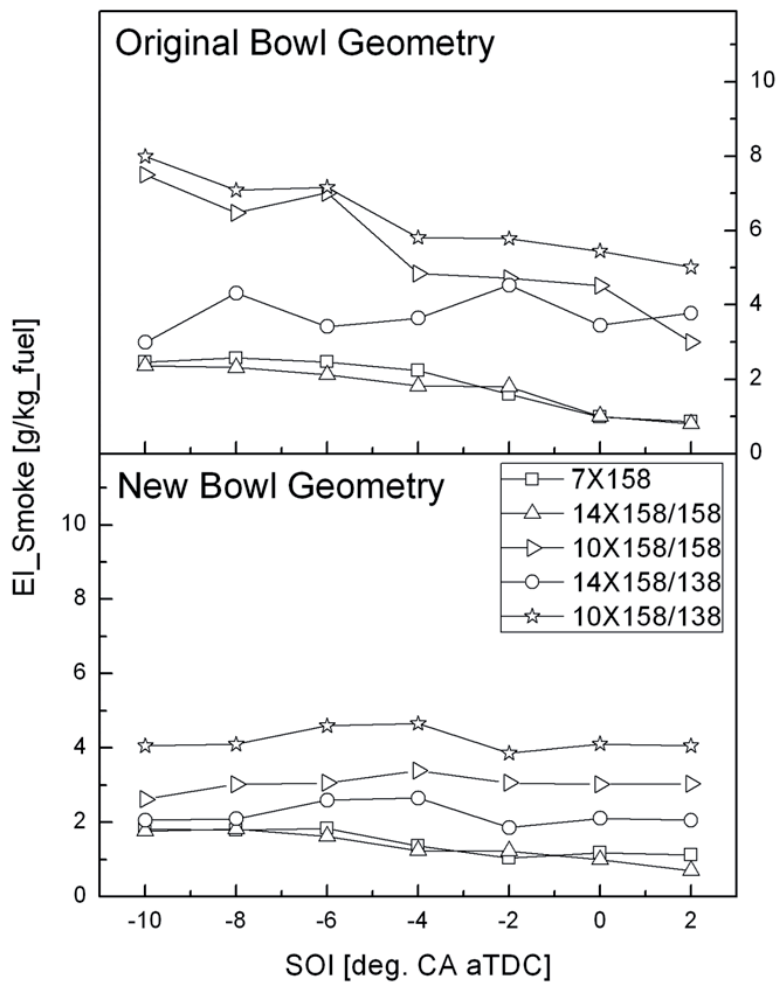

Figure 4.50: Smoke emissions with two bowls for TP3: 2800rpm, 1800bar rail pressure, 10.2bar IMEP, $4.5 \mathrm{~g} / \mathrm{kg}$ fuel NOx 


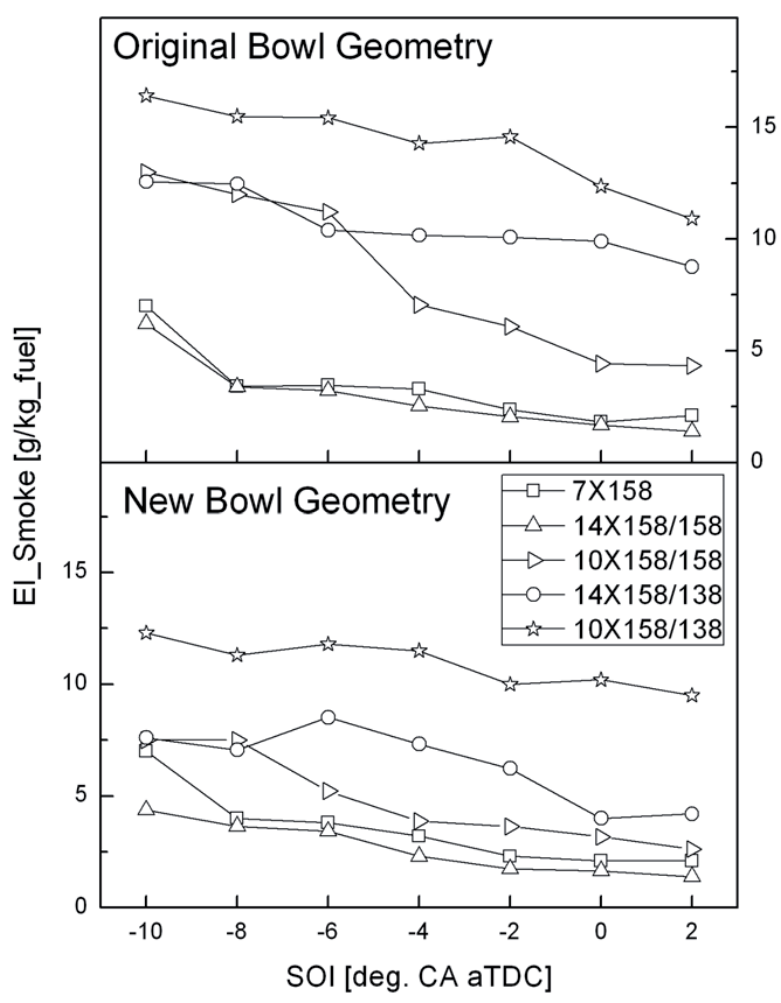

Figure 4.51: Smoke emissions with two bowls for TP4: 2800rpm, 2000bar rail pressure, 15.2bar IMEP, $5.0 \mathrm{~g} / \mathrm{kg}$ fuel $\mathrm{NOx}$

\subsubsection{Parametric study of the selected cluster nozzle}

As the final part of the study, Cluster $14 \times 158 / 158$ was selected for a parametric study. It was chosen because of showing the best results for smoke emissions in the first set of tests with the new bowl. The cluster was investigated to find the effects of swirl and spray targeting on engine operation with the new bowl design. The mixing process in diesel engines is significantly affected by the bulk flow and the spray targeting in the combustion chamber. Therefore it is necessary to match the bowl geometry with optimal initial flow motions like swirl and proper spray targeting. The cluster was measured for 3 different swirl ratios $(0.5,1.5$ and 3.0 of MSR) and 2 different lengths $(1.65 \mathrm{~mm}$ and $2.5 \mathrm{~mm}$ ) of NTP (Nozzle Tip Protrusion) with the new bowl. The protrusion length was changed by the thickness of the shim located between the injector and the cylinder head. 
The main purpose of the cluster concept is to reduce smoke emissions under high load condition while keeping the fuel consumption at a low level by improved atomization and evaporation of fuel. The cluster was investigated for conventional injection timings under TP2, TP3 and TP4 and the results were compared with the results of the reference nozzle with the original bowl. Tab. 4.2 shows the parameters of the experiments.

Table 4.2: Geometric specifications of the cluster nozzles and the reference nozzle

\begin{tabular}{|c|c|c|c|c|}
\hline Case & Nozzle & Piston Bowl & MSR & NTP $[\mathrm{mm}]$ \\
\hline Reference & $7 \times 158$ & $\begin{array}{c}\text { Original } \\
\text { bowl }\end{array}$ & 1.5 & 1.65 \\
\hline Case 1 & $14 \times 158 / 158$ & $\begin{array}{c}\text { Original } \\
\text { bowl }\end{array}$ & 1.5 & 1.65 \\
\hline Case 2 & $14 \times 158 / 158$ & New bowl & 1.5 & 1.65 \\
\hline Case 3 & $14 \times 158 / 158$ & New bowl & 0.5 & 1.65 \\
\hline Case 4 & $14 \times 158 / 158$ & New bowl & 3.0 & 1.65 \\
\hline Case 5 & $14 \times 158 / 158$ & New bowl & 1.5 & 2.50 \\
\hline
\end{tabular}

\subsubsection{Pressure and heat releases}

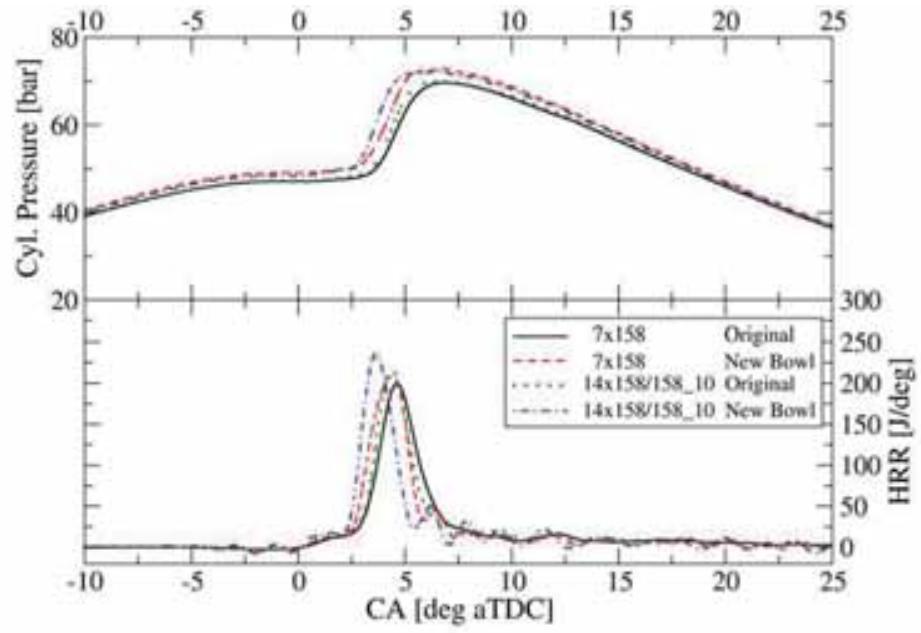

Figure 4.52: Pressure and heat release with two bowls for Cluster $14 \times 158 / 158$ and the reference nozzle under TP1: $-6^{\circ} \mathrm{CA}$ aTDC SOI, 1400rpm, 900bar rail pressure, $4.5 \mathrm{bar}$ IMEP, $4.0 \mathrm{~g} / \mathrm{kg}$ fuel $\mathrm{NOx}$ 
Fig. 4.52 shows the pressure and heat release rates of the Cluster $14 \times 158 / 158$ and the reference nozzle for the bowls under TP1. Ignition delay in case of the cluster is shorter than in case of the reference nozzle with both of bowls. Also the combustion periods of the cluster were shorter than the reference nozzle with both the bowls. The initial rate of heat release is higher for both of nozzles with the modified bowl. Fig. 4.53 shows the pressure and heat release rates under TP2. Heat release rates for clusters being higher during the premixed combustion and lower during the mixing controlled combustion. The ignition delay is shorter, while heat release rates are higher during premixed combustion with the new bowl. It seems that the nozzles have improved evaporation with the new bowl resulting in better fuel-air mixing. The oscillations visible in the heat release rates for measurements with the new bowl are due to filtering artifacts.

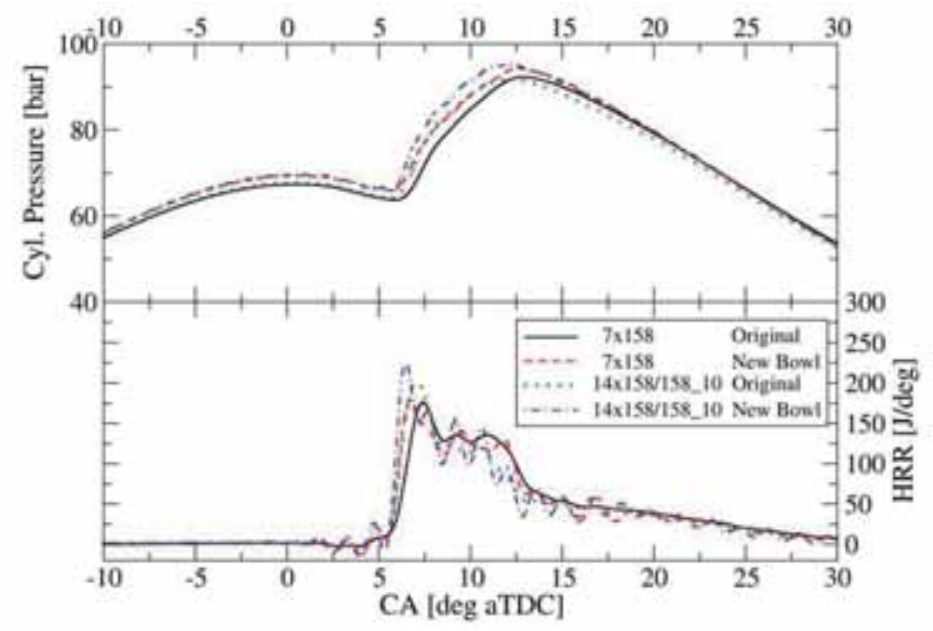

Figure 4.53: Pressure and heat release with two bowls for Cluster $14 \times 158 / 158$ and the reference nozzle under TP2: $0^{\circ} \mathrm{CA}$ aTDC SOI, 1400rpm, 1500bar rail pressure, 10.5bar IMEP, $4.5 \mathrm{~g} / \mathrm{kg}$ fuel NOx

\subsubsection{Emissions and fuel consumption}

The results of ISFC using the cluster and the reference nozzle are shown for a variation of SOI under TP2, TP3 and TP4 in Fig. 4.54. ISFC for the cluster is lower than the reference nozzle for all injection timing and test points. The new bowl should improve the fuel consumption for the cluster with better spray-wall interaction under these conditions. Swirl also helps to improve the fuel consumption for medium and high loads, so the case 4 with the highest swirl has the lowest ISFC for all test points. The $\mathrm{HC}$ emissions are generally low under high load condition. Most of the $\mathrm{HC}$ emissions form in flame 
quenching regions with low temperatures. Under high load condition, the temperature in cylinder and the temperature of combustion are relatively high, owing to greater mass of fuel and higher boost pressure and temperature. The HC emissions are shown in Fig. 4.55. They are quite similar and low for all the cases.

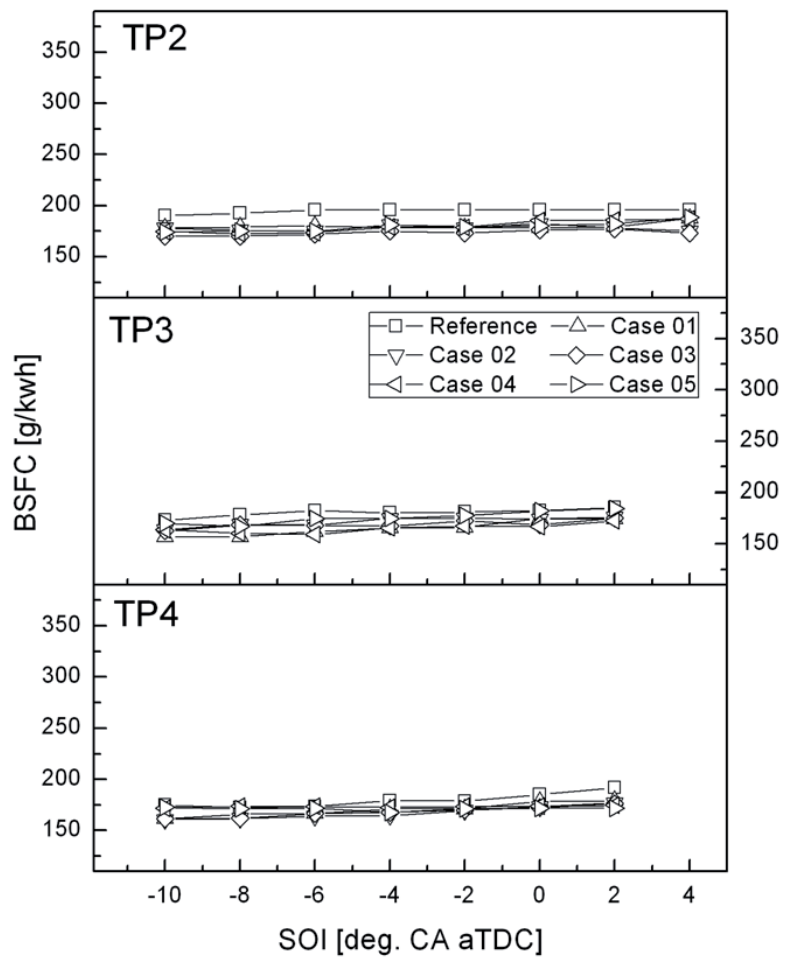

Figure 4.54: ISFC of Cluster 14x158/158 compare with the reference under TP2, TP3 and TP4 


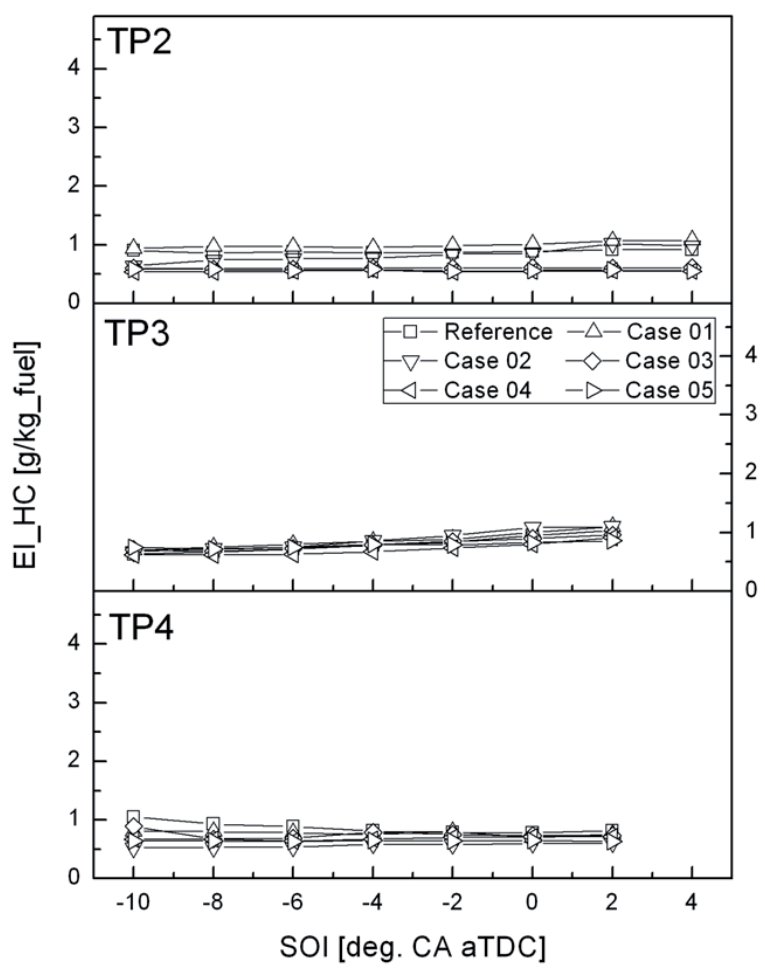

Figure 4.55: HC emissions of Cluster $14 \times 158 / 158$ compare with the reference under TP2, TP3 and TP4

The results of smoke emissions for all the cases under TP2, TP3 and TP4 are shown in Fig. 4.56. As shown in the previous sections, the Cluster $14 \times 158 / 158$ generally has slightly lower smoke emissions than the reference nozzle for case 01 (same conditions as reference case). In case 02 the cluster was tested with same conditions (swirl and shim) for the new bowl. The reductions in smoke emissions are stronger in this case than those in case 01 . Case 02 has the lowest smoke among all the test points. By using a smaller diameter bowl, a strong jet-wall interaction pushes the fuel-rich spray-spray interaction regions into the center of the chamber, where mixtures are predominantly lean $[28,29$, 57]. The smoke reduces with the spray motion near the piston bowl. The large toroidal radius bowl produces better combustion and hence better engine performance than the small toroidal radius under high load condition with high injection pressure [28]. 


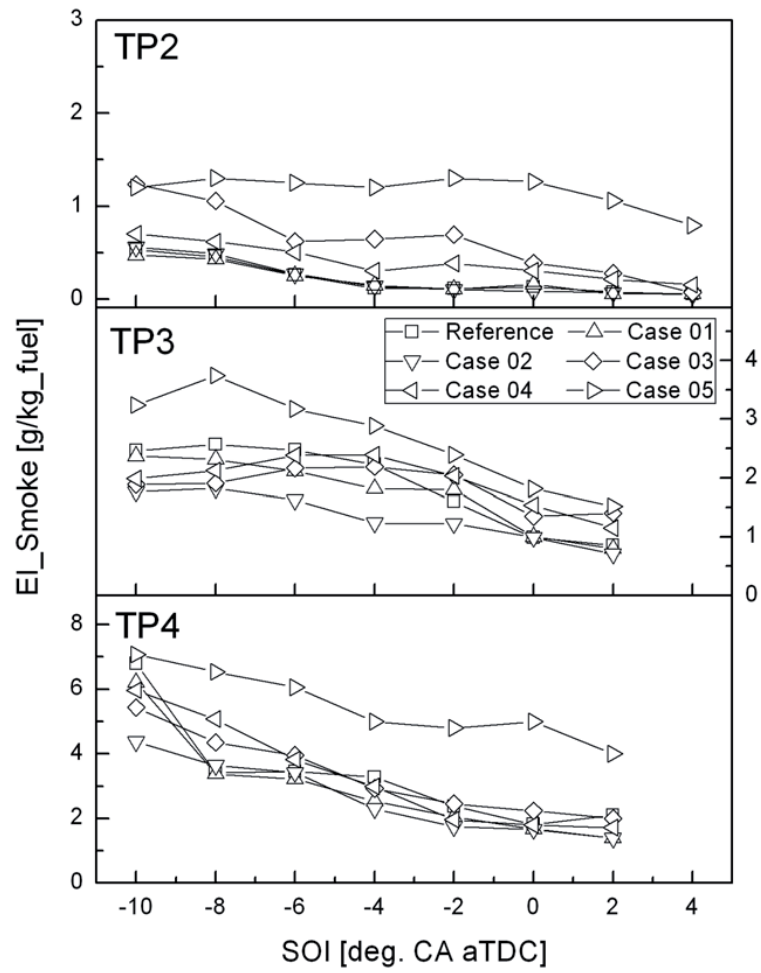

Figure 4.56: Smoke emissions of Cluster $14 \times 158 / 158$ compare with the reference under TP2, 3 and 4

The new bowl with smaller diameter and larger toroidal radius improves the air-fuel mixing. By comparing the results for case 03 and case 04 (variation of swirl ratio), it is evident that the smoke emissions for the cluster increase with a higher or lower swirl than the original. Based on the results for smoke emissions from section 4.4, an MSR of 1.5 seems to be close to the optimal swirl level for the cluster nozzles and the reference nozzle for the original bowl. Since case 03 and case 04 showed relatively higher smoke than the reference nozzle for most of the conditions, it seems that the MSR of 1.5 is close to optimal for the new bowl geometry also. In an effort to understand the effect of spray targeting on engine performance, case 05 was tested by changing the nozzle tip protrusion. The orifices of the cluster were located at a deeper position (Nozzle tip protrusion of $2.5 \mathrm{~mm}$ instead of $1.65 \mathrm{~mm})$ in the cylinder with a thinner shim $(2.15 \mathrm{~mm})$ than the original $(3 \mathrm{~mm})$. The injected fuel spray is targeted more towards the center of 
the bowl wall with a thinner shim. The smoke emissions increased significantly in case 05 and were higher than the other cases. This also suggests that air-fuel mixing near the bowl wall has an influence on the overall air-fuel mixing process. The spray-targeting is considered as one of the important factors in air-fuel mixture formation for the spray motion near combustion bowl surface. Among all the cases, the case 02 shows the lowest smoke emissions.

\subsubsection{Reduction in smoke emissions by using cluster nozzle}

As seen from the results of the parametric study, the cluster $14 \times 158 / 158$ combined with a swirl level of 1.5 MSR, 3mm shim and the new bowl reduces smoke emissions for all test points. Fig. 4.57 shows the lowest levels of smoke emissions for each of the test points for the cluster (case 02) and the reference nozzle (reference case) and the results of noise emissions in these conditions are shown in Fig. 4.58. The smoke emissions for low engine speed conditions (TP1 and TP2), which were already low with the reference nozzle, were further reduced by the cluster nozzle. For higher engine speeds (TP3 and TP4) considerable reduction in smoke levels is observed with the cluster. The reductions for the lowest emissions for TP3 and TP4 are 18.6\% and 33.8\% respectively. Though the reduction is not the same for all the injection timings, the cluster (case 02) does show generally lower smoke emissions, combustion noise and better fuel consumption than the reference nozzle for all injection timings and test points.

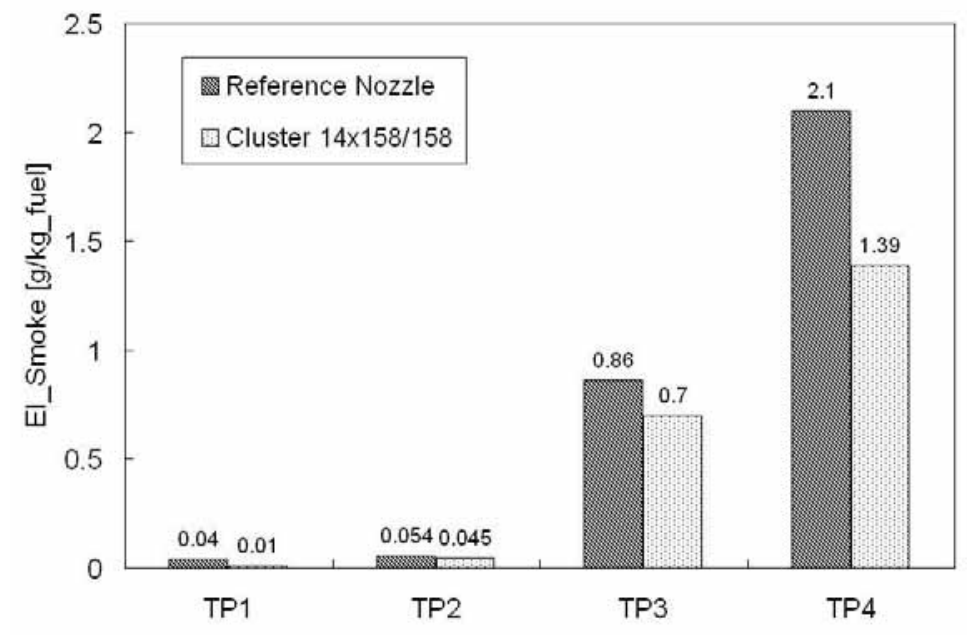

Figure 4.57: The reduction of the smoke emission with Cluster 14x158/158 compare with the reference nozzles under TP1, TP2, TP3 and TP4. 


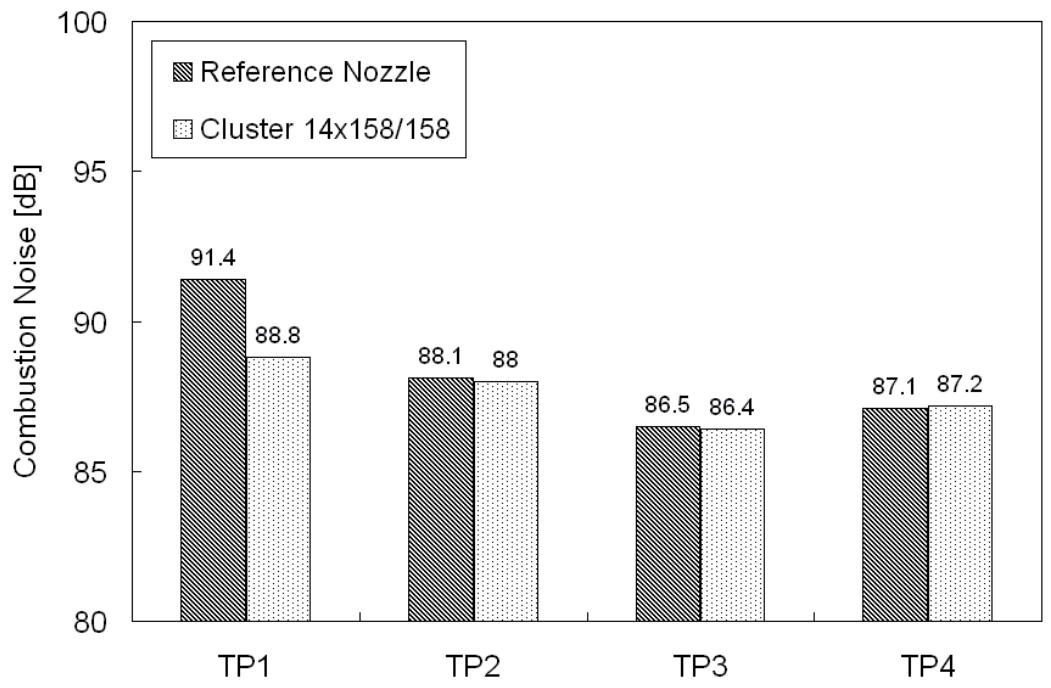

Figure 4.58: The noise emission with Cluster $14 \times 158 / 158$ compare with the reference nozzles under TP1, TP2, TP3 and TP4.

\subsubsection{Summary}

A modified bowl with a smaller diameter, a larger bowl depth and a larger toroidal radius was designed for use with cluster nozzles. The clusters show an improvement in smoke emission in the modified bowl. A cluster with the best results for smoke emissions in the first set of tests was also tested for 3 different swirl ratios and 2 different nozzle tip protrusion lengths with the new bowl. The Cluster $14 \times 158 / 158$ with the modified bowl consistently shows lower smoke emissions and better fuel consumption than the reference nozzle for all injection timings and test points. This provides a possible alternative for the diesel engines to solve the problem of high smoke emissions under high load operation. 


\section{Conclusion}

In the last decade, diesel engines have significantly progressed in reducing the most critical pollutants NOx and Soot. However, further stringent emission legislations require additional efforts. Despite continuous improvements in exhaust gas after-treatment, lower possible engine-out emissions have to be achieved by optimizing the combustion process in order to keep the cost of exhaust gas after-treatment minimum. A promising key parameter to affect combustion process in diffusion controlled combustion is air-fuel mixing which is mainly controlled by the fuel injection. The cluster concept is one of the advanced techniques for improving the mixing by modifying fuel injection.

Several nozzles based on the cluster concept were designed and tested under different conditions to better understand the behavior of cluster nozzles and to find a solution to the problem of high smoke under high load and high speed conditions.

For the first set of the clusters designed with a small spray cone angle, the investigations of soot formation in combustion vessel indicated towards the potential to reduce the amount of soot of diesel combustion process. The soot reduction potential of cluster nozzles was confirmed under early injection conditions, but the disadvantage due to improper targeting overweighed the advantage of the cluster concept under conventional timings. Simulations confirmed the findings of the experiments and it was decided to improve the spray targeting. The spray measurements of the first set of cluster nozzles also showed that they have a smaller spray penetration than the conventional nozzle.

Based on the experience with the first set, a second set of nine clusters was designed with larger spray cone angle and they demonstrated the applicability of cluster concept to high load operations under conventional injection timing and the advantage of cluster concept under early injection timings. Initially, six clusters were investigated to find optimal injection pressure for each test point. The clusters show higher smoke than the reference nozzle under conventional injection timing, but the smoke emissions of clusters were also reduced by increasing the rail pressure. Based on these results injection pressures were determined for further experiments.

A total of ten clusters were investigated for 4 different test points. They were evaluated by comparison with the reference nozzle and the results were also compared to each other. The clusters with smaller orifices showed an improvement over the conventional nozzle for fuel consumption, $\mathrm{HC}$ and smoke emissions for early injection timings under part load conditions. Cluster $14 \times 158 / 158 \_10^{\circ}$ performs better than the conventional nozzle though the other clusters perform worse. This cluster seems to have the best balance of atomization and evaporation versus spatial distribution and targeting of spray among all the tested clusters. Among the clusters, the ones with smaller orifices and larger included 
-angles perform better than the corresponding clusters with larger orifices and smaller included-angles. The horizontal clusters also have relatively lower smoke than the corresponding vertical clusters.

The investigation did not address the effects of jet-wall or jet-jet interactions, which occur in engines, or the effects of swirl. Therefore, the four clusters were investigated with different swirl levels. In PCCI operations, higher swirl helps for better fuel-air mixing and reduces smoke emissions for all the tested clusters. Deviations from the original swirl level cause slight disadvantage in terms of $\mathrm{HC}$ emissions and fuel consumption. Under high load condition the smoke emissions are reduced by increasing the swirl level while no significant effect of swirl is observed on $\mathrm{HC}$ emissions and fuel consumption. Based on the results for emissions and fuel consumption, an MSR of 1.5 seems to be close to the optimal swirl level for the cluster nozzles and the reference nozzle in this engine.

To make the use of clusters in a diesel engine feasible, a significant redesign of the typical in-cylinder geometry would likely be required to promote efficient air utilization. Since the clusters were found to have a shorter spray tip penetration a new piston bowl was designed with a smaller diameter and more depth. Four clusters were measured for both the original bowl and the modified bowl under 4 different test points. Under low engine speed, there is no strong effect of the bowl geometry and all the results are very similar for both the bowl geometries while the clusters show an improvement in smoke emissions in the modified bowl under high engine speed. The larger toroidal radius and the smaller throat diameter of the modified bowl help in redirecting the sprays along the wall towards the center of the bowl. The Cluster $14 \times 158 / 158$ with the best results for smoke emissions in the first set of tests was also tested for 3 different swirl ratios and 2 different nozzle tip protrusion lengths with the new bowl. For all test points the cluster with the modified bowl shows the lowest emissions. Under low load conditions, it further reduces the emissions which were already low with the reference nozzle, while it shows a considerable reduction in smoke emissions over the reference nozzle under high load conditions.

The study improves the understanding of the effects of some of the parameters involved with designing cluster nozzles. The final results show that the cluster concept, combined with a well matched bowl geometry and swirl can reduce emissions and improve fuel efficiency across the whole operating range of a diesel engine. 


\section{Bibliography}

[1] J. B. Heywood. Internal Combustion Engine Fundamentals. McGraw-Hill book, pages 517-562, 1988 .

[2] G. Stiesch. Modeling Engine Spray and Combustion Process. Heat Mass Transfer by Springer, pages 119-192, 2003.

[3] C. Baumgarten. Mixture Formation in Internal Combustion Engines. SpringerVerlag, 2005.

[4] D. R. Guildenbecher, C. Loepez-Rivera and P. E. Sojka. Secondary atomization. Journal of Experiments in Fluids, volume 46, number 3, pages 371-402, 2009.

[5] J. C. Dent. Basis for the Comparison of Various Experimental Methods for Studying Spray Penetration. Paper No. SAE 710571, SAE Trans., vol. 80, 1971.

[6] A. Pawlowski, R. Kneer, A. M. Lippert and S. E. Parrish. Investigation of the Interaction of Sprays from Clustered Orifices under Ambient Conditions Relevant for Diesel Engines. Paper No. SAE 2008-01-0928, 2008.

[7] S. Shundoh, T. Kakegawa and K. Tsujimura. The Effect of Injection Parameters and Swirl on Diesel Combustion with High Pressure Fuel Injection. Paper No. SAE 9100489, 1991.

[8] J. H. Van Gerpen, C. -W. Huang and G. L. Borman. The Effects of Swirl and Injection Parameters on Diesel Combustion and Heat Transfer. Paper No. SAE $850265,1985$.

[9] D. J. Timoney. Smoke and Fuel Consumption Measurements in a Direct Injection Diesel Engine with Variable Swirl. Paper No. SAE 851542, 1985.

[10] K. K. Rao, D. E. Winterbone and E. Clouh. Influence of Swirl on High Pressure Injection in Hydra Diesel Engine, Paper No. SAE 930978, 1993.

[11] P. S. Mehta and B. Tamma. Effect of Swirl and Fuel Injection Characteristics on Premixed Phase of Diesel Combustion. Paper No. SAE 980534, 1998.

[12] S. K. Singal, B. P. Pundir and P. S. Mehta. Fuel Spray-Air Motion Interaction in DI Diesel Engines: Paper No. SAE 930604, 1993.

[13] P. C. F. Gomes and D. A. Yates. The Influence of Some Engine Operating Parameters on Particulate Emissions, Paper No. SAE 922222, 1992.

[14] C. Espey, J. A. Pinson and T. A. Litzinger. Swirl Effects on Mixing and Flame Evolution in a Research DI Diesel Engine, Paper No. SAE 902076, 1990. 
[15] J. Benajes, S. Molina, J. M. Garcia and J. M. Riesco. The Effect of Swirl on Combustion and Exhaust Emissions in Heavy-Duty Diesel Engines, Journal of automobile engineering, Vol.218, 2004.

[16] M. E. McCracken and J. Abraham. Swirl-Spray Interactions in a Diesel Engine, Paper No. SAE 2001-01-0996, 2001.

[17] N. A. Henein. Analysis of Pollutant Formation and Fuel Economy in Diesel Engines. Progress in Energy and Combustion Science, pages 165-207, Pergamon Press, 1976.

[18] M. J. Bergin, R. D. Reitz, S. Oh and P. C. Miles. Fuel Injection and Mean Swirl Effects on combustion and Soot Formation in Heavy Duty Diesel Engines. Paper No. SAE 2007-01-0912, 2007.

[19] P. C. Miles. The Influence of Swirl on HSDI Diesel Combustion at Moderate Speed and Load, Paper No. SAE 2000-01-1829, 2000.

[20] N. A. Henein, A. Bhattacharyya, J. Schipper, A. Kastury and W. Bryzik. Effect of Injection Pressure and Swirl Motion on Diesel Engine-out Emissions in Conventional and Advanced Combustion Regimes, Paper No. SAE 2006-01-0076, 2006.

[21] T. Chikahisa, N. Yoneno and T. Murayama. Theoretical Study on Optimum Conditions for Fuel Injection System and Swirl Flow in DI Diesel Engines, Bulletin of the 8th Internal Combustion Engine Symposium, Japan, p. 7, 1990.

[22] G. M. Bianchi, P. Pelloni, F. E. Corcione, E. Mattarelli and F. L. Bertoni. Numerical Study of the Combustion Chamber Shape for Common Rail H. S. D. I. Diesel Engines. Paper No. SAE 2000-01-1179, 2000.

[23] K. Inagaki, S. Takasu and K. Nakakita. In-Cylinder Quantitative Soot Concentration Measurement by Laser-Induced Incandescence. Paper No. SAE 1999-01-0508, 1999.

[24] R. M. Montajir, H. Tsunemoto, H. Ishitani and T. Minami. Fuel Spray Behavior in a Small DI Diesel Engine: Effect of Combustion Chamber Geometry. Paper No. SAE 2000-01-0946, 2000.

[25] Y. Zhu, H. Zhao, D. A. Melas and N. Ladommatos. Computational Study of the Effects of the Geometry of the Piston Bowl Pip for a High-Speed Direct Injection Diesel Engine. Proc. Instn Mech. Engrs Vol. 218 Part D: Journal of Automobile Engineering, 2004

[26] L. Lin, D. Shulin, X. Jin, W. Jinxiang and G. Xiaohong. Effects of Combustion Chamber Geometry on in-Cylinder Air Motion and Performance in DI Diesel Engine. Paper No. SAE 2000-01-0510, 2000.

[27] L. Dahlén. Topics Related to Combustion and Emissions Formation in Direct Injected Diesel Engines, Volume 1: Soot mediated oil thickening. Licentiate Thesis TRITA-MMK 2000:21, KTH 2000

[28] Y. Zhu, H. Zhao and N. Ladommatos. Computational Fluid Dynamics Study of the Effects of the Re-entrant Lip Shape and Toroidal Radii of Piston Bowl on a 
High-Speed Direct-Injection Diesel Engine's Performance and Emissions. Proc. IMechE Vol.219 Part D: Journal of Automobile Engineering, 2005.

[29] L. C. Genzale and D. R. Reitz. Effects of Piston Bowl Geometry on Mixture Development and Late-Injection Low-Temperature Combustion in a Heavy-Duty Diesel Engine. Paper No. SAE 2008-01-1330, 2008.

[30] I. D. Middlemiss. Characteristics of the Perkins 'Squish Lip' Direct Injection Combustion System. Paper No. SAE 780113, 1978.

[31] T. Saito, Y. Daisho, N. Uchida and N. Ikeya. Effects of Combustion Chamber on Diesel Combustion. Paper No. SAE 861186, 1986.

[32] M. Ikegami, M. Fukuda, Y. Yoshihara and J. Kneko. Combustion Chamber Shape and Pressurized Injection in High-Speed Direct-Injection Diesel Engine. Paper No. SAE 900440, 1990.

[33] Y. Kidoguchi, C. Yang and K. Miwa. Effect of High Squish Combustion Chamber on Simultaneous Reduction of $\mathrm{NO}_{\mathrm{x}}$ and Particulate from a DirectInjection Diesel Engine. Paper No. SAE 1999-01-1502, 1999.

[34] J. B. Heywood. Internal Combustion Engine Fundamentals. McGraw-Hill book, pages 491- 516, 1988.

[35] G. Stiesch. Modeling Engine Spray and Combustion Process. Heat Mass Transfer by Springer, pages 5-28, 2003.

[36] J. B. Heywood. Internal Combustion Engine Fundamentals. McGraw-Hill book, pages 567- 572, 1988.

[37] D. X. Du, H. Wang and C. K. Law. Soot Formation in Counter-flow Ethylene Diffusion Flames from 1 to 2.5 Atmospheres. Combustion and Flame, 113:264270, 1998.

[38] C. J. Sung, B. Li, H. Wang and C. K. Law. Structure and Sooting Limits in Counter-flow Methane/Air and Propane/Air Diffusion Flames from 1 to 5 Atmospheres. In proc. Combust. Inst., volume 27, pages 1523-1530. The combustion Institute, Pittsburgh, 1998.

[39] S. T. Bagley, L. D. Gratz, D. G. Leddy and J. H. Johnson. Characterization of Particle and Vapor Phase Organic Fraction Emission from a Heavy Duty Diesel Engine Equipped with a Particle Trap Having Regeneration Controls. Research report no. 56, Health Effects Institute, Cambrige, 1993.

[40] K. J. Richards, M. N. Subramaniam, R. D. Reitz, M. -C. Lai, N. A. Henein and P. Miles. Modeling the Effects of EGR and Injection Pressure on Emissions in a High- Speed Direct Injection Diesel Engine. Paper No. SAE 2001 01-1004, 2001.

[41] S. Kimura, O. Aoki, E. Kitahara, E. Aiyoshizawa. Ultra-Clean Combustion Technology Combining a Low-Temperature and Premixed Combustion Concept for Meeting Future Emission Standards. Paper No. SAE 2001-01-0200, 2001. 
[42] R. M. Wagner, J. B. Green, T. Q. Dam, K. D. Edwards, J. M. Storet. Simultaneous Low Engine-Out $\mathrm{NO}_{\mathrm{x}}$ and Particulate Matter with highly Diluted Diesel Combustion. Paper No. SAE 2003-01-026, 2003.

[43] L. M. Pickett and D. L. Siebers. Non-Sooting, Low Flame Temperature MixingControlled DI Diesel Combustion. Paper No. SAE 2004-01-1399, 2003.

[44] S. S. Sluder, R. M. Wagner, S. A. Lewis and J. M. Storey. Exhaust Chemistry of Low- $\mathrm{NO}_{x}$, Low-PM Diesel Combustion, Paper No. SAE 2004-01-0114, 2004.

[45] K. Kawamoto, T. Araki, M. Shinzawa, S. Kimurra, S. Koide and M. Shibuya. Combination of Combustion Concept and Fuel Property for Ultra Clean DI Diesel Paper No. SAE 2004-01-1868, 2004.

[46] K. Nakakita, K. Miwa, K. Ohsawa, T. Takahashi, S. Watanabe, and H. Sami. Effects of High Pressure Fuel Injection on the Combustion and Exhaust Emission of a High-speed DI Diesel Engine. JSAE Review, Vol. 12, No.1, January, 1991.

[47] H. Yokata, T. Kamimoto, H. Kosaka and K. Tsujimura. Fast Burning and Reduced Soot formation via Ultra-High Pressure Diesel Fuel Injection. Paper No. SAE 910225, 1991.

[48] T. F. Su, C. T. Chang, R. D. Reitz, P. V. Farrell, A. D. Pierpont and T. C. Tow. Effect of Injection Pressure and Nozzle Geometry on Spray SMD and D.I. Emissions. Paper No. SAE 952360, 1995.

[49] K. S. Varde and T. Watanabe. Characteristics of High Pressure Spray and Exhaust Emissions in a Single Cylinder DI Diesel Engine. Paper No. SAE 2000-05-0333, 2000.

[50] N. A. Henein, A. Bhattacharyya, J. Schipper and A. Kastury. Effect of Injection Pressure and Swirl Motion on Diesel Engine-out Emission in Conventional and Advanced Combustion Regimes, Paper No. SAE 2006-01-0076, 2006.

[51] N. Ishikawa and K. Niimura. Analysis of Diesel Spray Structure Using Magnified Photography and PIV. Paper No. SAE 960770, 1996.

[52] J. S. Han, P. H. Lu, S. B. Xie, M. C. Lai and N. A. Henein. Investigation of Diesel Spray Primary Break-up and Development for Different Nozzle Geometries. Paper No. SAE 2002-01-2775, 2002.

[53] H. Hiroyasu, M. Arai and M. Tabati. Empirical Equations for the Sauter Mean Diameter of a Diesel Spray. Paper No. SAE 890464, 1989.

[54] W. S. Stanton and C. J. Rutland. Modeling Fuel Film Formation and Wall Interaction in Diesel Engines. Paper No. SAE 960628, 1996.

[55] J. E. Dec. A Conceptual Model of D. I. Diesel Combustion Based on Laser Sheet Imaging. Paper No. SAE 970873, 1997.

[56] D. L. Siebers and B. S. Higgins. Effects of Injector Conditions on the Flame LiftOff Length of DI Diesel Sprays. Sandia Report SAND 2000-8249, 2000. 
[57] M. Sjoeberg. Correlation Between Flame Pattern, Heat-Release and Emissions for a DI Diesel Engine with Rotating Injector and Variable Swirl. Paper No. SAE 2001-01-2003, 2001.

[58] D. Jefer. Pilot Injection Engineering, 1937.

[59] S. Simescu, T. W. Ryan III, G. D. Neely, A. C. Matheaus and B. Surampudi. Partial Premixed Combustion with Cooled and Un-cooled EGR in a Heavy Duty Diesel Engine. Paper No. SAE 2002-01-0963, 2002.

[60] S. Koot and C. Bae. Combustion Control using Two-Stage Diesel Fuel Injection in a Single Cylinder PCCI Engine. Paper No. SAE 2004-01-0938, 2004.

[61] K. Okude, K. Mori, s. shiino and T. Moriya. Premixed Compression Ignition (PCI) Combustion for Simultaneous Reduction of $\mathrm{NO}_{\mathrm{x}}$ and Soot in Diesel Engine. Paper No. SAE 2004-01-1907, 2004.

[62] F. Wahlin, A. Cronhjort, U. Olofsson and H. E. Anstroem. Effect of Injection Pressure and Engine Speed on Air/Fuel Mixing and Emissions in a Pre-Mixed Compression Ignition (PCCI) Engine Using Diesel Fuel. Paper No. SAE 2004-012989,2004

[63] T. J. Jacobs, S. V. Bohac, D. N. Assanis and P. G. Szymkowicz. Lean and Rich Premixed Compression Ignited Combustion in a Light Duty Diesel Engine. Paper No. SAE 2005-01-0166, 2005.

[64] T. kanda, T. Hakozaki, T. Jchimoto, J. Hatano, N. Kitayama and H. Sono. PCCI Operation with Early Injection of Conventional Diesel Fuel. Paper No. SAE 200501-0378, 2005.

[65] A. minato, T. Tanaka and T. Nishimura. Investigation of Premixed Lean Diesel Combustion with Ultra High Pressure Injection. Paper No. SAE 2005-01-0914, 2005.

[66] M. Araki, T. Umino, T. Obokata, T. Ishima, S. Shiga, H. Nakamura, W. Q. Long and A. Murakami. Effects of Compression Ratio on Characteristics of PCCI Diesel Combustion with a Hollow Cone Spray. Paper No. SAE 2005-01-2130, 2005.

[67] N. Dronniou, M. Lejeune, I. Balloul and P. Higelin. Combustion of High EGR Rates and Multiple Injection Strategies to Reduce Pollutant Emissions. Paper No. SAE 2005-01-3726, 2005.

[68] K. J. Richards, M. N. Subramaniam, R. D. Reitz, M. C. Lai, N. A. Henein and P. C. Miles. Modeling the Effects of EGR and Injection Pressure on Emissions in a High Speed Direct Injection Diesel Engine. Paper No. SAE 2001-01-1004, 2001.

[69] S. M. Aceves and D. L. Flowers. A Detailed Chemical Kinetic Analysis of Low Temperature, Non-Sooting Diesel Engine. Paper No. SAE 2005-01-0923, 2005.

[70] M. Kim, R. D. Reitz and S. C. Kong. Modeling Early Injection Pressures in HSDI Diesel Engine. Paper No. SAE 2006-01-0056, 2006. 
[71] Y. Sun and R. D. Reitz. Modeling Diesel Engine $\mathrm{NO}_{\mathrm{x}}$ and Soot Reduction with Optimized Two-Stage Combustion. Paper No. SAE 2006-01-0027, 2006.

[72] L. M. Pickett and D. L. Siebers. Non-Sooting, Low Flame Temperature Mixing Controlled DI Diesel Combustion. Paper No. SAE 2004-01-1399, 2004.

[73] N. Peters and J. Weber. The Effects of Spray Formation and Evaporation on Mixing, Auto-Ignition and Combustion in Diesel Engines. In THIESEL 2006, Conference on thermo- and fluid dynamic processes in diesel engine, 2006.

[74] B. Walter and B. Gatellier. Development of the High Power NADITM Concept Using Dual Mode Diesel Combustion to Achieve Zero $\mathrm{NO}_{\mathrm{x}}$ and Particulate Emissions. Paper No. SAE 2002-01-1744, 2002.

[75] Y. Kim, H. Kim, K. Kim, D. Lee and K. Lee. A Study on the Characteristics of Mixture Formation and Combustion in a PCCI Engine Using an Early Multiple Injection Strategy. In proceedings of the $10^{\text {th }}$ international conference of liquid atomization and spray systems (ICLASS-2006), 2006.

[76] R. M. Siewert. Spray Angle and Rail Pressure Study for Low $\mathrm{NO}_{\mathrm{x}}$ Diesel Combustion. Paper No. SAE 2007-01-0122, 2007.

[77] R. M. Wagner, J. B. Green, T. Q. Dam, K. D. Edwards and J. M. E. Storey. Simultaneous Low Engine-Out $\mathrm{NO}_{\mathrm{x}}$ and Particulate Matter with Highly Diluted Diesel Combustion. Paper No. SAE 2003-01-0262, 2003.

[78] M. P. B. Musculus, Multiple Simultaneous Optical Diagnostic Imaging of Early Injection Low Temperature Combustion in a Heavy Duty Diesel Engine. Paper No. SAE 2006-01-0079, 2006.

[79] K. Akihama, Y. Takatori, K. Inagaki, S. Sasaki and A. Dean, Mechanism of the Smokeless Rich Diesel Combustion by Reducing Temperature. Paper No. SAE 2001-01-0655, 2001.

[80] S. Kobori, T. Kamimoto and H. Ksaka. Ignition, Combustion and Emissions in a DI Diesel Engine Equipped with a Micro-Hole Nozzle. Paper No. SAE 960321, 1966.

[81] L.M. Pickett and D.L. Siebers, An Investigation of Diesel Soot Formation Processes using Micro-Orifices. Proceedings of the Combustion Institute, Vol. 29, pp. 655-662, 2002.

[82] J. Benajes, S. Molina, K. De Rudder, D. Maroteaux and H. Ben Hadj Hamouda. The Use of Micro-Orifice Nozzles and Swirl a Small HSDI Engine Operating at a Late Split-Injection LTC Regime. Proceedings of the I MECH E Part D: Journal of Automobile Engineering, vol. 220, pp. 1807-1817, 2006.

[83] B. Fasolo, A. Doisy, A. Dupont, and F. Lavoisier. Combustion System Optimization of a new 2 liter Diesel Engine for Euro IV. Paper No. SAE 2005-010652, 2005.

[84] P. Adomeit, H. Rohs, T. Koerfer and H. Busch. Spray Interaction and Mixture Formation in Diesel Engines with Grouped-Hole Nozzles. THIESEL conference on thermo- and fluid dynamic processes in diesel engines, Valencia, Spain, 2006. 
[85] J. Schommers, F. Gulde, M. Hoppenstedt, G. Gruber, W. Fick, W. Ruisinger, G. Renner and A. Lingens. Evolution des Vierzlinder-Dieselmotors von MercedesBenz. Motortechnische Zeitchrift, 2007, 68, 20-29.

[86] P. Bergstrand and I. Denbratt. The Effects of Multi-Row Nozzles on Diesel Combustion. Paper No. SAE 2003-01-0701, 2003.

[87] J. Gao, Y. Matsumoto and K. Nishida, Effects of Group-Hole Nozzle Specifications on Fuel Atomization and Evaporation of Direct Injection Diesel Spray. Paper No. SAE 2007-01-1889, 2007.

[88] K. Nishida, J. Gao and Y. Matsumoto, Experimental Study On Spray and Mixture Properties of The Group-Hole Nozzle for Direct-Injection Diesel Engines, Part II: Effects o Included Angle and Interval Between Orifices. J. of Atomization and Sprays, vol. 19(4), pp. 339-355, 2009.

[89] K. Nishida, S. Nomura and Y. Matsumoto, Spray and Mixture Properties of Group-Hole Nozzle for D.I. Diesel Engines. In Proceedings of ICLASS-2006, ICLASS 06-171 (Available on CD), 2006.

[90] J. Gao, Y. Matsumoto, and K. Nishida, Experimental Study On Spray and Mixture Properties of The Group-Hole Nozzle for Direct-Injection Diesel Engines, Part I: A Comparative Analysis with The Single-Hole Nozzle. J. of Atomization and Sprays, vol. 19(4), pp. 321-337, 2009.

[91] J. Gao, Y. Matsumoto, M. Namba and K. Nishida, Group-Hole Nozzle Effects on Mixture Formation and In-Cylinder Combustion Processes in Direct-Injection Diesel Engines. Paper No. SAE 2007-01-4050, 2007.

[92] Y. Zhang, K. Nishida, S. Nomura, and T. Ito, Spray Characteristics of Group hole Nozzle for D.I. Diesel Engine. Paper No. SAE 2003-01-3115, 2003

[93] U. Dohle, M. Krueger, D. Naber, J. O. Stein and Y. Gauthier. Results of Combustion Optimization by Use of Multi-Hole Nozzles in Modern Passenger Car Diesel Engines, 27. Internationales Wiener Motorensysmposium, Vienna, Austria, 2006.

[94] J. Kerekes, S. Ohoka and O. Horoda. The Design and Concept of the Duramax 6600 Diesel Engine. Paper No. SAE 2001-01-2703, 2001.

[95] K. Ohishi and T. Maeda. The New Common Rail Fuel System for the Duramax 6600 V8 Diesel Engine. Paper No. SAE 2004-01-2704, 2004.

[96] R. M. Siewert. Spray Angle and Rail Pressure Study for low $\mathrm{NO}_{\mathrm{x}}$ Diesel Combustion. Paper No. SAE 2007-01-0122, 2007.

[97] A. Dodd and Z. Holubecki. The Measurement of Diesel Exhaust Smoke. MIRA Report, 1965/10, 1965.

[98] L. Wolter. Aufbau und Inbetriebnahme eines Pruefstands zur Ermittlung des Einspritzverlaufs von Dieseleinspritzsystemen. Institut fuer Technische Verbrennung, RWTH-Aachen, Diplomarbeit, 1998. 
[99] J. K. Dukowicz. A Particle-Fluid Numerical Model for Liquid Sprays. J. Comput. Physics., 35:229-253, 1980.

[100] F. A. Williams. Spray Combustion and Atomization. Phys. Fluids, 1:541-545, 1958.

[101] C. T. Crowe, M. P. Sharma and D. E. Stock. The Particle-Source-In Cell (PSICell) Model for Gas-Droplet Flows. J. of Fluids Engr., 99:325-332, 1977.

[102] T. F. Su, M. A. Petterson, R. D. Reitz and P. V. Farrell. Experimental and Numerical Studies of High Pressure Multiple Injection Sprays. Paper No. SAE 960861, 1996.

[103] L. M. Ricart, J. Xin, G. R. Bower and R. D. Reitz. In-Cylinder Measurement and Modeling of Liquid Fuel Spray Penetration in a Heavy-Duty Diesel Engine, Paper No. SAE 971591, 1997.

[104] M. A. Patterson and R. D. Reitz. Modeling the Effect of Fuel Spray Characteristics on Diesel Engine Combustion and Emission. Paper No. SAE 980141, 1989.

[105] L. M. Ricart, R. D. Reitz and J. Deck. Comparisons of Diesel Spray Liquid Penetration and Vapor Fuel Distribution with In-Cylinder Optical Measurements. Transactions of the ASME, volume. 122, pages 588-595, 2000.

[106] P. J. O'Rourke and A. A. Amsden. Three Dimensional Numerical Simulations of the UPS-292 Stratified Charge Engine, Paper No. SAE 870597, 1987.

[107] P. Hottenbach, G. Gruenefeld and T. Brands. An Experimental Investigation of Combustion and Soot Formation of Sprays from Cluster Nozzles for D.I. Diesel Engines. Paper No. SAE 2009-01-0855, 2009.

[108] M. Cardenas, P. Hottenbach, R. Kneer and G. Gruenefeld. Investigations of Clustered Diesel Jets under Quiescent High-Pressure and High-Temperature Conditions using Mie, Schlieren and Chemiluminescence Imaging. Paper No. SAE 2009-01-2771, 2009.

[109] H. W. Won, A. Sharma, P. Hottenbach, M. Gauding, F. X. Robert, N. Peters, G. Gruenefeld, R. Durrett, A. Plazas and S. Singh. Investigation of Particulate Emissions for Cluster-Nozzle Concepts in DI Diesel Engines, International conference of liquid atomization and spray systems, ICLASS 2009-148, 2009.

[110] H. W. Won, A. Sharma, S. E. Moon, A. Vanegas and N. Peters. An Experimental Study of Cluster Nozzles for DI Diesel Engine, Paper No. SAE 2009-24-0053, 2009.

[111] H. W. Won and N. Peters. Optimizing the Injection Pressure for Cluster Nozzle Concepts in DI Diesel Engine. International Journal of Engine Research, Vol. 11 JER05409, 2009.

[112] H. W. Won and N. Peters. A Cluster Nozzle Concept with High Injection Pressure for DI Diesel Engine, Towards Clean Diesel Engines (TCDE2009), Aachen, Germany, 2009. 
[113] H. W. Won and N. Peters. Investigation of Cluster-Nozzle Concepts for Diesel Engines. Journal of Atomization and Sprays, 19(10):983-996, 2009.

[114] H. W. Won and N. Peters. The Effects of Swirl for the Cluster Nozzles in DI Diesel Engines. Proceedings of International Journal of Engine Research, Submitted 2009.

[115] H. W. Won and N. Peters. Modified Bowl Geometry for Cluster Nozzles in DI Diesel Engines. Proceedings of the Institution of Mechanical Engineers, Part D, Journal of Automobile Engineering, JAUTO1371R1, 2009.

[116] G. s. Settles. Schlieren and Shadowgraph Techniques. Springer, 2001.

[117] J. Canny. A Computational Approach to Edge Detection. IEEE Transactions on Pattern Analysis and Machine Intelligence, volume 8, No. 6, pages 679-698, 1986.

[118] N. Otsu. A Threshold Selection Method from Gray-Level Histograms. IEEE Transactions on Pattern Analysis and Machine Intelligence, volume 9, No. 1, pages 62-66, 1979. 


\section{Definitions, Acronyms, Abbreviations}

\begin{tabular}{|c|c|}
\hline aTDC & after Top Dead Center \\
\hline bTDC & before Top Dead Center \\
\hline $\mathrm{CA}$ & Crank Angle \\
\hline CFD & Computational Fluid Dynamics \\
\hline $\mathrm{CO}$ & Carbon Monoxide \\
\hline $\mathrm{CO}_{2}$ & Carbon Dioxide \\
\hline DDM & Discrete Droplet Model \\
\hline DI & Direct Injection \\
\hline EGR & Exhaust Gas Recirculation \\
\hline EI & Emission Index \\
\hline FSN & Filtered Smoke Number \\
\hline $\mathrm{HC}$ & Hydro-Carbon \\
\hline HCCI & Homogeneous Charge Compression Ignition \\
\hline HRR & Heat Release Rate \\
\hline HSDI & High Speed Direct Injection \\
\hline ICCD & Intensified Charge Coupled Device \\
\hline IMEP & Indicated Mean Effective Pressure \\
\hline ISFC & Indicated Specific Fuel Consumption \\
\hline KH & Kelvin-Helmholtz \\
\hline LII & Laser Induced Incandescence \\
\hline LTC & Low Temperature Combustion \\
\hline MIRA & Motor Industry Research Association \\
\hline MSR & Mean Swirl Ratio \\
\hline $\mathrm{NO}_{\mathrm{x}}$ & Nitrogen Oxides \\
\hline NTP & Nozzle Tip Protrusion \\
\hline
\end{tabular}




$\begin{array}{ll}\text { PAH } & \text { Polycyclic Aromatic Hydrocarbons } \\ \text { PCCI } & \text { Premixed Charge Compression Ignition } \\ \text { PM } & \text { Particulate Matter } \\ \text { ppm } & \text { parts per million } \\ \text { RANS } & \text { Reynolds Averaged Navier-Stokes equations } \\ \text { RIF } & \text { Representative Interactive Flamelet } \\ \text { RT } & \text { Rayleigh-Taylor } \\ \text { SMD } & \text { Sauter Mean Diameter } \\ \text { SMR } & \text { Sauter mean radius } \\ \text { SOF } & \text { Soluble Organic Fraction } \\ \text { SOI } & \text { Start of Injection } \\ \text { TDC } & \text { Top Dead Center }\end{array}$

